Acta Crystallographica Section A

Foundations of Crystallography

ISSN 0108-7673

\section{Twenty-Second General Assembly and International Congress of Crystallography, Madrid, Spain, 22-30 August 2011}

\section{Introduction and Opening Ceremony}

By invitation of the Spanish Committee for Crystallography on behalf of the Subdirección General de Programas y Organismos Internacionales, Ministerio Educación y Ciencia, the Twenty-Second General Assembly and International Congress of Crystallography were held at the Municipal Congress Centre, Madrid, 22-30 August 2011.

The meetings were attended by 2655 participants and 113 accompanying persons from 73 countries and territories.

The General Assembly and Congress were opened on the evening of 22 August at the Congress Centre. Welcoming Addresses were made by Professor S. Larsen (President of the IUCr), Professor E. Gutiérrez-Puebla (Chair of the Local Organizing Committee), Professor P. Goya (Vice-President of the Spanish Royal Society of Chemistry) and Professor S. Garcia-Granda (President of the European Crystallographic Association). An historical enactment of gypsum cutting was performed. Professor R. Kuroda [Vice-President of ICSU (International Council for Science)] made a presentation concerning the work of ICSU. There followed a musical interlude. The Ewald Prize was then accepted by Professor E. Dodson, Professor C. Giacovazzo and Professor G. M. Sheldrick, who jointly presented the Ewald Award Lecture, introduced by Professor H. Schenk (Chair of the Ewald Prize Selection Committee). The evening ended with a Welcoming Reception.

\section{Twenty-Second International Congress}

\subsection{Scientific programme}

Four Plenary Lectures, 36 Keynote Lectures, 98 Microsymposia, Open Commission Meetings and poster sessions were held. The abstracts in the published book of Collected Abstracts were prepared from electronic submissions and were also provided on a CD-ROM.

\subsection{Exhibitions}

A commercial exhibition comprising 65 companies and booksellers was organized.

\subsection{Social events}

Evening entertainments included a Musical Event (Ballet Folclórico de Madrid) and the Congress Dinner. Various excursions were also arranged.

\section{Minutes of the Twenty-Second General Assembly}

These Minutes have been prepared by M. H. Dacombe, Executive Secretary, under the authority of S. Lidin, General Secretary and Treasurer of the IUCr and Secretary of the General Assembly.

\subsection{Introduction and list of delegates}

Sessions of the General Assembly were held on the evenings of Tuesday 23 August, Wednesday 24 August and Saturday 27 August. It was not found necessary to meet on Sunday 28 August, as originally planned. The following attendance list gives the names of official delegates appointed by the Adhering Bodies and the alternates who substituted at one or more sessions. Dates of attendance are given in parentheses for those who were not present at every session. The names are listed by the countries to which the respective Adhering Bodies belong, and the number of votes of the Adhering Body is given in parentheses after the name of the country. The names of the Chairs of the delegations are given in bold where they are known; those of alternates are marked by an asterisk. There were no delegates from Chile or Serbia.

Argentina (1): R. Baggio (23 and 24 August)

Australia (3): J. M. Guss, S. W. Wilkins, R. Withers

Austria (1): H. S. Effenberger

Belgium (2): L. Van Meervelt, J. Wouters

Brazil (1): I. Torriani

Bulgaria (1): S. Ferdov (23 August)

Canada (3): J. Britten, M. Cygler, J. Schrag

China, People's Republic of (4): S. Gao (23 and 27 August), X.-D. Su, J. Wang (23 and 24 August), N. Yang, D. Yin* (24 and 27 August) China, The Academy of Sciences Located in Taipei (2): S. M. Peng, Yu Wang

Croatia (1): M. Daković (23 and 27 August)

Czech/Slovak Republics (2): J. Kozisek, R. Kuzel

Denmark (1): G. R. Andersen

Egypt (1): A. M. M. Moustafa

Finland (1): K. J. Hämäläinen

France (4): J. Cherfils (23 and 24 August), R. Guinebretière, J.-L. Hodeau* (27 August) O. Perez*, P. Roussel

Germany (4): R. X. Fischer, U. Heinemann* (24 and 27 August), U. Pietsch, W. Schmahl (23 and 24 August), M. Weiss (23 and 27 August) Greece (1): I. Mavridis

Hungary (1): G. Faigel

India (3): P. Chakrabarti, P. Dastidar* (27 August), T. N. Guru Row (23 and 24 August), M. V. Hosur* (27 August), D. M. Salunke (23 and 24 August)

Ireland, Republic of (1): P. McArdle (24 and 27 August)

Israel (1): G. Kimmel

Italy (3): C. Mealli, R. Oberti, M. Saviano

Japan (4): Y. Kai, T. Kiyotani, A. Sekine, S. Wakatsuki

Korea (1): S. W. Suh

Mexico (1): J. Chavez Carvajar

The Netherlands (2): R. de Gelder, M. Lutz (23 and 24 August), C. Reiss* (27 August)

New Zealand (1): S. Telfer

Norway (1): C. H. Görbitz 
Poland (1): A. Pietraszko

Portugal (1): M. Duarte (27 August)

Regional Committee: Algeria/Latvia/Morocco/Tunisia/Turkey/ Ukraine (1): M. Debbabi

Regional Committee: Bangladesh/Malaysia/Singapore/Thailand/ Vietnam (1): A. Hussain

Russia (5): V. L. Aksenov, V. M. Kanevsky, S. S. Khasanov*, N. I. Sorokina, A. E. Voloshin

Slovenia (1): A. Meden (27 August)

South Africa (2): D. G. Billing, S. E. Bourne

Spain (3): S. García-Granda, E. Gutiérrez-Puebla (24 and 27 August),

C. Miravitlles, M. E. G. Mosquera* (23 August),

Sweden (2): E. Sauer-Eriksson (24 and 27 August)

Switzerland (2): P. Macchi (23 and 27 August)

UK (5): D. Allan (24 and 27 August), E. Garman (23 and 24 August), A. Griffin (23 and 24 August), A. Pearson, H. R. Powell* (27 August), G. M. Rosair, A. Thompson* (27 August), O. Zeldin* (23 August)

USA (5): C. Cahill, K. A. Kantardjieff, J. Ng, B. H. Toby, V. G. Young

Present as members of the Executive Committee: S. Larsen (President), P. Colman (Vice-President), S. Lidin (General Secretary and Treasurer), Y. Ohashi (Immediate Past President), E. Boldyreva, G. R. Desiraju, C. J. Gilmore, M. L. Hackert, C. Lecomte, J. M. PerezMato (Ordinary Members). M. H. Dacombe was in attendance as Executive Secretary.

Representatives from the Regional Associates were seated with the delegates.

\subsection{First Session, Tuesday 23 August 2011, 7:40 p.m.}

(1) Introductory remarks by the President

Professor S. Larsen welcomed the delegates and observers. The President began by recalling the sad loss of Professor L. T. J. Delbaere (Executive Committee member elected at the Osaka Congress in 2008) who had died in 2009. She thanked Professor M. L. Hackert who had taken over as his replacement.

\section{(2) Procedural matters}

In order to verify the list of voting delegates, the President requested the General Secretary to read this list, and asked delegates to indicate their presence when their names were called. Delegates were also asked to complete an attendance form. (At subsequent sessions of the General Assembly attendance forms were completed but only new delegates were asked to indicate their presence.)

Two delegates, one from Greece and one from Mexico, were appointed to act as tellers when votes had to be counted during the Assembly.

(3) Approval of Agenda

The Agenda and Appendices to the Agenda had been distributed to Secretaries of National Committees in May 2011. The Agenda were approved.

(4) Amendments to Statutes and By-Laws affecting adherence to the Union

The President reported that there were no proposals.

(5) Applications for membership of the Union

Applications for membership of the IUCr had been received from Bulgaria (Category I) and the Republic of Ireland (Category I). The Executive Committee recommended to the General Assembly that these be accepted. The applications were accepted by the General Assembly.
(6) Withdrawal of Adhering Bodies

The President reported that no Adhering Body was more than four years in arrears with payment of its dues.

(7) Changes in names of Adhering Bodies

The change in name of the Adhering Body of the People's Republic of China (to the Chinese Association for Science and Technology) was accepted by the General Assembly.

(8) Changes in Category of Adherence of Adhering Bodies

The President reported that no application for a change in Category of Adherence had been received.

(9) Approval of Minutes of Twenty-First General Assembly

The Minutes, which were contained in the published Report of the Twenty-First General Assembly and International Congress of Crystallography [Acta Cryst. (2009), A65, 390-442], were approved and two copies were signed by the President and the General Secretary, in accordance with By-Law 1.13. There were no matters arising from the Minutes.

(10) Amendments to Statutes and By-Laws not affecting adherence to the Union

At its meeting in Osaka in 2008 the Executive Committee establsihed a Committee to review the Statutes and By-Laws. The report of this Committee [membership: E. N. Baker (Chair), A. Authier, L. T. J. Delbaere (subsequently replaced by M. L. Hackert) and M. H. Dacombe] had been sent to National Committees in December 2010 and positive feedback had been received. The Chair of the Committee presented the following proposals:

(a) Statute 6.2 should be revised to ensure that the six ordinary members of the Executive Committee should always include at least one member from each of the three geographical regions: (i) Europe and Africa; (ii) the Americas; and (iii) Asia/Oceania.

(b) By-Laws 8.5 and 8.6, which covered the possibility for the lowest-polling candidate to be dropped off the list during elections, should be amended to ensure that no candidate could be elected without receiving a majority of votes.

(c) By-Law 8.6 should be amended to ensure that the requirements of Statute 6.2 were met [as amended above].

(d) By-Law 1.3 should be amended so that date and place of the next-but-one General Assembly could be confirmed six years in advance.

(e) A new By-Law 4.4 should be introduced to formalize the position of Executive Secretary.

(f) Statutes 5.4, 5.5, 12.1 and 13.1 and By-Laws 2.1, 2.2 and 2.7 should be revised to allow electronic means of communication.

All the above proposals were approved.

The President thanked the Committee for its work.

The UK National Committee proposed that Statute 12.2 should be amended so that in the event of the dissolution of the Union the available assets would be attributed to one or more institutions [formerly an institution] in pursuit of a goal of similar public interest to that of the IUCr.

This proposal was approved.

(11) Report of Executive Committee

The Report of the Executive Committee on the activities of the IUCr since the Twenty-First General Assembly had been submitted to the National Committees and the Commissions in May 2011, in accordance with Statute 6.8, and follows these Minutes as Appendix A1. The President particularly thanked the Spanish Committee for Crystallography on behalf of the Subdirección General de Programas y Organismos Internacionales, Ministerio Educación y Ciencia for the invitation to hold the present Congress in Madrid, and Professor E. Gutiérrez-Puebla (Chair of the International Programme Committee and of the Local Organizing 
Committee) for his hard work. The Report was accepted without discussion.

\section{(12) Financial Report}

A Financial Report, covering the calendar years 2008, 2009 and 2010 , had been prepared by the Treasurer and had been submitted to the National Committees and the Commissions in May 2011. The Report follows these Minutes as Appendix A2.

The Treasurer reported the composition of the Finance Committee. The Union operated in three currencies: member subscriptions were largely paid in CHF, two-thirds of the investments, income and most expenses were in GBP, and one-third of the investments and some expenses were in USD. The accounts had to be prepared in $\mathrm{CHF}$, which meant that a strong Swiss franc reduced the value of the assets given in the accounts when expressed in CHF. The annual turnover was about CHF 5000000 and assets at this level were required. The intention was to make a small profit so that the services provided to crystallographers could be maintained and developed.

The income for the journals came from three main sources: subscriptions, consortial sales and open-access payments. The Treasurer showed a plot showing how consortial income had increased during the triennium.

The publisher for International Tables had changed during the triennium and visibility and sales had increased.

The losses incurred on investments in 2007/2008 as a result of the well known market situation had largely been recovered by the end of 2010. Over $50 \%$ of the holdings were presently in cash as the aim of the investments was to keep the IUCr secure and not to speculate.

The continued success of the publishing operation was due to the dedicated work of the competent and productive staff.

The General Assembly thanked the Treasurer for his report with applause.

(13) Ewald Prize

Details of the Prize, awarded to Professor E. Dodson, Professor C. Giacovazzo and Professor G. M. Sheldrick at the Opening Ceremony, and the citation are given in Appendix A3.

The Selection Committee was thanked for its work.

(14) International Year of Crystallography

The President made a presentation summarizing the aims of the proposed International Year of Crystallography. Endorsement by the UN was important and National Committees would be contacted to ask them to seek the support of their permanent national delegations to the UN. The presentation was received with applause. See Appendix A4.

The President then adjourned the session at 9:10 p.m.

\subsection{Second Session, Wednesday 24 August 2011, 7:40 p.m.}

\section{(15) Commission on Journals}

The Report of the Commission on Journals had been distributed to the National Committees and the Commissions in May 2011 and is reprinted in Appendix A5.

The Chair (G. Kostorz) gave details of the numbers of papers and pages published in the journals in 2010 and presented the highlights of the triennium: the IUCr published three of the six top journals in crystallography (by impact factor); the 100000 th article had been published online; 9 million articles had been downloaded during the triennium; Acta Crystallographica Section E had been fully open access from January 2008 (11 835 articles published); the submission system had been upgraded; and papers covering free-electron lasers were included in Journal of Synchrotron Radiation. Problem areas encountered during the triennium were mentioned and the Chester publishing operation was reviewed. Statistics for individual journals were presented and forthcoming work by the editorial staff at Chester and by the Commission was summarized.

The General Assembly accepted the Report and Professor Kostorz was thanked with applause.

(16) Commission on International Tables

The Report by the Chair of the Commission on International Tables had been distributed to the National Committees and the Commissions in May 2011 and is reprinted in Appendix A5.

The President thanked Professor Brock for taking over as Chair. Professor Brock commented that she found International Tables Online to be particularly good, with excellent hyperlinking between the volumes. She summarized the status of all the volumes and thanked Nicola Ashcroft and the rest of the Chester staff for their work.

The Report was accepted with applause.

(17) Committee on Electronic Publishing, Dissemination and Storage of Information

The Executive Committee had closed this Advisory Committee at its meeting in Toronto, Canada, in 2009.

(18) Committee for the Maintenance of the CIF Standard (COMCIFS)

The Report of the Chair of the Committee for the Maintenance of the CIF Standard (COMCIFS) had been distributed to the National Committees and the Commissions in May 2011 and is reprinted in Appendix A6.

(19) IUCr Newsletter

The Report of the Editors of the IUCr Newsletter had been distributed to the National Committees and the Commissions in May 2011 and is reprinted in Appendix A7.

The President thanked the Editors for their work.

(20) Committee on Crystallographic Databases

The Executive Committee replaced this Advisory Committee by a Working Group of Database Users at its meeting in Toronto, Canada, in 2009 .

(21) IUCr/Oxford University Press Book Series

The Report of the Chair had been distributed to the National Committees and the Commissions in May 2011 and is reprinted in Appendix A8.

The President thanked the Chair and his Committee for their work.

(22) Non-publishing Commissions

The reports of the Commissions on their activities since the Twenty-First General Assembly had been distributed to the National Committees and the Commissions in May 2011. The reports are reprinted in Appendix A5.

The President reported that the Executive Committee had held indepth discussions with the Chairs.

The reports were taken as read and the Chairs of all the nonpublishing Commissions were invited to come to the front of the room to introduce themselves to the delegates.

The General Assembly accepted all the reports with applause.

(23) Proposal for new Commission

The Executive Committee had established an ad interim Commission on Magnetic Structures in January 2010. Professor B. Campbell presented the proposal and the Terms of Reference of the Commission.

The General Assembly approved the formation of a Commission on Magnetic Structures.

(24) Review of existing Commissions

The President reported that the Executive Committee had considered the work of the Commissions and had no recommendations to modify or discontinue any of the Commissions. 
(25) Determination of number of elected members of each Commission

In accordance with Statute $5.10(d)$, the Assembly had to determine the number of persons to be elected on the Commissions until the Twenty-Third General Assembly; these numbers did not include Chairs, Co-editors or ex officio members. The numbers of elected members approved by the General Assembly (Chairs not included) are set out below:

1. Commission on Journals

2. Commission on International Tables

3. Commission on Aperiodic Crystals

4. Commission on Biological Macromolecules

5. Commission on Charge, Spin and Momentum Densities

6. Commission on Crystal Growth and Characterization of Materials

7. Commission on Crystallographic Computing

8. Commission on Crystallographic Nomenclature

9. Commission on Crystallographic Teaching

10. Commission on Crystallography in Art and Cultural Heritage

11. Commission on Electron Crystallography

12. Commission on High Pressure

13. Commission on Inorganic and Mineral Structures

14. Commission on Magnetic Structures

15. Commission on Mathematical and Theoretical Crystallography

16. Commission on Neutron Scattering

17. Commission on Powder Diffraction

18. Commission on Small-Angle Scattering

19. Commission on Structural Chemistry

20. Commission on Synchrotron Radiation

21. Commission on XAFS

(26) Reports of Representatives on Regional and Scientific Associates

In accordance with Statute 8.5, the reports of the Representatives on Regional and Scientific Associates had been circulated with the Agenda papers in May 2011. These reports are reprinted as Appendix A10.

Tables for the Regional Associates were provided so that their (non-voting) representatives could take their place with the delegates.

G. Phillips reported that the 2013 Annual Meeting of the ACA would be held in Hawaii and that an ACA Fellows Program had been introduced.

Se Won Suh reported that the 2010 AsCA meeting in Korea had been attended by 600 scientists from over 30 countries. The next AsCA meeting would be held in Adelaide, Australia, in December 2012, in conjunction with the meeting of SCANZ (Society of Crystallographers in Australia and New Zealand) and the Bragg Symposium celebration.

S. Garcia-Granda reported that the ECA had established a new General Interest Group for Young Crystallographers and this was operating well.

All the reports were accepted.

(27) Reports of Representatives on bodies not belonging to the Union

In accordance with Statute 8.5, the reports of the Representatives had been circulated with the Agenda papers in May 2011. These reports are reprinted as Appendix A11.
The President noted that Professor R. Kuroda, Vice-President of ICSU, had been one of the speakers at the Opening Ceremony.

B. McMahon reported that CODATA had increased visibility and that he had been asked to make presentations at the 2008 and 2010 CODATA conferences.

H. Dabkowska reported that both COSPAR and the IOCG supported the proposal for an International Year of Crystallography.

J. R. Helliwell reported that he worked closely with the CODATA representative and the Managing Editor of IUCr journals.

All the reports were accepted.

(28) Sponsorship of meetings: Sub-committee on the Union Calendar

The Report of the Chair had been distributed to the National Committees and the Commissions in May 2011 and is reprinted in Appendix A9.

The Committee was thanked with applause for its hard work and major contribution to the community.

(29) Confirmation of date and place of Twenty-Third General Assembly

The invitation from the National Research Council of Canada to hold the Congress and General Assembly in Montreal, Canada, 5-12 August 2014, which had been preliminarily accepted in 2008, was formally accepted.

(30) Determination of date and place of Twenty-Fourth General Assembly

In accordance with the amended By-Law 1.3 [see Minute $(10)(d)$ ] the General Assembly could determine the place of the next but one General Assembly, namely the Twenty-Fourth General Assembly to be held in 2017. The President announced that invitations had been received from the Regional Committee of the Czech and Slovak Crystallographic Association to hold the Congress in Prague, Czech Republic, and from the Indian National Science Academy and the Indian Crystallographic Association to hold the Congress in Hyderabad, India. She reported that the Executive Committee had considered the applications and found them to be in order. R. Kuzel presented the formal invitation for the Czech and Slovak Republics and P. Chakrabarti presented the formal invitation for India. A decision on which invitation to accept was delayed until the next session to give the delegates time to consider the choice [see Minute (31)].

The President adjourned the session at 10:00 p.m.

\subsection{Third Session, Saturday 27 August 2011, 7:30 p.m.}

(31) Determination of date and place of Twenty-Fourth General Assembly (continued)

The General Assembly accepted the invitation to hold the TwentyFourth General Assembly in 2017 in India.

(32) Determination of general policy and timetable for period to Twenty-Third General Assembly

There were no comments on this item.

(33) Preliminary consideration of activities for period 2014-2017

There were no comments on this item.

(34) Budget estimates for period to Twenty-Third General Assembly: determination of unit contribution

These budget estimates had been distributed with the Agenda papers and are printed as Appendix A12 to these Minutes.

The General Assembly accepted the budget estimates and approved the recommendation of the Executive Committee to continue the unit contribution unchanged, at CHF 1000, for the years 2012, 2013 and 2014. 
Union

In accordance with Statute 7.1, the initial appointments and the reappointments of the Editors of the publications of the IUCr were made by the Executive Committee and were subject to confirmation by the General Assembly.

The Assembly unanimously confirmed the following appointments and reappointments:

Editor-in-Chief of IUCr journals: G. Kostorz (Switzerland)

Editor of Section A of Acta Crystallographica: W. Steurer (Switzerland)

Editor of Section B of Acta Crystallographica: S. van Smaalen (The Netherlands)

Editor of Section C of Acta Crystallographica: A. Linden (Switzerland)

Editors of Section D of Acta Crystallographica: E. N. Baker (New Zealand) and Z. Dauter (USA)

Editors of Section E of Acta Crystallographica: W. T. A. Harrison (UK), H. Stoeckli-Evans (Switzerland), E. R. T. Tiekink (Malaysia) and M. Weil (Austria)

Editors of Section F of Acta Crystallographica: H. M. Einspahr (USA) and M. S. Weiss (Germany)

Editor of Journal of Applied Crystallography: A. Kaysser-Pyzalla (Germany)

Editor of Journal of Synchrotron Radiation: G. Ice (USA)

General Editor of International Tables: C. P. Brock (USA)

Editor of Volume A: M. Aroyo (Spain)

Editor of Volume B (Third Edition): U. Shmueli (Israel) [G.

Chapuis subsequently appointed as Editor of Fourth Edition]

Editor of Volume C: T. R. Welberry (Australia)

Editor of Volume D: A. Authier (France)

Editors of Volume E: V. Kopský (Czech Republic) and D. B. Litvin (USA)

Editors of Volume F: M. G. Rossmann (USA), E. Arnold (USA) and D. M. Himmel (USA)

Editors of Volume G: S. R. Hall (Australia) and B. McMahon (UK)

Editor of Volume A1: U. Müller (Germany)

Editors of Volume H: C. J. Gilmore (UK), J. A. Kaduk (USA) and H. Schenk (The Netherlands)

(36) Election of Chairs and members of Commissions

The nominations made by the Executive Committee for the Chairs and members of Commissions, after consultation with the Commissions through their Chairs, had been notified to delegates.

Since no other nominations had been made by the delegates, the persons recommended by the Executive Committee were considered elected.

The current full memberships of all the Commissions, including the ex officio members, together with the addresses of the Chairs, are given as Appendix C.

(37) Election of Representatives on bodies not belonging to the Union and on Regional and Scientific Associates

The nominations made by the Executive Committee for those Representatives to be elected by the General Assembly had been notified to delegates. As no other nominations were made, these persons were considered elected.

The names and addresses of the Representatives of the Union, including those appointed ex officio, are given in Appendix C.

(38) Election of Officers of the Union

The nominations made by the Executive Committee for Officers of the Union had been included in the Agenda papers distributed in May 2011. G. R. Desiraju (India) was nominated for President, C. J.
Gilmore (UK) and C. Lecomte (France) were nominated for VicePresident and L. Van Meervelt (Belgium) was nominated for General Secretary and Treasurer. Nine nominations were made for the three six-year vacancies for Ordinary Members: W. Depmeier (Germany), J. M. Guss (Australia), M. L. Hackert (USA), W. T. Klooster (Singapore), C. Mealli (Italy), A. Pietraszko (Poland), Xiao-Dong Su (People's Republic of China), S. Wakatsuki (Japan) and Yu Wang (Taipei). The same nine nominations were made for the one threeyear vacancy for an Ordinary Member. H. A. Dabkowska (Canada) was nominated by delegates for the six-year and three-year terms as Oridinary Member. As there was only one candidate for President and one candidate for General Secretary and Treasurer these candidates were considered elected. Elections for the Vice-President, three ordinary members for the normal six-year term and one vacancy for a three-year term were held by secret ballot. The following nominees were elected:

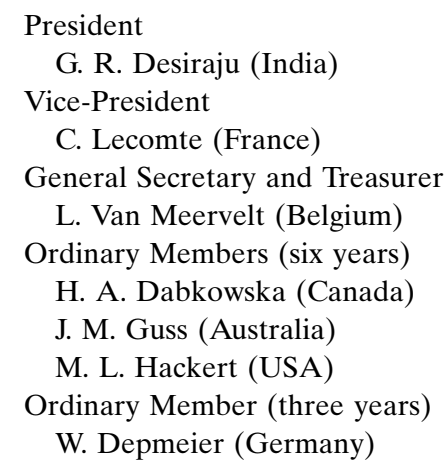

The President congratulated the new members of the Executive Committee and thanked those who would be retiring.

(39) Any other business

As there was no other business and therefore no need for the final session of the General Assembly that had been scheduled for Sunday 28 August, the President declared the Twenty-Second General Assembly closed at 10:20 p.m.

\section{Closing Ceremony, Monday 29 August 2011}

E. Gutiérrez-Puebla (Chair of the Local Organizing Committee) presented a short review of the Congress. Poster Prizes were presented by S. Larsen (retiring President).

S. Larsen, on behalf of the IUCr and the attendees, congratulated the organizers for making the Congress so rich and stimulating, and thanked E. Gutiérrez-Puebla and members of the International Programme Committee and staff for such a successful Congress. The whole Spanish crystallographic community had done a splendid job at a very good venue. S. Larsen thanked the retiring and the continuing members of the Executive Committee for their work and welcomed the new members. G. R. Desiraju, the newly elected President, noted that he had attended IUCr Congresses since 1981 and that as someone who had been trained as a chemist he would be the first President not trained in crystallography. The presence of so many young people at the present Congress and the good progress being made in developing countries showed great hope for the future of crystallography. Scientific fields did not stay the same and it was important that crystallographers continued to redefine the role of crystallography as the field changed. The proposed International Year of Crystallography would help in this regard and he thanked S. Larsen for her work on this. The journals were an essential part of the IUCr and a Journals Review Committee had been established to see 
how new authors could be attracted and to help ensure the continuing success of the journals. He was looking forward to seeing everyone in Montreal in 2014. M. Cygler on behalf of the organizing Committees said a warm welcome would await delegates in Montreal. The Twenty-Second General Assembly and Congress was then declared closed.

\section{APPENDIX $A$ \\ Appendices to the Agenda of the Twenty-Second General Assembly}

\section{A1. Report of the Executive Committee}

A1.1. Executive Committee and Finance Committee meetings. The Executive Committee met in Osaka in August 2008 before and during the General Assembly, in Toronto, Canada, in July/August 2009 at the time of the American Crystallographic Association Meeting, in Darmstadt, Germany, in July 2010 at the time of the 26th European Crystallographic Meeting and in Busan, South Korea, in October 2010 at the time of the Asian Crystallographic Association Meeting. The Finance Committee met in March 2008, August 2008, March 2009, July 2009, March 2010 and August 2010, to prepare its advice and recommendations on finances, establishment and staff matters.

The most important items of business dealt with by the Executive Committee during the triennium at these meetings, and in postal and e-mail ballots between meetings, were:

(1) appointment of co-opted member of Executive Committee;

(2) editorial policy, pricing policy and subscription rates, approval of appointment of Editor for Acta E, approval of appointments of Co-editors, fraudulent papers, electronic publishing, archival policy, Special Issues, education papers, open access, facility information pages, and other matters concerning the IUCr journals;

(3) review of contract with Wiley-Blackwell (formerly BlackwellMunksgaard);

(4) appointment of Editor-in-Chief of Online Dictionary of Crystallography;

(5) approval of audited accounts;

(6) review of Statutes and By-Laws, procedures at General Assemblies;

(7) review of proposed revision to ICSU dues structure;

(8) General Fund estimates and level of unit contribution, status of membership subscriptions;

(9) investment policy;

(10) funding and uses of Publications and Journals Development Fund, Research and Education Fund and President's Fund;

(11) revision of guidelines for the Sub-committee on the Union Calendar, sponsorship and financial support for meetings, young scientists' support, revision of internal guidelines;

(12) revision of guidelines for the Sub-committee on the Union Calendar, sponsorship and financial support for meetings, young scientists' support, revision of internal guidelines;

(13) Journal Grants Fund;

(14) cooperation with databases, open-access databases;

(15) progress with Volumes A, A1, B, C, D, E, F and G of International Tables and development of associated software, appointment of Chair of Commission on International Tables, appointment of new Editors for Volumes B and C, consideration of suggestions for new volumes;

(16) change of publisher for International Tables from Springer to Wiley;

(17) IUCr Newsletter, World Directory of Crystallographers;
Table 1

Total annual number of pages published in IUCr journals.

\begin{tabular}{lrrr}
\hline & 2008 & 2009 & 2010 \\
\hline Acta Crystallographica Section A & 702 & 548 & 724 \\
Acta Crystallographica Section B & 791 & 790 & 706 \\
Acta Crystallographica Section C & 1197 & 1258 & 1134 \\
Acta Crystallographica Section D & 1294 & 1349 & 1354 \\
Acta Crystallographica Section E & 4261 & 5108 & 5195 \\
Acta Crystallographica Section F & 1187 & 1319 & 1684 \\
Journal of Applied Crystallography & 1197 & 1212 & 1543 \\
Journal of Synchrotron Radiation & 666 & $\underline{883}$ & 816 \\
\cline { 2 - 4 } Total & $\underline{11295}$ & $\underline{12467}$ & 13156 \\
\hline
\end{tabular}

(18) promotional activities;

(19) International Year of Crystallography;

(20) appointment of the Selection Committee for ninth Ewald Prize;

(21) sponsorship of other prizes;

(22) discussion of arrangements for Madrid Congress;

(23) approval of membership of Programme Committee for Madrid Congress;

(24) level of financial support for Madrid Congress;

(25) nominations and election procedures for officers of the IUCr and for Chairs and members of Commissions, proposals from National Committees for these positions.

Other items dealt with in this way were:

(26) implementation of the Crystallographic Information File (CIF) for Acta Crystallographica and other uses of CIF, work of Committee for the Maintenance of the CIF Standard (COMCIFS), provision of checking services to other publishers, chemical information, support for mmCIF project and CIF handling software;

(27) IUCr web site;

(28) collection of photographs;

(29) approval of publications, jointly with Oxford University Press, in the IUCr/OUP Book Series;

(30) crystallography in Africa;

(31) Visiting Professorship scheme;

(32) review of activities of Commissions;

(33) revision of General Statement of Principles for Commissions;

(34) proposal for new Commission;

(35) review of activities of Regional Associates;

(36) review of reports of IUCr Representatives on other bodies;

(37) relations with other Scientific Unions;

(38) replacement of Committee on Crystallographic Databases by Working Group of Database Users;

(39) closure of Committee on Electronic Publishing, Dissemination and Storage of Information.

Items concerning the Chester office were:

(40) staffing requirements in the IUCr office in Chester;

(41) risk analysis;

(42) upgrading office technology in the IUCr office in Chester, provision of internet services.

A1.2. Publications. The subscription prices of Acta Crystallographica, the Journal of Applied Crystallography and the Journal of Synchrotron Radiation were increased each year during the triennium.

The total annual number of pages published in 2008, 2009 and 2010 are shown in Table 1.

All the IUCr journals are available electronically through the Crystallography Journals Online service, including all back issues of the journals from 1948, and also through Wiley Online Library. 
The IUCr has two fully electronic journals available online only (Acta Crystallographica Section E: Structure Reports Online launched in 2001 and Acta Crystallographica Section F: Structural Biology and Crystallization Communications launched in 2005). Section E is a fully open-access journal. Section $F$ is available free of charge to subscribers to Section D.

The IUCr home page on the web (http://www.iucr.org/) contains information in the following categories: The Union and its Components (including information on Adhering Bodies, Commissions, Regional Associates, Annual Reports, Congress Reports etc.); Journals, International Tables for Crystallography and Other Publications; News (including the IUCr Newsletter, announcements, meeting reports etc.); Education (including the Online Dictionary of Crystallography); People (including the photographic archive); Resources (including discussion lists); and the International Year of Crystallography.

Full details on the publication of volumes of International Tables for Crystallography are given in the Triennial Report of this Commission (Appendix A5.2 to the Agenda).

The World Database of Crystallographers continues to undergo development to provide increased functionality and to allow online amendments and additions to be made by individual crystallographers.

The IUCr Newsletter is distributed free of charge to 587 libraries and more than 18000 crystallographers and other interested individuals in 102 countries. J. L. Flippen-Anderson and W. L. Duax are the Editors with the editorial office at the Hauptman-Woodward Medical Research Institute at Buffalo, New York, USA, which also handles the distribution. A report on the $I U C r$ Newsletter is given in Appendix A7 to the Agenda.

The IUCr/Oxford University Press Book Series continues to be successful. Details are given in Appendix A8 to the Agenda.

A1.3. Sponsorship of meetings. The Sub-committee on the Union Calendar considers and advises the Executive Committee on requests for IUCr sponsorship and financial support of meetings. The Chair of the Sub-committee is J. M. Perez-Mato. A list of IUCr-sponsored meetings is given in Appendix A9 to the Agenda.

Applications for sponsorship are considered if they are submitted at least nine months in advance of the date of the meeting. Applications will be considered by the Committee four times a year at the end of March, June, September and December. Applications for sponsorship should be timed accordingly. For example, for a meeting to be held in June an application should be submitted by September of the previous year at the latest.

Requests from satellite meetings must be submitted, and possible financial support requested, through the organizing committee of the main meeting.

Meetings (other than satellite meetings) scheduled to be held within two months before or after an IUCr Congress will not be considered for sponsorship. For any meetings scheduled to be held between two and three months before or after a Congress, the application for sponsorship requires the approval of the Chair of the Congress Programme Committee. Meetings (other than satellite meetings) scheduled to be held, in the respective region, within 15 days before or after a meeting of a Regional Associate (American Crystallographic Association, Asian Crystallographic Association, European Crystallographic Association) will not be considered for sponsorship. For any meetings scheduled to be held between 15 days and one month before or after a meeting of a Regional Associate, the application for sponsorship requires the approval of the Chair of the Regional Associate Programme Committee.
IUCr sponsorship can only be given to meetings that are international in character and open to participants from all countries. The membership of the Programme Committee is a good indication of this. National meetings are only supported if held in developing countries.

Active crystallographers should be involved in the organization of the conference and one or more sessions should deal with specific crystallographic topics. This does not automatically include any session on condensed matter physics, materials science or symmetry not related to crystallography. According to these criteria all meetings organized by IUCr Commissions automatically qualify.

The IUCr continues to support and uphold ICSU's policy of non-discrimination and adheres to its decisions and procedures concerning free circulation of scientists. Organizers of any meeting seeking IUCr sponsorship and support must assure the Subcommittee on the Union Calendar that the authorities of the country in which the meeting is to take place guarantee free entrance of bona fide scientists from all countries.

Explicit support from the relevant IUCr Commission(s) is required for any international meeting (except for meetings of Regional Associates).

Travel support for young scientists is available for all meetings (including schools). This money should not be used for waiver of registration fees.

Except in special cases, IUCr funds should not be used to sponsor more than one event per year in the same location.

Registration fees should be the same for both local and non-local participants.

A1.4. Commissions of the IUCr. Each Commission Chair is required to provide a written triennial report to the General Assembly. These reports are included as Appendices to the Agenda. Financial assistance has again been offered to the Commission Chairs, to enable them to attend the General Assembly for the presentation and discussion of their reports and to meet the Executive Committee prior to the General Assembly.

A1.5. Regional Associates, Scientific Associates, and other bodies. The reports of the Representatives on these bodies are given as separate Appendices to the Agenda.

A1.6. IUCr staff. The present members of staff in the IUCr offices in Chester are: M. H. Dacombe (Executive Secretary), M. J. Robinson (Administrative Assistant to the Executive Secretary), P. R. Strickland (Managing Editor), B. McMahon (Research and Development Officer), C. A. Moore (Editorial Systems Developer), A. S. Berry, G. F. Holmes, J. K. Bradshaw, L. E. Jones, S. Conway, N. J. Ashcroft, A. Weight, E. S. Froggatt, S. J. Glynn, L. Stephenson and A. Hill (Assistant Technical Editors), M. A. Hoyland, D. Holden and D. Hoare (Systems Developers), L. Rathbone (Journals Production Assistant), C. Cook (Administrative Assistant) and A. J. Sharpe (Promotions Officer).

A1.7. Acknowledgements. On behalf of the IUCr, the Executive Committee wishes to express its deep gratitude to the Spanish Committee for Crystallogrpahy on behalf of the Subdirección General de Programas y Organismos Internacionales, Ministerio Educación y Ciencia for the invitation to hold the Twenty-Second General Assembly and International Congress of Crystallography in Madrid. It particularly wishes to thank E. Gutiérrez-Puebla (Chair of the Local Organizing Committee and Chair of the International Programme Committee) and M. Martínez-Ripoll and P. Gómez-Sal (Vice-Chair and Secretary General of the Local Organizing Committee, respectively).

Finally, the Executive Committee wishes to thank all crystallographers who have assisted in the work of the IUCr in so many 
Table 2

Balance Sheet, Fund Accounts (Swiss Francs).

\begin{tabular}{|c|c|c|c|}
\hline & $\begin{array}{l}31 \text { December } \\
2007\end{array}$ & $\begin{array}{l}\text { Fluctuations } \\
\text { in rates of } \\
\text { exchange }\end{array}$ & $\begin{array}{l}31 \text { December } \\
2010\end{array}$ \\
\hline General Fund & 247595 & -928362 & -1756091 \\
\hline President's Fund & 91583 & -10581 & 109650 \\
\hline Acta Crystallographica & 1486166 & -233123 & 3068820 \\
\hline Journal of Applied Crystallography & 809248 & -81099 & 844607 \\
\hline Journal of Synchrotron Radiation & 62407 & -5495 & 62163 \\
\hline International Tables & -201479 & 33929 & -420756 \\
\hline $\begin{array}{l}\text { Publications and Journals } \\
\text { Development Fund }\end{array}$ & 901099 & -93648 & 969060 \\
\hline Research and Education Fund & 984254 & -100396 & 947915 \\
\hline Ewald Fund & 529974 & -51767 & 504628 \\
\hline Newsletter Fund & 74015 & -6600 & 9421 \\
\hline $\begin{array}{l}\text { General Assembly and } \\
\text { Congress Fund }\end{array}$ & 34468 & -17907 & 319305 \\
\hline Total accumulated balance & 5019330 & -1495049 & 4658772 \\
\hline Excluding exchange rates & 5263361 & & 5135199 \\
\hline
\end{tabular}

ways. This cooperation between crystallographers of different nationalities constitutes a most valuable aspect of the IUCr's activities.

\section{A2. Financial Report}

The accounts of the IUCr for the calendar years 2008 and 2009 have already been published [Acta Cryst. (2010), A66, 98-126 and (2011), A67, 96-124]. The accounts for 2010 have been audited and will be published in due course in Acta Crystallographica Section A. Extracts from the full financial statements for the three years 2008, 2009 and 2010 are summarized in Tables 2-4. All amounts are expressed in Swiss Francs. The notations used in this report for the various currencies of the IUCr's activities are CHF = Swiss Franc, GBP $=$ Pound Sterling, USD = US Dollar.

A2.1. General financial development. Table 2 shows a comparison of the fund accounts at the beginning and the end of the triennium. The total assets have decreased by CHF 360608 from CHF 5019330 to $\mathrm{CHF} 4658722$, or $7 \%$, over the triennium. These figures include the fluctuations in exchange rates. If the exchange-rate fluctuations are disregarded, the total assets decreased by CHF 128162 from CHF 5263361 to CHF 5135 199, or 2\%, over the triennium.

Table 3 shows the distribution of the assets. The great majority of the amounts under debtors and creditors have been settled since year end.

The total holding of investments at 31 December 2010 is CHF 2458959 at market value, as shown in Table 3, of which $35 \%$ is held by Merrill Lynch and $65 \%$ by Close Brothers. The IUCr bank accounts and short-term deposits are held with the Union Bank of Switzerland, the National Westminster Bank and Merrill Lynch, involving the currencies CHF, GBP and USD.

As an association incorporated in Switzerland, the IUCr is exempt from Swiss Federal and Geneva Cantonal Tax. Under the terms of the United Kingdom/Switzerland Double Taxation Agreement dated 8 December 1977, investment income arising within the UK under present circumstances is not subject to United Kingdom tax. Investment income received from other countries with which Switzerland has a Double Taxation Agreement is also exempt from tax. In October 1985, a recognition of tax-exempt status in the USA was received from the Internal Revenue Service, Department of the US Treasury.

Income and expenditure account. In order to present an overall picture of the state of the Union's affairs, an income and expenditure
Table 3

Balance sheet, Assets (Swiss Francs).

\begin{tabular}{|c|c|c|c|c|}
\hline \multirow[b]{2}{*}{ Fixed assets } & \multicolumn{2}{|c|}{31 December 2007} & \multicolumn{2}{|c|}{31 December 2010} \\
\hline & & & & \\
\hline Tangible fixed assets & & 45456 & & 52746 \\
\hline \multirow[t]{2}{*}{ Investments at market value } & & 3663796 & & 2458959 \\
\hline & & 3709252 & & 2511705 \\
\hline \multicolumn{5}{|l|}{ Current assets } \\
\hline Stock & & 200701 & & 93829 \\
\hline \multicolumn{5}{|l|}{ Cash at banks and in hand } \\
\hline Current accounts & 28811 & & 46360 & \\
\hline Deposit and savings accounts & 637242 & & 1327174 & \\
\hline Cash with Union officials & 17161 & 683214 & 9347 & 1382881 \\
\hline $\begin{array}{l}\text { Debtors, accrued income } \\
\text { and payments in advance }\end{array}$ & & 878821 & & 1070171 \\
\hline Subscriptions due & & 39000 & & 5500 \\
\hline Total current assets & & 1801736 & & 2552381 \\
\hline Deduct Creditors and accrued charges & & -491658 & & -405364 \\
\hline Net current assets & & 1310078 & & 2147017 \\
\hline Total assets & & 5019330 & & 4658722 \\
\hline
\end{tabular}

account for the triennium is included as Table 4. This shows that following a period when the Union was operating at a loss owing to the investment in developing Crystallography Journals Online and International Tables Online, it is now operating with a small surplus of income over expenditure. The Union is predicted to continue to operate with a small surplus in the coming triennium.

A2.2. General Fund. This fund carries the income and expenditure related to the IUCr's administration and its regular scientific activities, other than publications. Table 5 shows a comparison of the budget and accounts for the triennium. The income has two main sources, the subscriptions from Adhering Bodies and the interest income from investments and bank accounts. The subscriptions from Adhering Bodies are based on the unit contribution, which was CHF 1000 for 2008, 2009 and 2010. The income is $16 \%$ lower than the budgeted amount and the expenditure is $5 \%$ lower. It should be noted that the investments are held primarily for long-term gain and now that the Union is operating with a surplus there should be no need to realize any of the investments to any significant extent. The proportion of the investments held as bonds and cash is about $55 \%$. All investment income is assigned to the General Fund.

The administration expenses for the journals are calculated as $45 \%$ of the general administration costs of the IUCr, including the work of the Executive Secretary and his office and of the General Secretary and Treasurer. The Executive Committee met annually (twice in 2010), while the Finance Committee held two meetings in each of 2008, 2009 and 2010. The cost of these meetings varies depending on the location and the circumstances. These costs are included in the expenses of administrative meetings, together with the costs of the IUCr representatives on other bodies. The expenses of scientific meetings include the travel grants and other expenses for the Osaka Congress in 2008, the cost of the 2010 meeting of the Programme Committee for the Madrid Congress, the expenses of the nonpublishing Commissions, financial support to meetings and schools, and the IUCr/FIZ Agreement (which generated income in each year of the triennium). Proportions of the research and development and promotion costs are charged to the General Fund. The financial support for young scientists attending meetings and schools is charged to the Research and Education Fund. 
international union of crystallography

Table 4

Income and expenditure.

2008

Income

Membership subscriptions

Sales

Journals, back numbers and single issues

Books

Open Access grant

Investment income

Income from investments

Bank interest

Profit/(loss) on sale of investments

Other income

Royalties and copyright fees

Advertising income

STAR/CIF income

Total income

Expenditure

Journals

Publication costs

Editorial expenses

Technical editing

Subscription administration

Books

Publication costs

Editorial expenses

Technical editing

Newsletter

Publication costs

Editorial expenses

President's Fund, other grants and young scientists support

General Assembly and Congress costs

Committee meetings and expenses

Publications and journals development

General

Editor meetings

STAR/CIF

Promotion

Subscriptions paid

Visiting Professorships

Administration expenses

General Secretary and Treasurer, including honorarium

Audit and accountancy charges

Legal and professional fees

Travelling expenses

Bank charges

Executive Secretary's office

Salaries and expenses

Travel expenses of IUCr Representatives on other bodies

Commission (income)/expenses

Sponsorship of meetings

IUCr/FIZ Agreement

Bad debts

Depreciation

Total expenditure

Excess of income over expenditure

Realised fluctuations in rates of exchange on trading activities

(Deficit)/surplus of income over expenditure (after realised exchange rate losses)

Movement in market value of investments

Unrealised fluctuations in rates of exchange

Trading activities

Investment activities
159353

4334082

268897

46284

102284

32996

$-22993$

13744

227689

7793

249213

1624148

122410

33566

72304

228159

105873

121678

93642

114660

119870

673563

4466

42686

245389

13302

61756

12032

4795

2514

341547

14279

6621

$-17131$

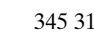

45921

4999783

170346

$-349133$

$-178787$

-972646

$-1151433$

28347

$-872743$

$-844396$

2009

2010

158046

153000

4428868

120359

31728

4580955

4125605

277625

4883

4408113

89373

2064

88162

971

91437

89133

8533

193711

12709

214953

5045391

216563

13719

189731

13113

4866809

606104

322575

1470547

109885

2509111

612887

333134

1371567

108200

2425788

96605

32340

103122

54802

68842

$232067 \quad 79378$

203022

112630

123384

236014

165977

40614

71129

113779

113157

226936

137421

30058

125750

587946

2079

21302

162268

773595
11167
4862

538906

8667

165831

713404

11400

5048

10537

66097

7649

18051

2112

104446

300892

14656

11611

5638

314052

41570

4504604

540787

122575

663362

9544

59186

16450

5279

2569

93028

305507

16922

$-8908$

4479

$-18862$

$-3170$

295968

41481

4309304

557505

$-161625$

395880

639751

1303113

198698

594578

Total recognised (losses)/gains relating to the year

Accumulated balance at 1 January

Accumulated balance at 31 December

$-22019$

$-68593$

$-246259$

$-314852$

$-1995829$

5019330

3023501

1355495

3023501

4378996 
Table 5

General Fund. Comparison of budget and accounts for the years 2008-2010 inclusive (Swiss Francs).

\begin{tabular}{|c|c|c|c|c|c|c|}
\hline & Budget & & Accounts & & Difference & \\
\hline Subscriptions from Adhering Bodies & 456000 & & 470399 & & 14399 & \\
\hline $\begin{array}{l}\text { Yield from investments and bank accounts } \\
\text { (including profit/loss on disposal of investments) }\end{array}$ & 450000 & 906000 & 292861 & 763260 & -157139 & -142740 \\
\hline \multicolumn{7}{|l|}{ Expenditure } \\
\hline Administration (net) & 1434500 & & 1400719 & & -33781 & \\
\hline Subscriptions to ICSU/ICSU bodies & 36000 & & 34804 & & -1196 & \\
\hline Unfavourable variant from budget & & & & & & -47627 \\
\hline Estimated profit or deficit & & -893500 & & & & -893500 \\
\hline Deficit of income over expenditure & & & & -941127 & & -941127 \\
\hline
\end{tabular}

The unfavourable deviation from budget of CHF 47627 is almost entirely accounted for by the drop in investment income, which was $35 \%$ lower than predicted, for the well known financial market reasons that developed in 2008.

A2.3. President's Fund. This Fund is intended mainly for use in emergencies and under special or difficult circumstances, to help crystallographers from countries with currency problems to take part in the activities of the IUCr (especially in connection with the triennial Congresses).

A2.4. Journals Funds. The total number of pages printed for Acta, $J A C$ and $J S R$ were 11 295, 12467 and 13156 in 2008, 2009 and 2010, respectively. The Finance Committee and the Executive Committee have monitored the financial development for all journals very closely. The Crystallography Journals Online service has been available throughout the triennium and is a great success. The onlineonly Acta Section E Structure Reports Online has been fully open access since the beginning of 2008. The online-only Acta Section F Structural Biology and Crystallization Communications was launched at the beginning of 2005 and is accessible free of charge to subscribers to Acta $D$. For further details see the Triennial Report by the Chair of the Commission on Journals (Appendix A5.1 to the Agenda).

A2.5. International Tables. The eight-volume International Tables series was completed in 2005 with the publication of Volume G Definition and Exchange of Crystallographic Data. International Tables Online was launched in 2007. For further details see the Triennial Report by the Chair of the Commission on International Tables (Appendix A5.2 to the Agenda).

A2.6. Publications and Journals Development Fund. This Fund was established in 1984 and has been built up through transfers from other funds. During the triennium the major expenses have been related to the purchase of computer hardware and software, programming and development, promotion, Special Issue costs and projects related to the development of CIF-related products to facilitate deposition of data in crystallographic databases and submission to IUCr journals. It remains the policy of the Executive Committee to support and encourage the IUCr's highly qualified staff by supplying them with the best equipment. Also charged to this Fund are costs of maintaining Crystallography News Online, the crystallographic neXus project (for making CD-ROMs containing a wealth of crystallographic software, extracts of web sites etc. available free of charge to those in developing countries who do not have ready access to the web) and support for the Journal Grants Fund. As the programming and development activities underpin much of the
Union's activity, in 1997 the Executive Committee decided that the associated costs should be assigned to the Journals Funds, the International Tables Fund and the General Fund. In 2001 this principle was extended to the promotion expenses.

A2.7. Research and Education Fund. The fund was also established in 1984 and, like the Publication and Journals Development Fund, has been built up through transfers from other funds. CHF 3624558 was given as young scientists' support during the triennium. Other expenditure involved the Visiting Professorship Programme (CHF 18 904) and a project to support PhD students as part of the Crystallography in Africa initiative (CHF 33 904).

A2.8. Ewald Fund. This Fund is used to finance the triennial Ewald Prize.

A2.9. Newsletter Fund. The fund was established in 1994 following the successful launch of the IUCr Newsletter in 1993. The IUCr Newsletter is currently distributed free of charge to 587 libraries and more than 18000 crystallographers and other interested individuals in 102 countries. The costs to the IUCr were CHF 52353 in 2008, CHF 89331 in 2009 and CHF 91310 in 2010.

A2.10. General Assembly and Congress Fund. The fund was established in 2007 so that the costs associated with the General Assembly and Congress could be spread over the triennium.

\section{A3. Ewald Prize}

The establishment of the Ewald Prize, for outstanding contributions to the science of crystallography, was announced in February 1986 and was given wide publicity. The name of the Prize was chosen with the kind consent of the late Paul Peter Ewald, to recognize Professor Ewald's significant contributions to the foundations of crystallography and to the founding of the International Union of Crystallography, especially his services as the President of the Provisional International Crystallographic Committee from 1946 to 1948, as the first Editor of the IUCr's publication Acta Crystallographica from 1948 to 1959, and as the President of the IUCr from 1960 to 1963.

Shortly after the death of Professor Ewald in 1985, his family informed the President that Professor Ewald had wished to make a bequest to the IUCr. After consulting Mrs Ewald, this generous bequest, together with a donation from the Ewald family and a donation from the IUCr, was used as starting capital for the Ewald Prize. The interest from this capital and further donations from the IUCr are used to finance the Prize. 
The Prize consists of a medal, a certificate and an award of USD 30000 . It is presented once every three years during the triennial International Congresses of Crystallography. The first Prize was presented during the Perth Congress, being awarded jointly to J. M. Cowley and A. F. Moodie. The second Prize was presented during the Bordeaux Congress to B. K. Vainshtein. The third Prize was presented during the Beijing Congress to N. Kato. The fourth Prize was presented during the Seattle Congress to M. G. Rossmann. The fifth Prize was presented during the Glasgow Congress to G. N. Ramachandran. The sixth Prize was presented during the Geneva Congress to M. M. Woolfson. The seventh Prize was presented during the Florence Congress to P. Coppens. The eighth Prize was presented during the Osaka Congress to D. Sayre. In April 2011 it was announced that the ninth Ewald Prize had been awarded to Professor E. Dodson, Professor C. Giacovazzo and Professor G. M. Sheldrick for the enormous impact they have made on structural crystallography through the development of new methods that have then been made available to users as constantly maintained and extended software. Their invaluable contributions to computational crystallography have resulted in the leading program suites $C C P 4, S I R$ and SHELX, respectively. All over the world thousands of crystallographers benefit from their achievements on a daily basis.

The presentation of the Ewald Prize was made during the Congress Opening Ceremony.

\section{A4. International Year of Crystallography}

In 1912 Max Laue showed that X-rays were diffracted by crystals and W. L. (Lawrence) Bragg presented a paper to the Cambridge Philosophical Society both presenting Bragg's Law and the correct structure of zinc blende, which he derived from the X-ray diffraction data obtained from Laue. W. H. and W. L. Bragg rapidly carried out a number of key diffraction experiments of their own that led to the determination of crystal structures that were published in 1913. These groundbreaking experiments mark the birth of modern crystallography. The International Union of Crystallography is marking the centennial of these events by declaring 2013 the International Year of Crystallography (IYCr2013).

The results of a logo competition for IYCr2013 were announced at the Congress.

At their recent meeting in Cuba the ICSU (International Council for Science) Executive agreed to support the proposal that 2013 should be IYCr and this would be on the Agenda for the ICSU General Assembly meeting in Rome in September 2011.

The Director of UNESCO's Division for Basic and Engineering Sciences reports that at the last meeting of the Scientific Board of UNESCO International Basic Sciences Programme (IBSP), the issue of the Year of Crystallography was discussed, and endorsed with strong support. The IBSP Board is an advisory body to the Director General of UNESCO, and it gives recommendations on various actions with which UNESCO may, or may not wish to be associated. In its Report to the Director General the Board thus gives a strong positive recommendation on the IYCr, advising that UNESCO should do whatever is needed to secure formal establishment of the year, and its successful implementation.

One of the UNESCO member states must formally present the proposal so this is the important next step (UNESCO's Executive Board meets in September/October 2011). The IUCr is very grateful to its Moroccan colleagues who have been active in promoting the proposal and it is essential that as many countries as possible lend their support. National Committees for Crystallography are asked to approach their UNESCO country contact to lobby them to support the proposal and it is encouraging that this is now happening. These efforts will be vital in obtaining formal recognition of the IYCr and will be much appreciated by the crystallographic community.

A meeting was arranged at the Congress so that all interested parties could discuss their plans for IYCr2013.

\section{A5. Reports of Commissions of the Union}

\section{A5.1. Commission on Journals}

A5.1.1. Overview. After a large increase in the previous triennium, the number of pages published in the journals fell back to a more normal level, mainly as a result of a shorter article format for Acta Crystallographica Section E. The number of pages published in 20082010 was 42074 compared with 48261 for 2005-2007 and 31521 for 2002-2004. Publication times remained low in the triennium.

The citation impact of IUCr journals continued to be high, with the journals occupying two or three of the top six ranking positions in crystallography. One of the highlights of the triennium was an impact factor of 49.9 for Section A. The primary cause of this record value was a single feature article by G. M. Sheldrick, A Short History of SHELX, which was published in the January 2008 issue of Section A.

Another highlight of the triennium was the publication of the 100 000th article on Crystallography Journals Online. This online service has continued to be popular, with a total of nearly 9 million downloads of journal articles in the triennium. The highest number of downloads was for Section E. A major overhaul of the Crystallography Journals Online platform is planned for the next triennium.

The move of Section E to full open-access publication from 2008 has been a success with 11835 articles published in the triennium and this, combined with the continuing popularity of the hybrid openaccess option for the other journals, has made the IUCr into an important open-access publisher.

Ethics in science publication has been a topic of general concern. The triennium witnessed a number of high-profile retractions in the literature, and the end of 2009 saw the discovery during routine testing of checking software of scientific fraud involving papers published in Section E. This problem emphasized the importance of the role of Co-editors and reviewers in making sure that we carefully and thoroughly review all articles that are submitted for publication. Measures have been taken to improve the checking software as a result of experience with the falsified structures, but in the end the quality of our publications relies heavily on the judgements our Coeditors make based on experience and competent advice.

Obtaining competent reviews within a reasonable time is getting more and more difficult. To assist with this problem, a review panel has been introduced for Section F, and similar panels may be set up for other journals in the future. Other aspects of the submission and review system have been improved during the triennium and referees are now able to provide their reports online.

During the triennium more than 160 Section Editors and Coeditors worked on IUCr journals. The work of all these dedicated colleagues and of the competent and equally dedicated staff at Chester is essential to the well-being of the journals and is highly appreciated.

Finally, let me especially thank the following retiring Section and Main Editors for their major commitment to serving the IUCr journals, namely D. Schwarzenbach (Section Editor of Acta Cryst. Section A), C. P. Brock (Section Editor of Acta Cryst. Section B), J. Simpson (Section Editor of Acta Cryst. Section E), and $\AA$. Kvick and T. Ohta (Main Editors of Journal of Synchrotron Radiation). New Section Editors and Co-editors (over 70 across the eight journals) have been 
sought and nominated during the triennium. Extensive efforts were made to find suitable candidates for each particular position.

\section{G. Kostorz, Editor-in-Chief and Chair of Commission}

A5.1.2. Acta Crystallographica Section A. Section A has continued to publish six issues per year. Among these, there were two full and one partial Special Issues: (a) A 271-page celebration issue entitled Crystallography Across the Sciences 2 on the occasion of the 60th anniversary of the IUCr, containing 24 feature articles, was edited by H. Schenk and published in January 2008. It contains several very well cited articles. (b) A 148-page issue entitled Dynamical Structural Science, containing 14 research papers on time-resolved crystallography, was edited by E. Collet and published in March 2010. (c) Five research papers on Structural Transitions in Solids comprising 53 pages were edited by S. Leoni and published in September 2010. In addition to the Special Issues, Section A published two Lead Articles (28 pages on Three-dimensional Euclidean nets from two-dimensional hyperbolic tilings: kaleidoscopic examples in 2009, and 33 pages on Mode crystallography of distorted structures in 2010) and two historical Feature Articles [on 60 years of IUCr journals in 2009 and on The birth of the European Crystallographic Committee (ECC) and of the European Crystallographic Meetings (ECMs) in 2010].

In the following, numbers always refer to the three years 2008, 2009 and 2010, respectively. The total number of pages published was 702 , 548 and 724 . Of these, 677,455 and 674 pages were devoted to 66,43 and 68 scientific articles (Research Papers, and Lead and Feature Articles) and to 6, 5 and 3 Short Communications. The number of submitted Research Papers, 42, 41 and 47, remained roughly constant, but the total number of scientific papers and pages is larger than in the period 2005-2007. There were no very slim issues. The shrinking of Section A has thus stopped, and this trend is not solely due to the Special Issues (there were also Special Issues in the previous triennial period). The average length of scientific articles remains at about 10 pages $(10.0,10.3,9.8)$. Publication times $(5.3,5.0$, 5.7 months) in the current triennium have increased to an average of about 5.3 months compared with 5.1 months in the previous triennium. Refereeing and deciding on acceptance take about 3.7 months, which seems to be rather long. However, finding willing referees for certain submissions is not always easy: some referees do not respond and others ask for significant extensions of deadlines. Important revisions sometimes demand a major effort of authors. Rejection and withdrawal rates remained high at 33,39 and 39\%. The geographical distribution of the origins of the articles (counted as integral and halfintegral numbers) is remarkably stable with $60 \%$ for Europe, $23 \%$ for the Americas and $17 \%$ for Asia-Australia. The impact factors of 2.4 in 2007 and 2.1 in 2008 are somewhat higher than in previous years, but a record value of 49.9 was attained in 2009 owing to a single publication as explained in the editorial of November 2010. The journal also published 642 pages of Abstracts for the Osaka Congress, 345 pages for ECM-25 and 320 pages for ECM-26.

Section A covers all topics within crystallography, which may be defined as the science of the structure of matter at atomic resolution. The contents of the papers are diverse. The topics may be grouped somewhat arbitrarily into three categories: (i) structure determination with any radiation (phasing, refinement, charge density, aperiodic structures); (ii) structure properties (group theory, tensorial properties, crystal chemistry, topology); (iii) other forms of matter (diffraction physics, diffuse scattering, nanoscience, time-resolved studies, single-particle studies). These categories are on average of about equal importance, even though percentages vary from year to year. A few years ago, it seemed that electron diffraction was disappearing from Section A, but this trend has reversed with submissions belonging to categories (i) and (ii). Neutron diffraction is nearly absent. There is continued submission of manuscripts of macromolecular interest. Some referees would like to see all publications on macromolecular phasing methods in Section D while others applaud the choice of Section A.

Authors now use the electronic submission system almost exclusively. Some referees ask to receive the manuscript directly from, and send the report directly to, the Co-editor. Since Section A Co-editors handle relatively few but often rather long and difficult manuscripts, each of which presents its own characteristics and problems, the handling through Chester does not seem to facilitate operations as much as for other Sections. The electronic system works well enough for all operations a submission might require, but a direct contact with the author is easier when there is no appropriate form letter available.

The success of Section A is due to the combined efforts of many persons. The collaboration with the editorial office in Chester is extremely good, always efficient with very fast and competent answers to all questions. I thank in particular Sue Barnes and Nicola Ashcroft for their competent work and friendly communication. I also thank all the Co-editors, many of whom will retire in 2011, for their often difficult work and decisions. And I thank their successors for their willingness to carry on.

\section{Schwarzenbach, Editor}

A5.1.3. Acta Crystallographica Section B. During the triennium 2008-2010 Section B of Acta Crystallographica continued to publish articles of very high quality. Some articles compared large numbers of structures; others reported new ways of extracting information from diffraction patterns. Still others reported structures in more detail than seemed possible even a few years ago.

The journal continued to publish, as it has since Section C was split off in 1983, six issues per year. There were 91, 90 and 73 articles, and 791,790 and 706 pages during the three years of the triennium. The numbers for 2008 and 2009 were in line with historical averages, but during June-August 2010 a decline in submitted and accepted articles became apparent and has continued into 2011.

Papers came from 41 countries. The one paper not written in English was in German.

The average length of a paper has continued to increase. For 2002 2006 the average was 9.1 pages per article but by 2010 the average was 9.8 pages per article. The amount of supplementary material deposited also continued to rise. Some authors submitted CIFs for structures determined at many temperatures, pressures or degrees of reaction, but included only some of the results in the standard table of experimental details. Other authors attached movies, extra and enhanced figures, and spreadsheets to their articles.

Many articles in Section B have proved to be of very long-lasting value. Two examples are Effective ionic radii in oxides and fluorides (Shannon \& Prewitt, 1969) and Bond-valence parameters obtained from a systematic analysis of the Inorganic Crystal Structure Database (Brown \& Altermatt, 1985), which were downloaded circa 300-400 times each in both 2009 and 2010. The much-discussed 'impact factor' that measures citation rates over a three-year window does not do justice to the continuing importance of the papers published in Section B. The impact factor peaked at 5.4 in 2004 as a result of a special database issue, then dropped to 1.9 in 2005 . It rose steadily to 2.3 in 2008 but then dropped to 1.8 in 2009 . The reasons for the most recent drop are not yet clear. It seems certain, however, that a careful study of citations over a period longer than three years would 
give a more accurate and satisfying picture of the journal's scientific value.

The combined rejection/withdrawal rate for the journal remained high at 35, 34 and $40 \%$ for the years 2008-2010.

While there is a perception that the percentage of papers discussing inorganic structures (i.e. those with primarily ionic or network bonding) is rising, statistics for the years 2002-2010 do not provide convincing support for that idea. Over the last six years the proportions of 'inorganic' and 'organic' papers have fluctuated but are roughly equal overall.

During 2008-2010 four Feature Articles were published. One of these, entitled Significant progress in predicting the crystal structures of small organic molecules - a report on the fourth blind test [Day et al. (2009). Acta Cryst. B65, 107-125], topped both the 2009 and 2010 lists of Section B articles most frequently downloaded.

The average time from submission to publication has dropped from circa six months to five, with authors' revisions accounting for a significant fraction of that time. The submissions system developed in Chester has become very efficient and is easy for all involved (Coeditors, authors and reviewers) to use. We all greatly appreciate the efforts of the Editorial staff to provide solutions to special problems associated with unusual papers.

The efforts of reviewers should also be highlighted. Crystallographers seem to be especially generous with their time and expertise, and they often go far beyond expectations in helping authors improve manuscripts. The journal is in their debt.

The Editorial staff, and especially Jill Bradshaw, continue to turn accepted manuscripts into attractive, carefully edited journal pages. Jill negotiates tactfully, but firmly, with authors when figures need to be improved, and she has a real flair for doing layouts. The quality of the editing is very high. As a crystallographer wrote to us late in 2010: 'I think we can take great pride in the quality of Section B.'

Since the last IUCr Congress a number of Co-editors retired, or will soon retire, from the editorial board. They include Gervais Chapuis, Doug Dorset and Chick Wilson. During their many years of distinguished service they helped the journal learn how to publish papers describing incommensurate structures, diffuse scattering, powder diffraction and electron diffraction. It has been a privilege and a pleasure to work with them.

\section{P. Brock, Editor}

A5.1.4. Acta Crystallographica Section C. The strength of Section $\mathrm{C}$ is the rapid publication of high-quality studies of novel and challenging crystal and molecular structures of interest in the fields of chemistry, biochemistry, mineralogy, pharmacology, physics and materials science, for which a detailed discussion of the structures is presented that goes beyond reporting just the principal numerical and geometrical data.

In 2010, Section C published 284 papers (33 inorganic, 101 metalorganic, 146 organic and 4 communications) in a total of 1134 pages, which is down from the 331 papers $(-14 \%)$ and 1258 pages produced in $2009(-10 \%)$. In the same period, the number of submitted papers fell from 687 to $592(-14 \%)$. The proportion of inorganic $(12 \%)$, metal-organic $(36 \%)$ and organic papers $(52 \%)$ remains within the bands of previous years. The citation impact factor has increased from 0.56 in 2009 to 0.78 , its highest value since 2006. Average publication times remained at 1.9 months. Approximately $53 \%$ of submissions to Section $\mathrm{C}$ in the past year were either subsequently withdrawn by the authors or rejected, which is consistent with the rate generally found over the last seven years. The average number of pages per article continues its upward trend - 3.6 in 2008, 3.8 in 2009 and 4.0 in 2010.

In 2010, Section C published fewer papers than in 2009 and this continues a longer-term trend, which is a concern. In 2005-2007, Section C published around 440 papers annually, but this decreased to 332,331 and 284 in the period 2008-2010. The number of submitted papers was 928 in 2007 and has decreased steadily to 592 in $2010(-36 \%)$. This correlates with the introduction of the new open-access format for Section E. One possible explanation for the decrease in submissions to Section $\mathrm{C}$ is the requirement for an extensive and detailed Comment section in Section $\mathrm{C}$ papers compared with the shorter discussion normally required in a Section E paper. The latter is attractive for authors whose language skills are limited or for those who do not wish to spend so much time on manuscript preparation. Compared with 15 or 20 years ago, authors of Section C papers are probably expected to write much more substantial discussions, so as to keep the journal's style distinct from Section E, but this may be having an effect on the popularity of Section C.

On the other hand, it is pleasing to see an increase in the number of quite substantial papers reporting several related structures in excellent detail, as well as a few manuscripts whose content extends beyond a routine structure report and includes less common aspects of an analysis or results from other techniques, while remaining briefer than what would be required for a Section B style paper. The increase in average paper length appears to be mainly a result of an increasing number of figures in papers.

The time required from submission to acceptance has risen slightly over the last three years. This mostly reflects the increasing difficulty in obtaining responses from reviewers. I have seen numerous cases where Co-editors have to approach extra referees in order to obtain reviews. This is probably systemic of the peer-review system these days. One way to alleviate the difficulty may be to establish a review board.

The requirements in the Notes for Authors have not changed significantly over the last three years, but it has been emphasized more clearly that the journal accepts reports of difficult or challenging structures not meeting all validation criteria, provided the presented structures are correct and unambiguous, and the difficulties and strategies used to treat them are scientifically discussed and properly documented. This is to avoid any misconception that the journal only accepts near-perfect structures.

A few innovations and developments have occurred in the reporting period, although most of these are not specific to Section C. Authors now have the facility to generate additional enhanced crystallographic diagrams online either before or at the time of submission. These diagrams can have dynamic functionality when viewed online. The validation of structure-factor files has been introduced and is now an integral part of the checkCIF suite. This often reveals inconsistencies between the CIF data and the structure factors, which may result from incomplete updating of CIF data after a new refinement, uploading the incorrect version of the structurefactor file or a missed property in the refinement, such as twinning. The submission system has been upgraded by the Editorial staff and now allows better tracking of activity during the review process.

A new initiative planned for the latter part of 2011 is the introduction of virtual issues of the journal. As the journal specializes in the rapid publication of papers, it does not lend itself easily to the production of Special Issues for which long lead times or the holding over of relevant submissions is required. Nevertheless, online publishing readily facilitates the creation of virtual issues, which can 
be used to bring together and highlight papers on specific topics that had been published over the preceding several months. The contents page of the virtual issue then provides suitable links to the original papers. Such virtual issues may focus on topics of current interest, such as twinned structures, polymorphs, metal-organic frameworks, particular classes of chemical compounds and so on. The virtual issue makes it easier for readers to find papers relevant to their field of interest, thus increasing the visibility and impact of those papers. The first virtual issue will focus on polymorphism.

I wish to warmly thank all the Section C Co-editors who have given generously of their time, expertise and effort during the reporting period, as well as the many reviewers and authors, without whom the journal could not exist. I am also grateful to Sandy Blake, Deputy Section Editor, for his assistance with the proof-reading of manuscripts. The invaluable support of the Editorial Office staff is much appreciated, in particular the tireless efforts of Sean Conway, Mike Hoyland, Peter Strickland and the technical editors.

\section{A. Linden, Editor}

A5.1.5. Acta Crystallographica Section D. Section D of Acta Crystallographica continues to play a key role in biological crystallography, focusing both on methods and on structural papers and the insights they bring to biology and chemistry. Structural biology is still expanding rapidly, and crystallographic studies have become integral to many areas of biology. As a result, many more journals now publish crystallographic results and Section D competes in a very large field for structural papers. On the other hand, with increasing automation, crystallographic methods are of intense interest and importance, and Section D is pre-eminent in this area. On average, about half of the papers published by Section D are methodological, with the remainder reporting structural results on biological macromolecules or their complexes. We are pleased that the journal does attract a steady flow of good-quality structural papers, at a rate of about 6-10 such publications per month.

Many important methodological papers each year are contained within the very popular CCP4 Study Weekend series. A CCP4 Special Issue is published each year, with a different theme each time. We are very grateful to the Guest Editors who put these issues together: in 2009, R. J. Read, G. Kleywegt and C. Ballard on Low-Resolution Structure Determination and Validation; in 2010, E. Garman, A. Pearson, C. Vonrhein and C. Ballard on Experimental Phasing and Radiation Damage and in 2011, K. Wilson, K. Cowtan, P. Emsley and C. Ballard on From Crystal to Structure with CCP4. Other Special Issues have also focused on methods: in 2009, papers from a workshop on New Algorithms in Macromolecular Crystallography and Electron Microscopy, with N. Pannu, R. Ravelli and J. P. Abrahams as Guest Editors; and in 2010 a Special Issue on Neutrons in Biology, brought together by P. Langan. This latter issue highlights a renewed interest in the applications of neutron scattering.

A very troubling issue arose during the past triennium, with the discovery of a series of fabricated protein structures, published in a variety of journals. After a lengthy investigation by the University of Alabama, the host institution of the individual involved, it was concluded that at least 13 protein structures had been fabricated. Two papers published in 1999 by Section D have now been retracted, and similar actions have been taken by other journals. It is probably impossible to eliminate fraud completely, but this event has highlighted the need for rigorous validation of structural results. Sections $\mathrm{D}$ and $\mathrm{F}$ now require that validation reports be made available for referees, and more sophisticated validation tests are currently being developed.
We also note an issue that is of importance to all IUCr journals, and particularly Section D. This is the practice, in some high-profile journals, of describing crystallographic procedures only in supplementary data. This means that citations are not picked up by searches, reducing the credit to the authors of methods papers and the apparent impact of our journal. Editorials raising this issue were published in IUCr journals last year and the issue has been raised with the major journals involved.

The technical, visual and production quality of Section D remains superb, and further enhancements of the electronic submission system have made it very user-friendly for editors, authors and referees. The Editorial Office in Chester deserves great credit for this. Publication times are good, at an average of $\sim 4.5$ months for full articles. The size of the journal, after falling in the last triennium with the launch of Section F, has increased gradually in the current triennium from 1294 pages in 2008 to 1354 pages in 2008. The rejection rates in the two triennia were similar at about $12 \%$.

Finally, we thank the many people who contribute to the success of the journal. We particularly wish to thank those Co-editors who step down in 2011 after their nine years of service: N. Chayen, S. E. Ealick, J. M. Guss, H. Holden, W. N. Hunter, M. Pusey and P. A. Timmins. They, together with our other Co-editors, have given much time and wisdom to shepherding papers through to acceptance. We also welcome as newly nominated Co-editors C. S. Bond, Z. S. Derewenda, J. Newman, R. J. Read and M. Schiltz. We also thank our authors and readers; the reviewers whose efforts are critical for maintaining quality; Louise Jones and Simon Glynn for their efforts at the Editorial Office in maintaining superb production quality; and Peter Strickland, as Managing Editor, and Gernot Kostorz, Editor-inChief, for their guidance and management.

\section{E. N. Baker and Z. Dauter, Editors}

A5.1.6. Acta Crystallographica Section E. The years 2008-2010 have seen numerous positive developments and some challenges for our journal. The operational statistics are summarized in Table 6 .

Over the first two years of the reporting period the distribution of papers by country remained approximately constant. In $200947 \%$ of papers had authors from the People's Republic of China, $8 \%$ from India and Malaysia, 5\% from Pakistan, 4\% from the USA and Germany, 3\% from Turkey and smaller percentages from other countries; in total, authors from 75 countries published in Section E during 2009. 2010 saw a sharp decrease in the submissions from the People's Republic of China to $38 \%$ of the total. This fall has, however, been adequately compensated for by increased submissions, particularly from Malaysia to $12 \%$ and with smaller increases from a number of other countries. Despite these annual variations, the openaccess environment of the journal is now fully established and the future of the journal seems secure.

Significant developments in 2008. In August 2008, the founding Section Editors of the journal, W. Clegg and D. J. Watson, retired. They were replaced by W. T. A. Harrison from Scotland, J. Simpson from New Zealand and M. Weil from Austria. As the year progressed it became obvious that the move to open access for Section $\mathrm{E}$ had not only been successful, but experience of continued growth allayed the fears of many sceptics who felt that the requirement to pay for publication would lead to the journal's demise. The checkCIF software was further developed thanks to the efforts of A. L Spek and M. A. Hoyland. In 2008, some new checks on submitted structurefactor (.fcf) files were incorporated into the submission process. These additional checks compare values reported in the CIF with the contents of the structure-factor file and other metrical information 
Table 6

Statistics for Section E.

\begin{tabular}{llll}
\hline & 2008 & 2009 & 2010 \\
\hline Number of papers published & 3556 & 4166 & 4113 \\
Number of pages & 4261 & 5108 & 5195 \\
Average number of pages per paper & 1.2 & 1.2 & 1.3 \\
Average publication time in months & 0.8 & 0.7 & 0.7 \\
Percentage of inorganic papers & 3 & 2 & 2 \\
Percentage of metal-organic papers & 34 & 31 & 30 \\
Percentage of organic papers & 63 & 67 & 68 \\
Number of papers rejected & 391 & 542 & 536 \\
Number of papers withdrawn & 247 & 383 & 404 \\
Impact factor & 0.51 & 0.37 & 0.41 \\
Number of Co-editors & 52 & 57 & 59 \\
\hline
\end{tabular}

that can be calculated directly from the reflection data. One of the results of these additional checks was evidence for some manual editing of CIF files to report better $R$ factors or to alter parameters such as minimum and maximum difference peaks that generate alerts requiring additional input from authors. In such cases the journal's policy is always to challenge the authors directly and, if a suitable explanation is not forthcoming, to reject the article with no right of re-submission. Other difficulties noted in 2008 arose from authors being dropped from or added to papers with no satisfactory explanation. The statement on authorship in the Notes for Authors was modified in an attempt to minimize such occurrences and in more recent times this appears to have been reasonably successful.

Significant developments in 2009. This was a difficult year for the journal, its Editors, Co-editors and editorial staff with the discovery that, in earlier years, it had been subjected to scientific fraud. With tremendous and much valued assistance from A. L. Spek, G. Ferguson and a number of the editorial staff in the IUCr Chester office more than 100 papers were investigated, over a period in excess of six months, and were shown to be fraudulent. The articles were retracted and the retractions were accompanied by an Editorial drawing the attention of readers and the wider scientific community to the existence and nature of the fraudulent activities and exposing the corresponding authors and their institutions. Intense interest was generated by these revelations, both among the scientific community and in all forms of the media. The original Editorial alerting the scientific community to the problems attracted over 15000 downloads. This publicity did give us the opportunity to stress that it was the continuous improvements to our validation systems that first alerted us to the problems and would in future make such problems much easier to detect. The singular benefits of retaining and providing access to .fcf (structure-factor) data files, at that time a unique feature of publications in IUCr journals, was also stressed at every opportunity. These validation procedures, underpinned by checkCIF software, continued to evolve and improve again thanks to A. L. Spek and M. A. Hoyland. Checks on submitted structure-factor (.fcf) files are now routine and a majority of authors are coming to terms with the fact that they need to check their review documents carefully after submission. Occasional problems still occur, particularly with twinned crystals, and work to overcome these is currently in progress in consultation with COMCIFS.

Significant developments in 2010. 2010 has been another extremely busy year for the journal. Fortunately, the frauds that clouded the end of 2009 are now behind us with only 11 further retractions, also of earlier submissions, made recently. Over the past year there have only been a handful of isolated incidents in which submissions have raised concerns for Co-editors. It is pleasing to note that, as we anticipated, the updated validation procedures make early detection of such problems relatively straightforward and also that Co-editors are clearly alert to the possibility of additional frauds. These improvements have been important in ensuring that problems such as element swapping are more readily identified and challenged. We have spent some time this year advocating the inclusion of structure factors amongst material required to be deposited for papers in any journal reporting small-molecule structures. This approach has worked very successfully for protein structures, with data being deposited at the Protein Data Bank (PDB). It would be a major advance if this could also happen for all reports of small-molecule and inorganic structures. A really positive advance came with the checks on submitted structure-factor (.fcf) files, which have been a routine component of the submission process for some time, becoming an option in the checkCIF procedure. This will hopefully minimize the number of 'unexpected' alerts that Co-editors have to deal with.

One possible consequence of last year's fraud revelations has been a significant fall in the number of papers from the People's Republic of China from $46.5 \%$ to $37.6 \%$ of the total. These have largely been compensated for by growth in other areas, with the number of submissions to the journal increasing by a small amount in 2010 (5128 compared to 5113 in 2009). The overall number of published papers fell very slightly in 2010 with 4113 papers published compared to 4166 in 2009 .

We cannot over-emphasize the excellent work done by our Coeditors or thank them sufficiently. Without their commitment, generally acting as referees as well as Co-editors for the papers they receive, this journal would not exist. We have been particularly fortunate in the past year to recruit 18 new Co-editors to join the journal's hard-working team, which now numbers 76 , including the three joint Section Editors. We also gratefully acknowledge the work of several Co-editors who have retired over the past three years. Thanks also to a number of founding Co-editors who, having achieved nine years of tireless service to the journal, will also be leaving the team after the Madrid Congress. J. Simpson will be stepping down as an Editor of Section E at the Madrid Congress. He will, however, remain as a Co-editor. We are delighted to announce that the Executive Committee will be nominating H. Stoeckli-Evans and E. R. T. Tiekink as Section Editors of Acta Cryst. Section E at the General Assembly in Madrid.

Finally, we are especially grateful for the excellent support that we receive from the staff in Chester, in particular Gillian Holmes, Sean Conway and Mike Hoyland for their constant help and support, and to Peter Strickland for his sound advice and continued expert guidance.

\section{W. T. A. Harrison, J. Simpson and M. Weil, Editors}

A5.1.7. Acta Crystallographica Section F. Section F was launched as the IUCr's first online-only biological journal in 2005. In its second triennium, the journal solidified its position as the home for the rapid publication of structure and crystallization communications on biological macromolecules. In 2008-2010 the journal published 990 papers and 4190 pages. The average time from submission to publication, including peer review, rose from an average of 2.3 months in the previous triennium to 3.5 months in 2010, a rise that we suspect reflects an increase in the length of papers (from 3.8 to 4.5 pages) and closer editorial scrutiny sparked by the discovery in 2009 that fabricated structures had been published in a number of important journals.

The initiative to develop a streamlined route from database deposition to publication was completed in 2008. Further evolution, however, has produced dramatic new capabilities, principally a tool 
for authors for drafting either crystallization or structure communications, including tables, figures and text.

Two important new initiatives were launched in the triennium. The first is the creation of a referee panel, a group of about 30 experienced scientists who have agreed to referee 12 papers a year, to reply to requests promptly and to return reports within two weeks. The panel is now in its second year of operation and has reduced referee recruitment delays and provided expert reports, thereby helping to improve scientific quality while at the same time helping to hold down publication times. It has also provided a pool of potential recruits for new Co-editors and two panel members were appointed as Co-editors in 2010.

The second initiative is to provide a dedicated platform for publication of papers from individual structural genomics consortia. The first instance was a special section in the December 2009 issue for eight papers from the RIKEN-UK collaboration. The second was the entire October 2010 issue, which contained some 30 articles from JCSG, the Scripps-based consortium led by I. Wilson. A second Special Issue is now in preparation to highlight the product of the Seattle-based SSGCID, which focuses on the structural genomics of infectious diseases. Each of the Special Issues was made entirely open access at the request of the consortia.

The journal remains a high-quality publication and has been included in Medline and other abstracting and indexing services. Its first impact factor, for 2007 announced in 2008, was 0.645 and, for 2008 and 2009, impact factors were 0.606 and 0.551 , respectively.

\section{H. M. Einspahr and M. Weiss, Editors}

A5.1.8. Journal of Applied Crystallography. During the triennium, the journal continued to attract high-quality papers on a wide range of topics. 1197 pages were published in 2008, 1212 in 2009 and 1543 in 2010. The increase in the number of pages is due to an increase in the number of articles with the average length of articles being 8.1 pages.

One Special Issue was published during the triennium. The issue, which contained 16 articles, covered the important topic of Crystallography Education and Training for the 21st Century, and was edited by K. A. Kantardjieff.

Articles are now exclusively submitted and reviewed electronically, and there was a decrease in the average publication time (from 6.4 months for 2005-2007 to 5.6 months for 2008-2010). The average combined rejection and withdrawal rate was $35 \%$ compared with $27 \%$ for $2005-2007$. The impact factor continued at a high level, peaking at 3.6.

During this triennium a number of Co-editors have retired, or will soon retire, from the Editorial Board. They include D. Chateigner, E. Dodson, S. E. Ealick, J. L. Hodeau, K.-I. Ohshima and T. R. Welberry. It has been a privilege and a pleasure to work with them.

Finally, my sincere thanks are due to the many members of the crystallographic community who have served as reviewers of submitted papers and ensure that this is a high-quality journal, to the Co-editors who oversee the publication fate of the submitted manuscripts, and to the staff at Chester, who have done an excellent job in bringing the articles to publication.

\section{A. Kaysser-Pyzalla, Editor}

A5.1.9. Journal of Synchrotron Radiation. During the period 20082010, a total of 366 articles comprising 2365 pages were published, an increase on the previous triennium. This increase reflects the journal policy of including Special Issues focused on a particular topic, providing informative summaries of important developments in the field to the synchrotron-radiation community. In total, four such Special Issues have been published over the last three years, with further ones planned for the future.

The average impact factor remains high, peaking at 2.3 in 2008 . The average publication time during this period has been reduced, falling from 6.4 months in 2008 to 5.2 months in 2010. The combined rejection and withdrawal rate is just below $30 \%$.

In the next triennium we expect the interest in this field will continue to grow as new facilities for the generation of radiation, including free-electron lasers (FELs), become operational. We fully expect that $J S R$ will remain the pre-eminent journal dedicated to reporting scientific and instrument advancements, regardless of the source technology, in the years to come.

\section{Å. Kvick, D. M. Mills and T. Ohta, Editors}

A5.2. Commission on International Tables. The book series International Tables for Crystallography at present includes eight volumes, A through G and A1. All of them are available both in print and online. A Brief Teaching Edition of Volume A is also available in print.

Since 2008, the second editions of Volumes A1 (Symmetry Relations Between Space Groups, edited by U. Müller and H. Wondratschek) and E (Subperiodic Groups, edited by V. Kopský and D. B. Litvin) have been published, and the second edition of Volume F (Crystallography of Biological Macromolecules, edited by E. Arnold, D. M. Himmel and M. G. Rossmann) will go to press in 2011. The sixth edition of Volume A (Space-Group Symmetry, edited by M. I. Aroyo) is in preparation for publication in 2012 and a fourth edition of Volume C (Mathematical, Physical and Chemical Tables, edited by T. R. Welberry) is planned. A new volume on powder diffraction to be edited by C. J. Gilmore, J. A. Kaduk and H. Schenk is also in the planning stage. New volumes on magnetic symmetry groups (by D. B. Litvin) and on EXAFS have been proposed. Because of the spread of information on space-group symmetry into other volumes in the series, the Chair of the Commission is considering expanding the scope of the Teaching Edition of Volume A so that it would form an introduction to all those volumes in the series, and sections of volumes, that include information about symmetry groups.

All the print volumes are available online as part of International Tables Online, a web site designed by the IUCr. International Tables Online also includes material not available in the printed books. Several new online-only resources are planned, including a symmetry database developed by M. I. Aroyo and co-workers. The database will allow users to retrieve symmetry-group data for any setting of their choice.

The volumes in the series are published by the IUCr in conjunction with a co-publisher. At the start of 2010, the IUCr's co-publishing contract moved from Springer to Wiley. Since then, corrected reprints of the fifth editions of Volume A and the Brief Teaching Edition (edited by Th. Hahn), the third edition of Volume C (edited by E. Prince) and the first editions of Volumes D (Physical Properties of Crystals, edited by A. Authier) and G (Definition and Exchange of Crystallographic Data, edited by S. R. Hall and B. McMahon) have appeared.

The print volumes are selling well and the number of subscribers to International Tables Online continues to grow, in part due to a successful marketing campaign by Wiley. An advantage of the move to Wiley is that the IUCr journals and International Tables are now available from the same co-publisher.

U. Shmueli (editor of Volume B: Reciprocal Space), H. Wondratschek (editor of Volume A1) and H. Fuess (former Chair of the 
Commission) have announced their retirement from the Commission. We thank them warmly for their many valuable contributions to the International Tables series.

Further information about the volumes can be found at the home page of the Commission, http://www.iucr.org/resources/commissions/ international-tables.

\section{P. Brock, Chair}

A5.3. Commission on Aperiodic Crystals. Official meetings of the Commission took place during the Osaka Congress in 2008 and during Aperiodic 2009, in September 2009 in Liverpool, UK. Commission members and consultants have also kept in regular contact via e-mail as well as at various national and international conferences and workshops. The Commission has continued to be active in the promotion of aperiodic crystallography, in organizing meetings and in coordinating activities between the quasicrystalline and incommensurate structure communities. As a major part of these activities, the Commission continued to promote aperiodic crystallography at national, regional and international meetings. The Commission has also been promoting education on aperiodic crystals by organizing several schools and workshops.

International conferences. During the Osaka Congress, aperiodic crystallography was again strongly represented. Three Keynote Lectures were presented in well attended sessions. In addition, four separate Microsymposia were held and again were well attended.

During 2009, the triennial flagship meeting of the Commission, Aperiodic 2009, took place in Liverpool, UK, 13-18 September. Aperiodic 2009 was chaired by R. McGrath and U. Grimm. 110 delegates from 21 different countries attended the conference. The programme started with three tutorial lectures on Sunday afternoon. A public lecture entitled Simple Sets of Shapes that Tile the Plane but Cannot Ever Repeat by Professor Sir Roger Penrose FRS attracted a wide audience.

It was decided at this meeting that Aperiodic 2012 will be held in Cairns, Australia, 2-7 September 2012, and will be chaired by R. Withers.

Further to the activities associated with Aperiodic 2009, one Keynote Lecture and a Microsymposium were dedicated to aperiodic crystals at the 25th European Crystallographic Meeting, Istanbul, Turkey, 6-21 August 2009.

The 11th International Conference on Quasicrystals (ICQ11), took place in Sapporo, Japan, 13-18 June 2010, and was chaired by T. Ishimasa and Y. Ishii. More than 130 delegates from 19 different countries attended the conference. A few talks on incommensurately modulated and composite structures were included in order to favour exchange within the aperiodic crystal community. Three satellite meetings were also organized before or after the conference: International Workshop on Strengthening of Magnesium Alloys by Application of Quasicrystal and Related Phases; International Workshop on Surface of Quasicrystals; and Mathematics of Quasiperiodic Order. During ICQ11 it was decided that ICQ12 will take place in 2013 in Cracow, Poland, and will be chaired by J. Wolny.

Further to the activities associated with ICQ11, two Keynote Lectures and four Microsymposia were dedicated to aperiodic crystals at the 26th European Crystallographic Meeting, Darmstadt, Germany, 29 August - 2 September 2010.

A Special Symposium on quasicrystals honouring Distinguished Professor D. Shechtman on his 70th birthday was organized in Haifa Israel, 12-13 January 2011.

The most important upcoming meeting for the Commission in 2011 is the Madrid Congress. There will be three Keynote Lectures and six
Microsymposia in the field of aperiodic crystallography, which the Commission has helped organize.

Schools and workshops. During the triennium, the Commission has been active in the promotion of aperiodic crystals and in particular for education in this field. Indeed, whereas aperiodic crystals are encountered in many different materials, this area of research remains difficult to tackle for non-specialists.

The Commission thus organized the first International School on Aperiodic Crystals, Carqueiranne, France, 28 September - 2 October 2010 (M. de Boissieu, G. Chapuis, S. van Smaalen). It gathered 54 participants from 19 different countries. This was the first school presenting in the same framework the structure determination and properties of aperiodic crystals.

The Commission is also organizing the two-day satellite meeting Aperiodic Crystals for Beginners as a satellite of the Madrid Congress. This satellite is aimed at providing an easy introduction to aperiodic crystals for beginners in the field and will be held at Alcala de Henares, Spain, 31 August - 2 September 2011.

Several specialized workshops on aperiodic crystals are also organized regularly:

S. van Smaalen organizes a dedicated workshop entitled Workshop on Structural Analysis of Incommensurate Crystals every two years in Bayreuth, Germany. The 6th workshop was held 5-8 March 2009 and attracted about 25 participants. The 7 th workshop will be held 17-20 March 2011.

M. Dusek is organizing the Jana2006 ad-hoc workshop at the Institute of Physics, Prague, Czech Republic. The content (and date) of these specialized lectures is organized on demand. Seven ad-hoc workshops have been organized to date.

Three workshops on the mathematics of aperiodic crystals have been organized:

An EPSRC (Engineering and Physical Sciences Research Council)-supported workshop on Mathematical Aspects of Aperiodic Order was held in Leicester, UK, in August 2009, before Aperiodic 2009, and attracted about 40 participants.

The ICQ11 satellite workshop on the Mathematics of Quasicrystals, June 2010, attracted about 40 participants.

A Workshop on the Mathematics of Aperiodic Order was held in Seoul, Korea, 27 September - 1 October 2010, and attracted about 50 participants.

The 6th Asian International Workshop on Quasicrystals will be held in Seoul, Korea, 30 May - 2 June 2011.

CIF dictionary and web site. Work has continued on updating the CIF dictionary for modulated structures. G. Madariaga is the Commission representative most involved with this in cooperation with the Committee for the Maintenance of the CIF Standard. A new database for incommensurate structures is being implemented within the Bilbao Crystallographic Server.

The Commission maintains web pages on the IUCr web site. A web site on all aspects of the crystallography of aperiodic crystals is maintained by the special interest group (SIG) on aperiodic crystals of the European Crystallographic Association. It is maintained by M. Dusek (Prague, Czech Republic), and may be found at http://wwwxray.fzu.cz/sgip/aphome.html.

\section{M. de Boissieu, Chair}

A5.4. Commission on Biological Macromolecules. The Commission has continued to support the vitality of the biological crystallography community, particularly through recommending and supporting IUCr proposals to hold meetings, workshops and schools. Many meetings of this type have been held worldwide from 2008 to 
2010, notably spanning six continents, and additional meetings are planned and underway.

The Commisison has coordinated with the Protein Data Bank regarding structure-factor deposition requirements, which are now uniformly applied at time of submission. Commission member $\mathrm{T}$. Terwilliger has been appointed as a liaison with the Protein Data Bank and other structural databases to facilitate communication between the IUCr and these essential scientific resources.

A central activity of the Commission has been to contribute to the design of the Madrid Congress. The biologically oriented portion of the International Programme Committee has organized an exciting programme with topics ranging across the field of biological and macromolecular structure. A key highlight of the meeting is that the three macromolecular crystallographers who received the Nobel Prize for Chemistry in 2009 for determination of the ribosome structure (V. Ramakrishnan, T. A. Steitz, A. Yonath) will each give a Plenary Lecture. A large number of students from all corners of the world are expected to attend and participate.

Upcoming activities for the Commission include the appointment of new members and Chair. A related activity is the development of a second edition of International Tables Volume F: Crystallography of Biological Macromolecules, edited by E. Arnold, D. M. Himmel and M. G. Rossmann, which should be ready by the end of 2011. Additional schools and meetings will be sponsored by the IUCr to help in disseminating crystallographic knowledge in the most effective ways to deserving bodies of students. The annual reports of the Commission have referred to specific meetings that have occurred and been sponsored by the IUCr during this period.

The current and future importance of structural biology involving biological macromolecules is great and continually growing. We will see more important intersections with other areas of science and medicine developing in coming times. Crystallography of biological macromolecules has attained a central role in medical discovery and such role(s) will expand in the coming years.

\section{E. Arnold, Chair}

A5.5. Commission on Charge, Spin and Momentum Densities. During the triennium, the Commission was actively and directly (or indirectly through some of its members) engaged in:

(a) organizing international dedicated meetings in the field of charge, spin and momentum densities (CSMD) or planning meeting sessions in these same fields at main crystallographic meetings; the general aim behind these actions was clearly that of developing the field and promoting it among different disciplines and among young scientists;

(b) teaching the specific theoretical and practical issues related to CSMD to new generations of crystallographers and to all those more mature scientists willing to enter into CSMD research or to improve understanding of its basic tenets;

(c) preparing a didactic book covering the main scientific themes relevant to CSMD research;

(d) promoting national or international activities aimed at coordinating the efforts and/or strengthening the impact of CSMD research on several other disciplines, including chemistry (organic, inorganic, metal-organic), physics, materials science, energy science, biology, pharmacology etc.;

(e) fostering the development of ongoing Commission projects and the discussion about and definition of new possible projects;

(f) preparing a Commission web site.

The points listed above are detailed in the following: (a) Special sessions on charge, spin and momentum densities were organized by the Commission or with the help of the Commission for the following crystallographic meetings: the Osaka Congress in 2008, ECM-25 in 2009 (Istanbul, Turkey), ECM-26 in 2010 (Darmstadt, Germany), AsCA '09 (Beijing, People's Republic of China) and AsCA '10 (Busan, Korea). The Commission has also been active in the Programme Committee for the Madrid Congress.

International special charge-density meetings were all very successfully attended. Sagamore XVI (Santa Fe, USA) was organized by P. Coppens in 2009 with over 105 participants from 16 different countries and seven main themes explored in eight oral and three poster sessions. Sagamore XVII will be organized by M. Takata (SPring-8) and will take place in Hokkaido, Japan, in July 2012. The last Gordon Research Conference (GRC) (Mount Holyoke College, USA, 2010) on Electron Distribution and Chemical Bonding was organized by D. Jayatilaka (Chair) and P. Macchi (Co-Chair); there were 92 participants, all the sessions were well organized, with about 20 speakers or discussion leaders who had not spoken previously at the GRC, and the discussions were all very intense. The next Gordon Research Conference will be chaired by P. Macchi in 2013, with W. Scherer as Co-Chair. The triennial 7th International Conference on Inelastic X-ray Scattering (IXS 2010) was organized jointly by the European Synchrotron Radiation Facility (ESRF) and the Politecnico di Milano, with M. Krisch (ESRF) and C. Dallera as conference Chairs. It was held in Grenoble, France, and attracted 162 participants (33 students) from 61 different institutions in Europe, America and Asia. The conference included overview talks, plenary talks, conference sessions organized in ten themes, two poster sessions and a visit to the ESRF. The next conference will be held in 2013 in the USA (exact location not yet available).

Europe is still very active in the field of electron density and in the dissemination of this powerful technique, in particular among the various branches of chemistry, through the European Charge Density Meetings. ECDM-5 was organized by C. Gatti, R. Destro and P. Macchi in Gravedona, Lake Como, Italy, in June 2008. The meeting attracted over 170 participants, from more than 20 countries and four continents, and was held jointly with the annual colloquium of the DFG1178 Project, which is a German-funded project in the field of electron-density research [see point $(d)$ below]. The next meeting (ECDM-6) will be held in High Tatras, Slovakia, in September 2012, and will be organized by J. Kozisek.

(b) As underlined in the previous triennial report of this Commission, the need for education becomes more and more important; in order to develop the field with our young colleagues, initiatives like international schools and advanced workshops to disseminate the emerging techniques in our field are indeed mandatory. Therefore, following also a precise request from the Executive Committee at the Osaka Congress, the Commission has actively promoted two main teaching events. The first was the International Workshop on the Refinement and Analysis of the Electron Density Obtained from High-Resolution X-ray Diffraction, which was organized by $\mathrm{N}$. Bouhmaida and held in Marrakech, Morocco, October 2009. The format was that of a three-day school with lectures given by international teachers and three practical sessions on the use of charge-density software. The workshop, aimed at disseminating knowledge on the most advanced electron-density studies from high-resolution X-ray diffraction data within the African/Magrebin communities, was attended by 35 students from four African countries and four European nations, and was a great success. The second initiative is the 2011 International School on Charge Density, organized by C. Lecomte and F. Lahoz, which will be held in Jaca, Spain, as a satellite of the Madrid Congress. This five-day 
school will include lectures and practical tutorials with charge-density software illustrated by the software authors themselves.

(c) A didactic book (C. Gatti and P. Macchi, editors) covering the state-of-the-art methods and applications of electron, spin and momentum densities research is almost complete. The book includes 21 chapters, with contributions from several authors and, for most chapters, also from different laboratories, to reflect different views or expertise on similar or closely related scientific issues. The book will be published by Springer in 2011 and, owing to the diversity of authors, may be seen as a collective contribution from the CSMD Commission and community to the didactical dissemination of the relevant progress that has occurred in the field in the last ten years.

(d) The Commission, through some of its members, has participated in various forms to the Deutsch Forschungsgemeinschaft (DFG) 1178 Project, which is a German-funded six-year project aimed at disseminating use of and expertise in the charge-density technique in chemistry laboratories, in particular in the field of metalorganic and organic chemistry, but also in materials science and pharmacology laboratories. The project, coordinated by D. Stalke and W. Scherer, and involving more than 30 research groups, is close to completion and seems to have resulted in a surge of interest in charge-density applications and basic understanding.

An initiative, promoted by B. B. Iversen and funded by the Danish National Research Foundation, to establish an international Center for Material Crystallography (CMC) across four continents, started in 2010. It includes four university partners (B. B. Iversen, M. Spackman, D. Cremer, C. Gatti) and three large-scale facilities groups (M. Takata, Spring-8, Japan; B. Chakoumakos, ORNL, USA; P. J. Vicaro, APS, USA), and it is aimed at combining in a unique platform strong competences in synthesis, charge-density characterization and theoretical modelling to tackle some of the key challenges in materials science.

(e) The project on the Constrained Experimental Wavefunction was started in 2005 and is coordinated by D. Jayatilaka (Perth, Australia). It involves seven groups worldwide and concerns the possibility of constraining theoretical wavefunctions of suitable model systems to fit accurate X-ray and polarized neutron experimental data to obtain 'experimentally derived' wavefunctions. The progress of the project has been discussed in a number of Commission meetings and the Commission Chair has solicited D. Jayatilaka to present and discuss the available, intermediate results during the Madrid Congress.

Planning of future projects has also been promoted by the Commission Chair on the occasion of the 2010 Gordon Research Conference. One potential project, coordinated by P. Nakashima, concerns the dissemination of new differential QCBED (quantitative convergent-beam electron diffraction) techniques in a number of international groups to test their performance on a range of materials and to compare them with the current charge-density techniques. Another potential project concerns the pros and cons of the existing and developing charge-density databanks, while a third concerns the charge-density study of some metal-organic compounds with medium-size crystals to compare the quality of data coming from different laboratories and the differences in chemical interpretations of the resulting static and dynamic densities, using the various available topological approaches.

A project on joint charge/spin/momentum density refinements has been considered very worthwhile and interesting, but premature, since presently three different groups are competing on such a relevant topic.

(f) An updated Commission web site (http://iucr_csmd.istm.cnr.it/), hosted at CNR - ISTM, Milano, Italy, and reachable from the
Commission web page maintained by the IUCr at http://www.iucr. org/iucr/commissions/charge-spin-momentum-densities, has been prepared.

The field covers electron, spin and momentum density attracting not only crystallographers but also chemists, physicists, biologists and materials scientists, as testified by the ongoing DFG1178 Project and the establishment in 2010 of the CMC initiative.

Charge-density analysis was traditionally associated with understanding the chemical bonding and the electrostatic properties of matter, but it is more and more moving into the prediction of properties and responses of materials (having organic, inorganic or hybrid nature, as in modern materials and bioscience, and used for functional devices or biomaterials). Both aspects explain the growing impact of charge-density analysis on modern fields of research, including supramolecular chemistry, crystal engineering, complex magnetic materials, molecular reactivity and recognition. With the ever increasing complexity of the systems and materials analysed, the need and the difficulty to enhance our understanding of the relationships among structure, bonding and functionality is also augmented, and the techniques and interpretive tools able to handle challenging topics such as the origin of self-assembly, the atomic level understanding of complex magnets and the bonding in flat potential energy surface materials are also being developed.

Despite, or perhaps just because of, such a widening focus of our field, considerable efforts are also devoted to making progress in fundamental problems in CSMD research - for example, the improvement of existing multipole refinements or maximum-entropy methods, the development of methods for aspherical structure-factor extraction from synchrotron powder data, and the determination of one-electron density matrices from experiment by combining in a unique refinement diverse data coming from different kinds of experiments, in position and momentum space, and from elastic and inelastic scattering.

The CSMD community is open to new complementary techniques such as convergent-beam diffraction, surface diffraction, inelastic $\mathrm{X}$-ray scattering (electronic resonant and non-resonant scattering in the soft and hard X-ray regimes), X-ray absorption, timeresolved X-ray and electron-diffraction experiments, the developing $a b$-initio techniques for handling electron correlation and relativistic effects in crystals. Forefront projects, for example electron density in position and momentum space of atoms, molecules and crystals under thermodynamic constraints: pressure, electric field, photoexcitation, are largely encouraged. Imprints on the experimental electron diffraction of the mixing of certain excited states into the ground state have been recently detected and rough charge-density maps for transient species begin to become available using femtosecond X-ray diffraction.

All these aspects envisage a bright future for our field, experimentally and theoretically.

\section{Gatti, Chair}

A5.6. Commission on Crystal Growth and Characterization of Materials. During 2008-2010 the members of the Commission met three times: in 2008 during the Osaka Congress, in 2009 at Lake Geneva, USA, during the 17th American Conference on Crystal Growth and Epitaxy (ACCGE-17), and in 2010 in Beijing, People's Republic of China, during the 16th International Conference on Crystal Growth (ICCG-16). Active support for crystal-growthoriented schools, conferences and workshops around the world was the main topic of our discussions at these meetings. This was also the main subject of our frequent e-mail interactions during the triennium. 
The next Commission meeting will take place on 23 August 2011, during the Madrid Congress.

The most important meeting for the crystal-growth community was ICCG-16, Beijing, People's Republic of China, 8-13 August 2010 (General Secretary: J. Wang, Commission member) (http:// www.iccg16.tipc.cn/), preceded by the 14th International Summer School on Crystal Growth (ISSCG-14), Dalian, People's Republic of China, 1-7 August 2010 (http://www.isscg14.org.cn/). Both venues were supported financially by the IUCr.

During ICCG-16 some Commission members (K. Byrappa, H. A. Dabkowska, J. M. Garcia-Ruiz, K. Kakimoto, J. Wang, A. Zapettini, E. Vlieg, S. Baldochi, E. Talik and K. Tsukamoto) had an opportunity to get together. Previously, another group of members (D. Bliss, H. A. Dabkowska, T. Duffar, K. Kakimoto, K. Tsukamoto and E. Vlieg) was able to meet in August 2009 at ACCGE-17, Lake Geneva, USA. At both meetings we discussed previous and future activities of the Commission and compared the different approaches to crystalgrowth support in different countries.

In the triennium the Commission received and considered for recommendation to the IUCr applications for support for many different meetings (conferences, schools and workshops) covering various topics from crystallization of biomacromolecular compounds and membrane proteins to crystal-growth methods and fundamentals. The financial support from the IUCr was greatly appreciated. The money was mostly used to help young scientists from several developing countries to take part in these meetings. Commission members and consultants were actively involved in all these and many other meetings, either by organizing the meetings or lecturing. The most important meetings were:

12th International Conference on the Crystallization of Biological Macromolecules (ICCBM-12), in association with the 12th International School on Biomacromolecular Crystallization (ISBC-12), which took place in Mexico, 2-9 May 2009, organized by Commission member A. Moreno.

Workshop on Crystallization: Focus on Membrane Proteins, 10-14 June 2008, Brookhaven, USA, organized by V. Stojanoff (http:// www.nsls.bnl.gov/newsroom/news/2008/07-Crys_Workshop.htm).

II Latin-American Symposium on Polymorphism and Crystallization of Drug and Pharmaceutical Products (LAPOLC 2009), Estancio de Sao Pedro, Brazil, March 2009.

Second International School on Biological Crystallization and International School on Crystallization: Drugs, Foods and Agrochemicals, Granada, Spain, May 2009, organized by Commission member J. M. Garcia-Ruiz (http://www.isbcgranada.org/).

Symposium on X-ray Techniques for Advanced Materials, Nanostructures and Thin Films - From Laboratory Sources to Synchrotron Radiation, European Materials Research Society, Strasbourg, France, June 2009, organized by F. Boscherini.

International Summer School on Fundamentals and Basic Methods of Crystal Growth, Brasov, Romania, August 2009, organized by H. Alexandru (http://rocam.unibuc.ro/intschool/).

Adsorption, Absorption and Crystal Growth, Gargnano, Italy, 1823 April 2010, chaired by Commission member A. Zappettini (http:// icg2010.imem.cnr.it).

Second International School of Crystallization: Drugs, Foods, Agrochemicals, Minerals, New Materials, Granada, Spain, 24-28 May 2010, organized by Commission member J. M. Garcia-Ruiz (http:// www.iscgranada.org/).

In preparation for the Madrid Congress, J. M. Garcia-Ruiz expertly represented the Commission on the International Programme Committee. Five Microsymposia, and two excellent Plenary Lectures (R. Fornari and J. Newman) were accepted.
We are also proud to mention that members of this Commission (S. Baldochi, H. A. Dabkowska, T. Duffar, K. Kakimoto, A. Moreno, E. Vlieg and J. Wang) are active in the International Organization of Crystal Growth (IOCG). This mutual interaction helps with understanding the goals and needs of both the IUCr and the IOCG.

On a personal note, it was a great pleasure and honour for me to Chair the Commission during the period 2005-2011. I believe that promoting understanding of crystal growth is essential for progress in materials science, and I wish the Commission the best in the future challenges.

\section{H. A. Dabkowska, Chair}

A5.7. Commission on Crystallographic Computing. There were several activities during the triennium.

(1) The Commission has organized a Computing School to be held in Mieres, Spain, 16-21 August 2011, immediately prior to the Madrid Congress. As previously, the School will be structured to have formal lectures and tutorials, so that ideas can be exchanged between new students and established programmers. More detailed information is available on the web pages of the School at http://www.iucr.org/ resources/commissions/crystallographic-computing/schools/mieres2011.

(2) Organization of sessions related to crystallographic computing at the Madrid Congress. It was noted at the International Programme Committee meeting in Alcalá de Henares, Spain, that attendance at Computing Commission Microsymposia is higher than at Microsymposia for other Commissions, and we anticipate that this will continue to be the case in Madrid.

(3) During the Chairmanship of the late L. M. D. Cranswick the Commission produced two Newsletters (2008 and 2009, available on the Commission's web site). A lack of response to invitations to contribute prevented the Commission from producing a Newsletter in 2010.

\section{H. R. Powell, Chair}

A5.8. Commission on Crystallographic Nomenclature. Meeting in Osaka. The Commission held a closed meeting on 25 August 2008 during the Osaka Congress.

Online Dictionary of Crystallography. A new Editor-in-Chief, G. Chapuis, was appointed in February 2009. The present Board of Editors is:
A. Authier, Founding Editor
G. Chapuis, Editor-in-Chief
H. M. Einspahr, Editor for biocrystallography
H. D. Flack, Editor
B. McMahon, Administrator

The Online Dictionary is a popular tool and seems to be very much appreciated by the scientific community. A rough estimate shows that some 320 crystallographic definitions are downloaded every day, and new definitions are entered regularly. Interesting exchanges have taken place relative to some definitions, and, in order to enable an online discussion of topics, the Editor-in-Chief and the Administrator have set up an IUCr forum (http://forums.iucr.org).

The Online Dictionary may be consulted at http://reference. iucr.org/dictionary/Main_Page.

Nomenclature issues. Several e-mail debates took place on nomenclature issues:

(a) Non-crystallographic symmetry and local symmetry: the proposed changes were not accepted.

(b) Nomenclature of directions in reciprocal and direct space: it was agreed that the present wording is fine; the use of $\langle 100\rangle^{*}$ to represent a direction in reciprocal space is acceptable. 
(c) Definition of the term 'asymmetric unit': the discussion will be continued at the Madrid Congress.

(d) Proposal to include Seitz symbols in Volume A of International Tables: the discussion will be continued at the Madrid Congress.

\section{A. Authier, Chair}

A5.9. Commission on Crystallographic Teaching. Following the principle of the importance of improving the teaching of the fundamentals of crystallography, during the past triennium the Commission continued to support a series of schools that are already well established, such as the traditional British Crystallographic Association Intensive Course on X-ray Structure Analysis and The Zürich Crystallography School - Bring Your Own Crystals, which Commission member G. Chapuis is strongly involved with.

The Commission also often collaborated with the Commission on Mathematical and Theoretical Crystallography, organizing many different schools: the Summer School on Mathematical and Theoretical Crystallography, Gargnano, Lake Garda, Italy, 27 April - 2 May 2008; the school on Crystallography Online: Databases and Programs on the Bilbao Crystallographic Server, Zarauz, Spain, 2127 June 2009, which was devoted to the use of the virtual possibilities available at the Bilbao Crystallographic Server for teaching and learning crystallography; a School of Fundamental Crystallography, Bloemfontein, South Africa, 12-16 April 2010, with Commission member M. Rademeyer local organizer and lecturer. A long list of teaching events was/is planned with the collaboration of the same Commission and I would like to emphasize that countries such as Morocco, Tunisia, Brazil, Argentina and, recently, Senegal and Zimbawe are starting to be 'active', and there are now plans for regular teaching courses in these countries.

As an example, Commission member R. Baggio reports that the Argentinian Crystallographic Association (AACr) has been promoting crystallographic teaching by including a dedicated school in each of its annual meetings. These have taken place as a satellite activity since 2009. The unexpected success of the schools showed the need for this type of educational venture. The first (2009) was held in the northern province of Misiones, and dealt with General Crystallography; the second (2010) was held at Buenos Aires, and concerned Structure Resolution from Single Crystal Data; the 2011 school will be an important one, taking place in the southern village of Bariloche, at the Balseiro Institute (a renowned Physics Centre in Argentina), with the main subject Powder Diffraction, both from X-ray and neutron sources, and its organization has been partially sponsored by the IUCr. The content of the 2012 school, to be held in mid-east Argentina (Santa Fe province), will be discussed and approved in the AACr meeting immediately following the 2011 school, the main proposed subject being Crystallography and Vibrational Spectroscopy: Two Complementary Visions.

Following the suggestion of the Executive Committee during the meeting in Osaka, the International School of Aperiodic Crystals was organized in September 2010 and held in La Valérane-Carqueiranne, France; Commission member G. Chapuis and the Commission on Aperiodic Crystals were the main organizers.

M. Weiss and P. Spadon were the Co-Chairs of a Microsymposium on Crystallographic Teaching during ECM-26 in Darmstadt, Germany, August 2010.

As the Commission representative on the International Programme Committee for the Madrid Congress, R. Baggio proposed two Microsymposia:

Web-Based Crystallography Teaching: the Use of Modern Communication Methods to Teach Crystallography - Chair. K. Kantardjieff, Co-Chair: G. Chapuis;
Application of Crystal Structure Information in Chemical Education - Chair: L. Infante, Co-Chair: G. Battle (joint proposal by this Commission and the Commission on Structural Chemistry).

P. Spadon and F. H. Allen will be the Co-Chairs of a session dedicated to the celebration of nearly 40 years of effort dedicated to crystallographic teaching by L. Riva di Sanseverino.

Following the positive response to sessions on teaching organized for the 2008 Osaka Congress, K. Kantardijeff collected a series of contributions and these were published as a Special Issue of Journal of Applied Crystallography in October 2010.

\section{P. Spadon, Chair}

A5.10. Commission on Crystallography in Art and Cultural Heritage. The Commission on Crystallography in Art and Cultural Heritage (CrysAC) was established at the Osaka Congress and has two main objectives: crystallography and symmetry in art, and crystallographic (e.g. diffraction-based) analysis of artworks and ancient materials.

Events in 2008. An Evening Session on Art and Crystallography was held at the Osaka Congress with M. Nespolo as Chair and K. Ohsumi as Co-Chair. This session was scheduled on the third day of the scientific programme of the Congress. The intrinsic beauty of crystals and their symmetry inspires artists, while the crystallographic understanding of the beauty of art has been achieved after great effort. Interesting and inspiring talks were presented in an enjoyable evening atmosphere.

A Workshop on X-ray Techniques in Investigations of the Objects of Cultural Heritage, Krakow, Poland, 18-19 September 2008, was organized by the Institute of Catalysis and Surface Chemistry, Polish Academy of Sciences, and the Faculty of Chemistry, Jagiellonian University (http://www.heritagescience.pl/).

Events in 2009. A satellite meeting on Symmetry and Crystallography in Turkish Art and Culture was held in association with ECM-25, Istanbul, Turkey, 14-16 August 2009. The Commission on Mathematical and Theoretical Crystallography in cooperation with CrysAC organized this satellite meeting, which was devoted to the analysis of the crystallographic aspects of art and culture in Turkey and neighbouring countries and regions, such as Middle Asia, Caucasus, Iran, Anatolia and the Middle East, including carpet ornaments and kilim frames. The satellite conference was completed by a workshop entitled Do it Yourself and a short excursion. For more details and the programme, see http://www.crystallography.fr/ mathcryst/istanbul2009.php.

Events in 2010. A Microsymposium on Crystallography in Art and Archaeology was part of ECM-26, Darmstadt, Germany, 29 August 2 September 2010, with the following programme: E. Dooryhée: Introduction; J.-M. Castera: Arabesques for Abu Dhabi - an Octagonal System; Y. Aboufadil: Classification of the Moroccan Ornamental Patterns Constructed by the 'Hasba' Method; J. Fabry: Quasiperiodic Symmetry in a Baroque Church in the Czech Republic; A. Haake: 'Bossenstein' - Unique Ornamentation of 'WeserRenaissance'.

At the poster sessions of ECM-26, J.-M. Castera presented an entertaining practical on patterning and tiling using Zellij tiles.

Commission members A. Rafalska-Lasocha and A. Zürn participated in the International School Hubert Curien: 3rd Course in Structural and Molecular Archaeology on Non-Invasive Analysis of Painting Materials, Erice, Italy, 14-21 June 2010 (http://www.nacho. ulg.ac.be/Summer_School.html).

A Workshop on X-ray Techniques in the Investigations of the Objects of Cultural Heritage, Krakow, Poland, 13-16 May 2010 (http://www.heritagescience.pl/workshop) included a one-day session 
dedicated to Around Rembrandt and his Workshop. This was the third in a series of meetings with the aim of bringing together scientists from relevant disciplines with museum professionals (conservators and curators) responsible for the organization and preservation of art collections. A full report of the meeting may be found at http://crysac.visual-chemistry.net/activities/2010_krakow_ report.html.

Madrid Congress. Two Microsymposia form part of the Madrid Congress: MS46 Powder Diffraction Methods in Archaeometry; MS91 X-ray Absorption, Diffraction and Imaging in Forensic Science and Ancient Materials.

Crystallography of Hispano-Islamic Ornamental Art: Visit to the Alhambra, Granada, Spain, 30 August - 1 September 2011, is an event that has been proposed by CrysAC; the lead person is E. Makovicky (see http://www.iucr2011madrid.es/index.php/satellitemeetings/crystallography-of).

E. Makovicky will present a Keynote Lecture: From Plane Groups to Quasilattices: Hispano-Islamic Ornamental Art of the Alhambra, Cordoba and Sevilla.

A. Zürn is leading a project for a slide/video projection presenting contemporary artists' work related to crystallography. This permanent art exhibition in Madrid in 2011 will possibly include a proposal to interview some artists/designers based in Europe. An exhibition of creative work by art-minded colleagues in crystallography is also being considered (an open call to crystallographers).

Other activities. A newly designed web site is now in place at http:// crysac.visual-chemistry.net/.

A Monograph for the IUCr/OUP Book Series is planned. This is intended to show how crystallography occupies a unique position in bridging the gap between the sciences and the arts, and will comprise three parts: (1) the mathematical theory of symmetry as applied to the study of human artefacts and the different manifestation of the arts; (2) applications of crystallographic techniques to the study of artistic artefacts in all its manifestations; (3) artistic renderings of crystallographic results.

\section{E. Dooryhée, Chair}

A5.11. Commission on Electron Crystallography. The last three years have seen the Commission (CEC) continue to grow in terms of activity, branching out into some new areas, such as reviewing the coverage of electron scattering in International Tables, while continuing to be active in arranging workshops on electron crystallography as well as participating in local and international meetings. For instance, the Commission has been active in sponsoring two or three workshops per year, and has been very involved in the development of precession electron diffraction, which is a tool that has started to penetrate the larger crystallographic community.

More workshops are in the planning stage, a total of five of which have links to the CEC.

Three of the Sub-committees have been very active over this period.

Sub-committee on International Tables. The Sub-committee has completed an extensive analysis of the contents of International Tables and the sections that need to be rewritten to reflect the substantial changes that have taken place (and continue to occur) in electron scattering. The details have been provided to the Commission on International Tables.

Sub-committee on Software for Electron-Based CIF Entries. The Sub-committee has prepared a partial list of CIF entries for electrons, and is continuing to discuss how to handle issues such as images.
Sub-committee on the Gjønnes Medal. This Sub-committee was responsible for publicizing the $2011 \mathrm{Gj} ø$ nnes Medal. After receiving nominations, based upon votes by the full CEC, the next Medal will be awarded to Professors A. Howie and M. Whelan for the development of the dynamical theory of diffraction contrast of electronmicroscope images of defects in crystals, and other major pioneering contributions to the development and application of electron microscopy, diffraction and spectroscopy of materials.

The Commission's home page is maintained by the Chair at http:// www.numis.northwestern.edu/IUCR_CEC.

\section{D. Marks, Chair}

A5.12. Commission on High Pressure. At the Osaka Congress in 2008, the membership of the Commission underwent some major updates with several of the very active members, including the past Chair M. Kunz, Secretary J. Loveday and Treasurer J. Tse, as well as S. Tolbert, R. Winter, N. Hamaya and M. Mezouar, departing after reaching the limit of their allowed terms. New appointments included a new Chair, P. Dera (previously Commission consultant), Secretary I. Loa, Treasurer S. A. T. Redfern, and new members R. Angel (previously Commission consultant), E. Boldyreva, F. Fabbiani, Y. Katayama and H. Liu. The Commission also appointed new consultants, including G. Shen, S. Klotz, J. Loveday and M. Kunz. Furthermore, E. Boldyreva, elected as a new member of the Executive Committee of the Union, has assumed a role as liaison between the Executive Committee and the Commission.

The Commission relies on its unusual size (ten members plus the Chair) to maintain sufficient expertise throughout the broad range of different scientific disciplines, from biology through materials science and engineering to solid-state physics, that cover the interdisciplinary field of high-pressure crystallography.

The past three years brought a number of new exciting and important developments in high-pressure crystallography. The Spallation Neutron Source (SNS) has been built at Oak Ridge National Laboratory, USA. The SNS features a dedicated highpressure beamline, SNAP, which became operational in 2009. A similar state-of-the-art spallation neutron facility, J-PARC, also featuring dedicated high-pressure beamlines, has been commissioned in Japan and received the first beam in 2011. New dedicated highpressure beamlines have been commissioned at two new synchrotrons - Diamond Light Source in Oxford, UK, and Petra III in Hamburg, Germany.

In addition to the new central facilities that have become available on the international scene, significant progress has been made in methodology development of both new and more established experimental approaches. One particular area that has attracted interest and attention is the exploration of amorphous and liquid structures at high pressure using total scattering techniques. Another important recent development is X-ray-based high-pressure imaging and computed tomography. Well established techniques, such as highpressure single-crystal and powder diffraction, have also experienced significant advancements which now permit the collection of data at much higher pressure, with significantly shorter data-collection times and better accuracy.

The role adopted by the Commission in this multidisciplinary and dynamically evolving field is to facilitate and enable the exchange of new ideas and developments. The main tool available to the Commission to achieve this goal is the holding of the annual workshops on high-pressure crystallography. The Commission also helps to shape a strong high-pressure programme at the triennial IUCr Congresses. In addition, Commission members and consultants are 
heavily involved in organizing a variety of summer schools dedicated to high-pressure crystallography (e.g. Erice, Italy, 2009).

Symposia and workshops. For the Osaka Congress, the Commission was represented on the 2008 International Programme Committee by N. Hamaya. The Commission secured six Microsymposia for the Osaka Congress, two of these in association with other Commissions. Two Keynote Lectures were presented by highpressure scientists - G. Galli on Quantum Simulations of Liquids and Solids Under Pressure: Synergy Between Theory and Experiment and S. Klotz on Advances in High-Pressure Neutron Scattering. Numerous posters on high-pressure research were presented under various topics in all three poster sessions. Finally, the Congress organizers offered an excursion to the SPring- 8 synchrotronradiation facility, which is one of the leading facilities for highpressure synchrotron X-ray diffraction.

2009 Commission workshop. The 2009 Commission workshop, entitled Advanced Crystallography at High Pressure, was held at the Harbin Institute of Technology (HIT) in Harbin, People's Republic of China, 19-22 July 2009. The meeting assembled more than 80 scientists from 13 countries. The Local Organizing Committee was chaired by Commission member Haozhe Liu (HIT, People's Republic of China). The topics of this workshop covered the whole range of activities of the Commission and included crystal structures and phase transitions, new materials, earth and planetary science, soft and biological matter, physical and chemical properties, theory and computations, and developments in techniques for high-pressure studies at synchrotron, neutron and laboratory-based facilities. The meeting organizers paid special attention to arrange dedicated slots for talented young scientists and students. All current and immediate past members of the Commission were actively involved in the organization of the work of the meeting, and several chaired sessions during the meeting. Six oral and six poster presentations were selected to be documented in a Special Issue of High Pressure Research. The meeting was financially supported by the IUCr and HIT.

2010 Commission workshop. The 2010 Commission workshop was held in Gatlinburg, TN, USA, near the site of the SNS at Oak Ridge National Laboratory, and was organized by C. Tulk (ORNL, USA). The workshop featured a Plenary Lecture delivered by J. Parise and ten scientific sessions on crystal structures and phase transitions, techniques for high-pressure studies, simple organic systems, geoscience and planetary science, theory and computations, chemistry, biological materials, amorphous, liquid, nano- and noncrystalline solids, and magnetic and electronic phenomena at high pressure. The 2010 workshop was well attended (53 participants from 16 countries) and 42 scientific abstracts were submitted.

2009 Erice International School on High-Pressure Crystallography. A total of 122 international participants convened at the Ettore Majorana Centre for Scientific Culture, Erice, Italy, 4-14 June 2009, for the 41st Course of the International School of Crystallography, co-directed by Commission members E. Boldyreva (Novosibirsk, Russia) and P. Dera (Chicago, USA). This was the second course dedicated to high-pressure research, which followed the very successful first course, organized in 2003 by A. Katrusiak and P. McMillan. The intensive programme of the School spanned ten days and covered a variety of topics, including elements of physics, chemistry, materials science, engineering, implications for geology, planetary sciences, biology and pharmaceuticals. 56 lectures were given by 46 speakers. The lectures were grouped into several thematic blocks: experimental techniques, phenomena, phase transitions, structures and properties, materials of technological importance, and materials and systems of biological importance, including pharma- ceuticals. Five workshops were an integral part of the School and provided hands-on experience for the student participants and a chance to assimilate and test their new knowledge and skills. The School also featured a round-table discussion on the improvement of data collection and processing in high-pressure single-crystal diffraction experiments. A detailed report on the 2009 School has been published in the IUCr Newsletter and is also available at the School web site. Proceedings of the School were published as a monograph in NATO Science for Peace and Security Series B: Physical Science. The School received over USD 100000 in funding from sponsors such as NATO, IUCr, ICDD, NSF, COMPRES, ECA and Kappa-psi, as well as from several industrial sponsors.

Commission meetings. The Commission held meetings during the 2008 Osaka Congress, the 2009 high-pressure workshop in Harbin, People's Republic of China, and the 2010 workshop in Gatlinburg, TN, USA.

Plans and preparations for the Madrid Congress. The Commission has been represented on the International Programme Committee by F. Fabbiani. The Commission secured seven scientific Microsymposia, three of which were co-proposed jointly with other Commissions (Structural Chemistry, Powder Diffraction, Neutron Scattering, Synchrotron Radiation). In addition to the Microsymposia, the Commission proposed two Keynote Lectures to be given by $\mathrm{K}$. Hirose and E. Boldyreva, which have both been approved.

\section{P. Dera, Chair, and I. Loa, Secretary}

A5.13. Commission on Inorganic and Mineral Structures. This report summarizes the activities of the Commission (CIMS) during its third triennium of existence, after its establishment at the Geneva General Assembly in 2002.

The aims that CIMS has pursued since its establishment are as follows:

To strengthen the links and interactions of structural inorganic scientists with the crystallographic community.

To promote the presence at the IUCr meetings of Microsymposia specifically dedicated to the Commission's aims.

To promote, support and organize conferences, symposia, workshops and schools of interest to the crystallographic inorganic community.

To promote the publication of inorganic crystallography matter in the journals and book series of the IUCr and elsewhere.

Contacts between members and consultants. CIMS and the Commission on Structural Chemistry (CSC) exchange consultants. The idea behind the exchange of consultants is to optimize the relationships between the Commissions and to join forces. A. Beatty is the CSC representative in CIMS, and P. Mercier represents CIMS in CSC.

Contacts among the members and consultants of CIMS have been maintained mainly via e-mail and the web site http:// www.crystallography.fr/cims/, administered by M. Nespolo.

Important meetings for additional personal contacts have been:

Osaka Congress (August 2008, http://www.iucr.org/iucr/cong/iucrxxi), where the new composition of CIMS was approved.

25th European Crystallographic Meeting (August 2009, Istanbul, Turkey, http://ecm25.ecanews.org/).

26th European Crystallographic Meeting (August/September 2010, Darmstadt, Germany, http://ecm26.ecanews.org/).

20th General Meeting of the International Mineralogical Association (August 2010, Budapest, Hungary, http://www.ima2010.hu/).

Co-organization and support of scientific meetings. The following meetings and conferences have been proposed/organized/sponsored 
by CIMS. Activities of members and/or consultants of CIMS as organizers/conveners/lecturers are indicated.

Osaka Congress (August 2008): P. A. Thomas was a member of the International Programme Committee; Open Commission Meeting (Coordinator W. Depmeier); MS30 From Minerals to Materials; MS40 Crystallography of Planetary Materials at Extreme Conditions (Co-Chair J. Parise); MS86 Perovskites and Related Materials (Chair D. Pandey); MS89 Space Groups and their Generalizations: A Tribute to E. Ascher and J. J. Burckhardt (Co-Chair M. Nespolo); Keynote Lecture: T. White (Chair G. Ferraris); S.-L. Wang, L. B. McCusker and W. Depmeier chaired Keynote Lectures. During the Congress two poster prizes for mineralogical crystallography (sponsored by EMU and restricted to young scientists up to 35 years of age) and for inorganic crystallography (sponsored by Zeitschrift für Kristallographie) were awarded. During the General Assembly a new Commission on Crystallography in Art and Cultural Heritage was approved with M. Nespolo and W. Depmeier as consultants.

VI International Symposium 'Mineralogical Museums', St Petersburg, Russia, 17-20 June 2008. The meeting was jointly organized by St Petersburg State University, Russia, and Kiel University, Germany. CIMS Chair W. Depmeier was Chair of the Symposium (http:// www.mineral.pu.ru/conf).

II International Workshop on Layered Materials: Structure and Properties, Vercelli, Italy, 28-29 March 2008. G. Ferraris was a member of the Organizing Committee, W. Depmeier, G. Ferraris and D. Pandey members of the Scientific Committee, and J. Rocha an invited speaker. An outcome of this workshop was a Special Issue (5/ 2009) of Zeitschrift für Kristallographie on Layered Materials (Guest editor: G. Ferraris).

4th International Conference on Neutron and X-ray Scattering 2009 (ICNX2009), Kuala Lumpur, Malaysia, 29 June - 1 July 2009.

European Minealogical Union (EMU) School on Advances in the Characterization of Industrial Minerals, Chania, Greece, 14-18 July 2009. G. Ferraris was a speaker. Commission member H. Effenberger is Secretary of the EMU. It is intended to further the cooperation between the EMU and CIMS.

Symposium on Crystallography of Inorganic Materials at High Pressure at AIRAPT2009, the International Conference on High Pressure Science and Technology, Odaiba, Tokyo, Japan, 26-31 July 2009. The symposium was proposed by Commission member $\mathrm{T}$. Nagai, who was also Convener of the Symposium. CIMS consultant J. B. Parise was an invited speaker.

XIX International Conference on the Chemistry of the Organic Solid State (ICCOSS-XIX), Sestri Levante, Italy, 14-19 June 2009. Despite its name, the conference was considered to provide sufficient overlap with the genuine interests of CIMS to justify support.

Conference on Clays, Clay Minerals and Layered Materials, Zvenigorod, Moscow, Russia, 21-25 September 2009. W. Depmeier was a member of the Scientific Committee and also a speaker.

Members of CIMS were actively involved in the 25th European Crystallographic Meeting, ECM-25, Istanbul, Turkey, 16-21 August 2009. Two poster prizes related to the mission of CIMS were awarded, viz the Zeitschrift für Kristallographie Prize (E. Mugnaioli and colleagues, one of whom was W. Depmeier) and the EMU Poster Prize. The selection panel for both prizes consisted of H. Effenberger and G. Ferraris. A. Thalal was a member of both the Scientific Committee and the Programme Committee. G. Ferraris and W. Depmeier chaired Keynote Lectures. O. Yakubovich and M. Nespolo chaired Microsymposia. Oral presentations were given by H. Effenberger, G. Ferraris and W. Depmeier. CIMS suggested that, after the retirement of $\mathrm{H}$. Fuess as officer of the Executive Committee of the ECA, its Focus Area 2 (Materials and Minerals) was under- represented. W. Depmeier was proposed by six councillors as a candidate for one of the open positions, and elected during the council meeting. His special task in the Committee is, amongst other things, the relationship with the IUCr, its Regional Associates and national organizations.

III International Workshop on Layered Materials: Design and Function, Bochum, Germany, 14-15 May 2010 (http://www. layeredmaterials.rub.de/). G. Ferraris and W. Depmeier were members of the Scientific Committee.

Minerals as Advanced Materials II (MAAMII), Kirovsk, Russia, 19-25 July 2010 (http://www.minsoc.ru/maam2010/). The International Programme Committee included T. Armbruster, G. Ferraris and W. Depmeier. The latter and O. Yakubovich gave lectures. W. Depmeier organized the funding for 15 participants from Germany through grants from the Deutsche Forschungsgemeinschaft. A book of the proceedings has been published ( $454 \mathrm{pp}$.).

Several members and consultants of CIMS attended the 26th European Crystallographic Meeting (ECM-26), Darmstadt, Germany, 29 August - 2 September 2010 (http://ecm26.ecanews.org/). P. A. Thomas gave a Keynote Lecture, H. Effenberger made an oral contribution and M. Nespolo chaired a Microsymposium.

Several members and consultants of CIMS attended the 20th General Meeting of the International Mineralogical Association (IMA), Budapest, Hungary, 21-27 August 2010 (http://www. ima2010.hu/). G. Ferraris was Convener of the session on Modularity and Modulation in Minerals and M. Nespolo of the session on Mineralogical Crystallography. T. Nagai made an oral contribution in the session on Mineralogy of the Deep Earth.

First North African Crystallography Conference (NACC1), Casablanca, Morocco, 23-26 November 2010. A. Thalal, who is President of the Moroccan Crystallographic Association (AMC), was a member of the Organizing Committee.

CIMS has supported the applications for financial support by the IUCr for the following meetings planned to be held in 2011:

(i) CCXRDS, XVII International Conference on Crystal Chemistry, X-ray Diffraction and Spectroscopic Studies of Minerals, St Petersburg, Russia, 20-24 June 2011 (http://onlinereg.ru/ccxrds). O. Yakubovich, D. Yu. Pushcharovsky, G. Ferraris and W. Depmeier are members of the International Programme Committee.

(ii) Symposium on X-ray Techniques for Materials Research From Laboratory Sources to Free Electron Lasers, at the EMRS Spring Meeting, Nice, France, 9-13 May 2011 (http://www.emrsstrasbourg.com/).

(iii) Second SMARTER Crystallography Workshop, Aveiro, Portugal, 23-27 May 2011 (http://smarter.web.ua.pt). J. Rocha chairs the Organizing Committee and is also a member of the Scientific Committee.

Other activities of CIMS members. H. Effenberger: Keynote Lecturer (Structural Aspects of Copper Minerals) at the Joint Seminar of the Australasian Mineral Societies, Tasmania, Australia, 3-7 November 2009; representative of the EMU in the Managing Committee of the European Journal of Mineralogy; Secretary of the EMU.

O. Yakubovich: Chair in the organization of the Microsymposium Minerals as Treasury for Advanced Materials at ECM-25 in Istanbul, Turkey; invited lecturer at the XXVIII memorial workshop dedicated to Academician N. V. Belov (Moscow, 18 December 2009): Defects' Ordering as a Parameter of Crystal Structure Stability (Illustrated by the Silicate Minerals); an Associate Editor of The Canadian Mineralogist.

D. Pandey: appointed Co-editor of Zeitschrift für Kristallographie; organizer of a CIMS-sponsored Microsymposium for the Madrid 
Congress; elected Vice President of the Indian Crystallographic Association and the Materials Research Society of India for 20112013.

G. Ferraris: appointed member of the Accademia Nazionale dei Lincei (http://www.lincei.it/); the paperback edition of Crystallography of Modular Materials by Ferraris, Makovicky and Merlino (2008) has been published in the IUCr/OUP Book Series; editor of a special themed issue of Zeitschrift für Kristallographie entitled Layered Materials: Structure and Properties, with contributions by J. Rocha and colleagues, and by W. Depmeier (http://www.oldenbourglink.com/toc/zkri/224/5-6) - the front cover picture was by W. Depmeier, one of the back cover pictures by J. Rocha and his colleagues; appointed series editor of EMU Notes (http://www. minersoc.org/EMU-notes/EMU-notes.html).

D. Yu. Pushcharovsky: elected Academician of the Russian Academy of Science; Assistant Editor of European Journal of Mineralogy, Zapiski RMO and Crystallography Reports; an author of Geology of the Earth's Mantle by Yu. M. Pushcharovsky and D. Yu. Pushcharovsky, Moscow, GEOS, 2010, 138 pp.; one of the organizers of a festival of sciences in October 2010, where he gave an introductory talk.

R. Withers: consultant of the Commission on Aperiodic Crystals (CAC). CIMS and CAC jointly organized a Microsymposium on Modulated Structures as part of the Osaka Congress.

T. J. White: a Co-editor of Acta Crystallographica Section B.

C. Cahill (consultant): has promoted inorganic and mineralogical crystallography by lecturing in the UK (Cardiff, Sheffield, Cambridge, Belfast), Ireland (Dublin) and Germany (Karlsruhe, Stuttgart and Siegen) while on sabbatical as a Fulbright Scholar; served as the 2011 Programme Chair for the Annual Meeting of the American Crystallographic Association; gave an invited lecture at MAM-10: 5th IUPAC Sponsored International Symposium on Macro- and Supramolecular Architectures and Materials, Ocho Rios, Jamaica, 15 August 2010; and is also a member of United States National Committee on Crystallography.

P. Mercier: organizer of a full-day Rietveld Session at the 60th Annual Conference on Applications of X-ray Analysis (http://www. dxcicdd.com/11/index.htm).

W. Depmeier: Following his presentation at ECM-25, he was invited to present three lectures in Austria covering the same topic, viz Minerals as Advanced Materials; member of the International Programme Committee of the Madrid Congress; a new mineral has been named after him; nominated honorary member of the Russian Mineralogical Society.

\section{W. Depmeier, Chair}

A5.14. Commission on Mathematical and Theoretical Crystallography. Meetings and schools. In the years 2008-2010 the Commission (MaThCryst) organized seven events, which were attended by a total of 296 unique participants (i.e. participants who attended several events are counted only once) from 39 countries from five continents:

Summer school in Gargnano, Italy, 27 April - 2 May 2008 (http:// www.crystallography.fr/mathcryst/gargnano2008.htm), in cooperation with the Commission on Crystallographic Teaching.

Crystallography Online: International School on the Use and Application of the Bilbao Crystallographic Server, Lekeitio, Spain, 21-27 June 2009, supported by the Spanish National Committee for Crystallography, the Commission on Crystallographic Teaching and the ECA Special Interest Group No. 5: Mineral and
Inorganic Crystallography (http://www.crystallography.fr/mathcryst/ bilbao2009.php).

Symmetry and Crystallography in Turkish Art and Culture, Satellite Conference of the 25th European Crystallographic Meeting (ECM-25), Istanbul, Turkey, 14-16 August 2009 (http://www. crystallography.fr/mathcryst/istanbul2009.php).

School on Fundamental Crystallography, Bloemfontein, South Africa, 12-16 April 2010, in cooperation with the Commission on Crystallographic Teaching (http://www.crystallography.fr/mathcryst/ SouthAfrica2010.php).

Summer Schools on Mathematical Crystallography: Topological Crystal Chemistry: Theory and Practice and Irreducible Representations of Space Groups, Nancy, France, 21 June - 2 July 2010 (http://www.crystallography.fr/mathcryst/nancy2010.php).

Satellite Conference of the XXVI European Crystallographic Meeting (ECM-26), Darmstadt, Germany, 27-29 August 2010 (http:// www.crystallography.fr/mathcryst/darmstadt2010.php).

International School on Fundamental Crystallography, followed by a one-day Workshop on the Representation Theory of Space Groups, Montevideo, Uruguay, 29 November - 4 December 2010 (http:// www.crystallography.fr/mathcryst/montevideo2010.php).

In addition to the above independent activities, MaThCryst also (co)-organized three events at the Osaka Congress:

KN29 Keynote lecture on Metal-Organic Materials: Strategies Toward Functional Porous Materials by M. Eddaoudi, Chair SueLein Wang, in cooperation with the Commission on Structural Chemistry.

MS89 Microsymposium in honour of E. Ascher and J. J. Burckhardt, Chairs H. Grimmer and M. Nespolo.

Evening Session on Art and Crystallography, in cooperation with the Commission on Crystallography in Art and Cultural Heritage, Chairs M. Nespolo and K. Ohsumi.

Publications. A Special Issue of Journal of Applied Crystallography - Volume 43, Part 5 Number 2 (October 2010) - devoted to Crystallography Education and Training for the 21st Century published an invited article by M. Nespolo and B. Souvignier (http:// journals.iucr.org/j/issues/2010/05/02/issconts.html).

The book Graph Theory in Crystallography and Crystal Chemistry (a Monograph in the IUCr/OUP Book Series), which was expected by 2009, has been delayed because of the passing away of J. Rutherford, senior author. B. Souvignier joined the pool of authors and the book is now expected by late 2011 - early 2012.

Didactic material and abstracts. Didactic material and abstracts from oral and poster presentations at MaThCryst schools and satellite meetings are available from the respective web sites (addresses given above).

Future activities. Planned activities include:

A School on Fundamental Crystallography in Mahdia, Tunisia, was planned for April 2011, but the recent events in the region obliged us to move it to a future date - most likely late 2011 (http:// www.crystallography.fr/mathcryst/mahdia2012.php).

Satellite meeting of Madrid Congress: Online Edition of International Tables for Crystallography: Databases and Applications of Space Groups and Their Symmetry Relations, Bilbao, Basque Country, Spain, 31 August - 3 September 2011 (http://www. iucr2011madrid.es/index.php/program/satellite-meetings).

A Workshop on Crystallographic Software at the Tokyo University of Science, Tokyo, Japan, was planned for 23-27 May 2011, but has been postponed until December 2011 because of the tsunami; the aim of the workshop is to give participants a detailed introduction to the theory and approaches behind the packages that will be presented, 
not a blind-user approach (http://www.crystallography.fr/mathcryst/ tokyo2011.php).

A Workshop on Mathematical Crystallography in Manila, Philippines, 2-6 November 2011 (http://www.crystallography.fr/mathcryst/ manila2011.php).

Other activities that are currently under discussion:

A workshop in India, under the responsibility of Commission consultant D. Pandey (dates to be fixed);

A contribution to an American meeting; W. L. Duax, former IUCr President, has promised to help MaThCryst to obtain logistic help since the Commission has more difficulties affirming its presence in North America;

A School on Graph Theory in Crystallography and Crystal Chemistry, after the publication of the book with the same title;

A Workshop on the Manifold Description of Modulated Structures and the Use of Differential Geometry to Describe Crystal Structures, proposed by Commission member S. Hyde;

A book entitled Geometric Algebra in Crystallography, currently under consideration by the IUCr/OUP Book Series Committee;

A School on Fundamental Crystallography in Uberlandia, Brazil (probably October 2012), which will be the natural successor to the school held in Montevideo, Uruguay, in 2010.

\section{Nespolo, Chair}

A5.15. Commission on Neutron Scattering. Following the threeyear cycle of the IUCr Congress and General Assembly, the Commission on Neutron Scattering (CNS) began and ended its term with the preparation and implementation of its proposals for Keynote Lectures and Microsymposia. The Commission has considered it to be more interesting for the community to make proposals on topics that emphasize the use of neutron scattering in different areas of research and the complementarities with other techniques. In this sense we have favoured synergy with other Commissions. We believe that these proposals highlight the special features of neutrons as a probe and show the areas of physics, chemistry, biology, materials science etc. where its contribution can be crucial.

Even if the severe selection from the very large number of propositions meant that not all of our suggestions were accepted, it was pleasing to see that in both Congresses neutron techniques are very well represented.

In 2008 the Commission was especially active as five Microsymposia were organized for the Osaka Congress, and three more Microsymposia were organized in collaboration with other Commissions. Two Keynote Lectures were proposed by the CNS; however, there were a number of lectures related to results obtained by neutron scattering proposed by other Commissions. Y. Fujii (former Chair of this Commission) was the Chair of the International Programme Committee (IPC) and T. Kamijama the Secretary of the IPC.

Similarly, in the programme prepared for the Madrid Congress, two Keynote Lectures proposed by the Commission have been retained and seven Microsymposia are directly related to neutron scattering.

During the last three years, a large number of international meetings and workshops on neutron scattering took place all over the world. Of particular interest for the neutron-scattering community is the International Conference on Neutron Scattering (ICNS), which took place in Knoxville, Tennessee, USA, in 2009. It is, nevertheless, noteworthy that a large number of sessions dedicated to the applications of neutron techniques were included in crystallographic conferences such as the American Crystallographic Association
Annual Meeting in Toronto, Canada, in 2009, the 26th European Crystallographic Meeting in Darmstadt, Germany, in 2010, and the Asian Crystallographic Association Conference (AsCA 2010) in Busan, Korea, in 2010.

During the last triennium an increasing number of schools and workshops have been devoted to the promotion of the use of neutrons. It can be observed that there is a broadening of the areas of application of neutron scattering, which starts playing a major role in energy-related materials, geology, and bio- and nanoscience.

The Commission has supported several of these workshops and in other cases its members were involved at different levels in many of these events.

It was good news that the Indian Neutron Scattering Society (INSS) was formed in June 2008 with the objective of promoting the research and development of neutron-scattering applications. Two years later, India became a member of the ILL to facilitate access to neutron techniques for its user community.

We also welcome the formation of the Asia-Oceania Neutron Scattering Association (AONSA), a coordinating body of activities of the neutron-scattering societies of the member countries (currently Australia, India, Japan, Korea, Taiwan), to liaise with the regional neutron-scattering societies of Europe and North America on international activities. The CNS is collaborating with AONSA to put forward a proposal to the International Council for Science (AsiaPacific region) to develop the training of promising young scientists to acquire experience with neutron methods beyond short training courses.

From the point of view of neutron sources, the last three years have been a particularly rich period. The Spallation Neutron Source (SNS), in the USA, broke the $1 \mathrm{MW}$ barrier and there are now 13 operating instruments. JPARC in Japan produced its first neutrons in 2008 and the power level of $200 \mathrm{~kW}$ was reached in December 2010. Ten instruments were completed and opened for users at the Material and Live Science Experimental Facility. OPAL in Australia restarted in May 2008 following approval of the new fuel design and seven neutron-beam instruments operated in 2010. The CARR reactor of the China Institute of Atomic Energy (CIAE) achieved first criticality on 13 May 2010.

In Europe, ILL in Grenoble, France, has completed the first phase of its Millennium Programme; the second phase is well underway and has already delivered upgraded instruments, giving an improvement factor of 20 in the average detection rate. In August 2008 the ISIS second target station project detected the first neutrons followed by the Phase Two Instruments Project with the aim of building four new instruments. FRM-II, the high-flux reactor source in Munich, Germany, has continued increasing its instrumental park and the ten-year programme for renovation of the IBR-2 reactor (Frank Laboratory of Neutron Physics, Joint Institute for Nuclear Research, Dubna, Russia) was finished in December 2010. Additionally, in 2009 it was decided that the site for the future $5 \mathrm{MW}$ long-pulse European Spallation Source (ESS) should be Lund, Sweden.

The Commission held an Open Meeting in 2008 with some of the previous members and some of the new. After this, interactions have been through mail exchanges or informal meetings of some of the members when attending conferences or neutron facilities.

It has been decided to renew contact with the publication Neutron News. Initially we will present the CNS to the neutron community (not only diffractionists) in order to use it as a link between crystallographers and neutron-scattering scientists.

The CNS has also decided to set up a Commission web site. Its content is being developed and it will be discussed in the next Open Meeting of the CNS to be implemented by the current Chair. 
The formation of a Commission on Magnetic Structures will be proposed at the Madrid General Assembly. The CNS supports this specialized group and has proposed some of its future members. The purpose of this new Commission would be very precise and focused; i.e. to promote and establish some standards in the description and the reporting of magnetic structures.

The CNS will maintain a great interest in magnetism, as neutron diffraction is the main technique for the determination of magnetic structures, and we look forward to working with the new Commission (if approved) in forthcoming years.

We would like to end this triennial report by remembering our colleague and Commission member Professor Robert Bau, who passed away on 28 December 2008. He was a distinguished chemist, diffractionist and neutron-scattering expert, and will be missed by the CNS and the whole neutron community. To honour his memory a symposium focused on research achievements and the future of studies involving hydrogen was held at the American Crystallographic Association Annual Meeting in Chicago, USA, in 2010.

\section{T. Fernandez-Diaz, Chair}

A5.16. Commission on Powder Diffraction. Web site and visibility. The most visible change in the activities of the Commission (CPD) during the triennium was the transfer of the Commission web site from the Rutherford Appleton Laboratory to servers based at the IUCr in Chester (http://www.iucr.org/resources/commissions/powderdiffraction). This gives the web site a permanent home. During the process a number of pages relating to the Quantitative Phase Analysis Round Robin were retrieved and are now available for viewing once more. Another addition to the web site concerned some suggestions for 'self-test' samples for structure determination from powder diffraction from organics.

A small information poster outlining the history and work of the CPD was created in 2009. The poster has been displayed by members at a number of meetings and increases the visibility of the CPD in the community using powder diffraction, be they chemists, materials scientists, mineralogists etc.

Projects. The 'self-test' organics partially addressed an ongoing project for an organic standard to validate structure solution from powder-diffraction data. Although a number of materials have been considered, none so far has combined the required complexity and stability. The various structure databases form one group of major stakeholders in the quality of structures determined from powderdiffraction data. The CPD Chair has discussed some of these issues with the Cambridge Crystallographic Data Centre (CCDC). Although the Cambridge Structural Database (CSD) has many quality-control checks, the CCDC understandably has less experience in gauging the quality of structures submitted that are derived from powder data. The IUCr journals have also expressed an interest in a quality-verification process for powder CIFs, since the findings from the checkCIF process are often not very valuable for powder structures. The CPD had considered holding a meeting around the general area of structure validation for many years and the recent controversy around publications of dubious and bogus structures gave this some impetus. Consequently the CPD is organizing a workshop in 2012 entitled Accuracy in Structure Solution from Powder Diffraction Data to be held as a satellite to the ECM in Bergen, Norway. The choice of the ECM as opposed to the powder-diffraction-focused EPDIC meeting was deliberate, given the increasing number of single-crystal practitioners beginning to publish structures from powder-diffraction data.
In late 2008 the CPD project to produce a comprehensive powderdiffraction book came to fruition with the publication of Powder Diffraction - Theory and Practice, edited by R. Dinnebier and S. Billinge, published by the Royal Society of Chemistry. As it happens, two other excellent texts were published around the same time (Fundamentals of Powder Diffraction and Structural Characterization of Materials, 2nd edition, by V. Pecharsky and P. Zavalij, and Principles and Applications of Powder Diffraction, edited by A. Clearfield et al.), so powder diffraction is better served with quality texts than has been the case for many years.

The usage of residuals in powder diffraction is troublesome given the many different residual functions available, but there exists no standard, well accepted approach. This is a widely known and acknowledged issue, but so far we have not been able to frame the problem in a way amenable to a project. It is certain that the subject will be revisited in the future.

Meetings. The Commission managed to hold a meeting each year, although the attendance at the meeting during the Toronto ACA meeting in 2009 was rather weak. C. J. Gilmore has been an observer on the CPD for the Executive Committee and has routinely attended the CPD meetings. He was unavailable for the 2010 meeting held in Darmstadt, Germany, and S. Larsen agreed to attend in his place to give feedback from the Executive Committee.

Madrid Congress. The CPD representation on the International Programme Committee was increased to three members from the single representative at the Osaka meeting: the current CPD Chair, R. Cerny (Geneva, Switzerland) and N. Masciocchi (Como, Italy). The capability for increased interaction with representatives from the other IUCr Commissions resulted in an improved and more integrated programme for Madrid from the perspective of powder diffraction.

International Tables. The IUCr Executive Committee approved the creation of a Volume H of International Tables dedicated to powder diffraction. Progress is moving along steadily under the guidance of C. J. Gilmore as a Main Editor. An outline of the contents has been distributed in the last year and J. A. Kaduk and H. Schenk have agreed to serve as additional joint Main Editors.

CCP14. The CCP14 web site has been a valuable resource to powder diffractionists globally for many years. The end of funding for the web site hindered what was a flourishing resource for freely available powder-diffraction software and educational materials. The CPD was asked by R. Cernik in 2010 to support an application to the UK's EPSRC to resume funding to CCP14, which was enthusiastically given. The year 2010 was also notable for the untimely passing of L. M. D. Cranswick, who had been the dynamo behind the CCP14 web site for many years and was heavily involved in many CPD activities.

Education. Education is an ongoing concern for all of the IUCr Commissions and the CPD is no exception. Despite the growing use and application of power diffraction, education in powder-diffraction techniques is particularly weak, as it is often given minimal mention during mainstream crystallography courses. The upcoming Erice powder-diffraction crystallography school in June 2011 may give an opportunity to provide teaching material accessible to non-specialists, either through the CPD web site or elsewhere. Ironically, although powder-diffraction education may be weak in the developed world, powder diffraction may be a starting point for crystallographic education in the developing world. The heavy use of powder diffraction in the resource sector and relatively simple instrumentation provide a good 'market' for diffraction education. The CPD is exploring the possibility of organizing a workshop in South Africa in 2013, hopefully including a hands-on component. 
One recent development impacting the need for improved education is the availability of mail-in services on highcalibre synchrotron and neutron diffractometers. Examples of this include the 11-BM mail-in programme (http://11bm.xor.aps.anl.gov/ GUPguideintro.html) at the APS, and the GEM-Xpress programme (http://www.isis.stfc.ac.uk/apply-for-beamtime/gem-xpress4412.html) at ISIS. By removing the requirement for travel, scientists from around the world, and in particular from developing countries, are able to perform synchrotron and neutron studies. However, the increasing volume of extremely high quality powder-diffraction data from such sources will present challenges in data analysis to provide the best possible outcomes for both the researchers and the facilities providing the data. This is likely to impact on instructional workshops. Such high-resolution synchrotron and neutron data will increasingly appear in the hands of relative novices, looking for skills beyond those normally required for laboratory-based analysis.

\section{P. Whitfield, Chair}

A5.17. Commission on Small-Angle Scattering. The details of the Commission's activities are presented in the Annual Reports of the Commission. The present report aims at providing an overview of these activities.

Meetings. The International Conference on Small-Angle Scattering (SAS) has taken place on a triennial basis since 1965. It is the main occasion for scientists practising small-angle scattering to meet and exchange ideas related to the technique itself across the boundaries of the various scientific disciplines and its broad range of applications. The 2009 SAS conference took place in Oxford, UK, and was chaired by A. J. Ryan, T. Wess, S. King and N. Terrill. Most of the Commission members served on the International Advisory Committee. The Conference was attended by 434 participants from 32 countries. There were 452 contributed presentations of which 144 were oral presentations and 308 were poster presentations. The scientific programme of the Conference contained ten Plenary Lectures from various scientific fields and 29 sessions. The sessions covered polymers, various aspects of instrumentation, biological systems, colloids, membranes and bilayers, ceramics, glasses and porous systems, magnetic systems, metallic systems, theory and modelling, fibre diffraction and hierarchical systems, liquid crystals and rheo-SAS, surfaces and interfaces, environmental science, imaging, dynamical techniques, and time-resolved techniques.

In coordination with the organizers of SAS 2009, the Commission made a call to the SAS community to prepare applications from scientific institutions willing to host the next SAS Conference in 2012. Together with the SAS organizers, the Commission formed a Committee with the task of evaluating the bids. After a ballot by the participants, Sydney, Australia, was selected as the venue of SAS 2012, and Berlin, Germany, was selected as the venue for SAS 2015. The Commission members were also very active during the Conference and were members of the Award Committees. The Prize for Lifetime Achievement in SAS (the 'Andre Guinier Award') was awarded to V. Luzzati, Emeritus Research Scientist, Centre de Génétique Moléculaire du CNRS, Gif-sur-Yvette, France, for his long and distinguished career in X-ray scattering.

Several Commission members are also on the Advisory Committee of the next SAS meeting in Sydney, Australia (18-23 November 2012) and the Commission has provided advice on a series of issues in connection with the planning of SAS 2012. J. Trewhella is a member of the Scientific Programme Committee of SAS 2012 and will, with D. McGillivray, be assembling the full Scientific Programme for that meeting.
Commission members were actively involved in the Osaka Congress. I. Torriani and N. Yagi were members of the International Programme Committee. A Keynote Lecture on Advances in Microand Nano-SAXS was given by Commission member P. Fratzl. Four Microsymposia were suggested by the Commission and Co-Chaired by Commission members. N. Yagi participated in the organization of the satellite meeting of the Osaka Congress at SPring-8 entitled X-ray and Neutron Techniques for Nano-Structural Research. D. Svergun organized the Commission meeting during the Osaka Congress and various topics were discussed. Among these were publication standard requirements for journal publications involving SAS. While no formal publication standard requirements are planned for the near future, it was agreed to look into the matter further. Requirements for SAS contributions to the Protein Data Bank were also discussed, and identified as an urgent issue. Subsequently, a document has been prepared with initial input from the laboratories of J. Trewhella and D. Svergun on the requirements for the presentation of biological macromolecule small-angle scattering data in publications. This document will provide a starting point for discussion at the Madrid Congress and SAS 2012 with the intent of working towards a set of community-agreed standards that would be available to journal editors in order to ensure SAS publications in this rapidly expanding area are of a standard and quality that will support the continued strong impact of the technique.

J. Trewhella has been a member of the International Programme Advisory Committee for the Madrid Congress and has coordinated with Commission members to propose an SAS-focused Keynote Lecture and Commission-related Microsymposia.

Scientists involved with data acquisition from the Helmholtz Association of German Research Centres met at DESY (Hamburg, Germany) in October 2010 to decide upon a common format in which to write data from their instruments. P. R. Jemian attended and advocated the use of the NeXus additions to the HDF5 file format. It is important to the SAS community to advocate the use of standards in data acquisition, since the development of common, re-usable software components relies on standard data structures and it is the data-acquisition systems that are the source of the data to be analyzed.

Education. Commission members are in general very active in organizing and participating in summer schools and tutorial workshops to promote small-angle-scattering techniques (see the Annual Reports for details). Since several Commission members are responsible for instruments at SAXS and SANS facilities, they interact regularly with user groups, and they educate and train students and postdocs in the practical aspects of small-angle scattering. D. I. Svergun organizes a biennial EMBO Practical Course on Solution Scattering from Biological Macromolecules (Hamburg, Germany, 2008, 2010) and J. S. Pedersen is a member of the Organizing Committee of the biennial European Summer School entitled Scattering Applied to Soft Condensed Matter (Bombannes, Gironde, France, 2008, 2010). H. Yagi is involved in the summer school at SPring- 8 , and he also contributes to the Cheiron school (International School on Synchrotron Radiation), which are both yearly events. R. Serimaa and J. S. Pedersen are very active in the Organization Committee of the Nordic Workshops on Scattering from Soft Matter that take place every year. In 2010 R. Serimaa headed the Organization Committee of the Seventh Nordic Workshop on Scattering from Soft Matter taking place in Helsinki, Finland, while J. S. Pedersen organized the Sixth Nordic Workshop on Scattering from Soft Matter that took place in Aarhus, Denmark, in 2009.

P. R. Jemian is involved in the biennial SAXS course Beyond RG (Advanced Photon Source, USA, 2008, 2010) and the annual 
National School on Neutron and X-ray Scattering (held jointly with APS and the Spallation Neutron Source, Oak Ridge National Laboratory, USA). V. V. Volkov delivered spring semester lectures at the Physical Chemistry Department of the Moscow State University on the theory and application of SAS methods.

Software development. The most important involvement of the Commission in software development is the package ATSAS, developed by D. I. Svergun's group. It enables data processing and advanced data analysis with an emphasis on biomacromolecules in solution. It is publicly accessible for academic institutions and it currently has a huge user group worldwide. In 2010, D. I. Svergun's group provided the community with a new release of ATSAS. Web access to several new programs was established.

P. R. Jemian is working with both the canSAS and NeXus communities on developing standards for exchanging data and metadata. In the past three years, the canSAS standard for communicating one-dimensional small-angle-scattering data in XML was released. This standard is now in use and has, among other things, been used to communicate the round-robin data associated with the publication regarding the use of glassy carbon as an absolute intensity standard [Metall. Mater. Trans A, (2010), 41, 1151-1158]. The NeXus Definition Language was developed to provide scientists with a simple way to use the NeXus data standard and describe applicationspecific data, such as reduced SAS data. The NXsas definition will be released in the spring of 2011.

A recent publication with J. Ilavsky, Irena: Tool Suite for Modeling and Analysis of Small-Angle Scattering [J. Appl. Cryst. (2009), 42, 347-353], describes the Irena tool suite, an IgorPro macro package containing tools for analysis of small-angle scattering applicable to investigations in materials science, chemistry, polymer science and a number of other fields where SAS is used. Both this paper (currently 42 citations) and the earlier $2006 \mathrm{~J}$. Appl. Cryst. paper detailing the NIST SANS reduction and analysis routines (currently 211 citations) have engendered widespread international use of these software tools. P. R. Jemian was also invited to review SAS software developed by NIST as part of the DANSE (Distributed Analysis of Neutron Scattering Experiments) project. SANSview is a new application for SANS-oriented system modeling and data analysis, and is being developed by a software group led by P. Butler (NIST). The SANSview software is able to read data from both the canSAS and NeXus data formats. It is encouraging to see the flourishing of new software tools that rely on the development of community-developed data standards such as canSAS and NeXus. For example, two tools used for data acquisition, OpenGDA (Diamond Light Source, UK) and EPICS Area Detector (Advanced Photon Source, USA), can create data in standard formats such as NeXus. P. R. Jemian will continue to work with software developers (both data acquisition and analysis) in their support of common data standards.

Community building. The Commission has a SAS list server on the IUCr web site for communication among subscribing SAS users. The support provided by S. King, ISIS, Oxford, UK, has ensured reliable use of this list server by the community.

Most Commission members serve on scientific committees at largescale facilities, national as well as international, in many countries, including, for example, Germany, France, UK, Italy, Denmark, USA, Japan, Australia and Brazil. They not only evaluate beam-time applications, but also participate in important discussions about the future development of the instrumentation and strategies of the facilities. The members of the Commission further contributed to the widening of the user community of the SAS instruments in their home laboratories and at large-scale facilities, offering service and help in data collection and analysis, as well as hands-on courses.
Technical issues. Reference and calibration samples are very important for small-angle scattering in order to obtain reliable data and to exploit the full information content of the data. Commission member A. Allen has been involved in the development of reference materials and standards at NIST. An international round robin exploring the potential of glassy carbon as a SAXS (and possibly SANS) intensity standard reference material was completed in 2009. On the basis of the results, plans moved forward in 2010 to develop an intensity reference material. In addition, a research paper Glassy carbon as an absolute intensity calibration standard for small-angle scattering has been published [Zhang, F., Ilavsky, J., Long, G. G., Quintana, J., Allen, A. J. \& Jemian, P. R. (2010). Metall. Mater. Trans $A, \mathbf{4 1}, 1151-1158]$. A prototype NIST standard reference material for SAXS intensity calibration, based on glassy carbon, is under development. NIST also pursues development of a standard reference material for small-angle X-ray wavelength calibration and has turned from a conventional diffraction standard (e.g. silver behenate) to the proposed fabrication of a nano-engineered diffraction grating artifact, which should have a stable long-term, perhaps unlimited, shelf life.

Commission members are also very active in designing and building new instruments for small-angle scattering in their own laboratories and also work as consultants at other beamlines at largescale facilities. N. Yagi designed a small-angle camera for BL03XU at SPring-8. D. I. Svergun's group implemented an automated pipeline for a biological solution SAXS experiment and data analysis at the EMBL synchrotron SAXS beamline (DESY, Hamburg, Germany). This opened the way for full automation of the SAXS experiment and even for remote access to the beamline. P. Thiyagarajan has been active in the development of new capabilities for GISAXS, ASAXS, XPCS and the area detectors at the APS. During 2008, I. Torriani has been coordinator of the SAXS beamlines of the LNLS. The SAXS2 beamline has undertaken the full load of external projects and installation of new experiments has had to be postponed until 2009.

A paper has been developed and commented on by members of the Commission on requirements for the publication of biological macromolecule small-angle scattering data for structural analysis that has been developed as a follow up to the discussion hosted by the Commission at the Osaka meeting. A discussion/workshop is being planned for SAS 2012 with the hope of developing a consensus paper for communication to journal editors.

G. Kostorz is Editor-in-Chief of the IUCr journals and G. Kostorz and A. Allen serve as Co-editors for Journal of Applied Crystallography.

\section{J. S. Pedersen, Chair}

A5.18. Commission on Structural Chemistry. Member tasks. The main tasks have been distributed among members and consultants, to rationalize the activities for the next three years: A. Bacchi and S. R. Batten update the new Commission (CSC) page on the IUCr web site; P. Bombicz, S. R. Batten and M. T. L. Duarte provide content for the IUCr Online Dictionary of Crystallography and link to the Commission on Crystallographic Nomenclature; A. Nangia, K. Ogawa, F. Lahoz and P. Mueller link to the IUCr/OUP Book Series Committee; S. A. Bourne, P. R. Raithby, P. Mueller, J.-C Daran and Shi Xiong Liu provide support and ideas for schools and link to the Commission on Crystallographic Teaching; F. Lahoz and A. Bacchi collected input for the programme for the Madrid Congress; A. Beatty links to the Commission on Inorganic and Mineral Structures; J. L. Flippen-Anderson links to the IUCr Newsletter. 
Commission activities. During the Osaka meeting the Commission organized an Open Meeting to collect opinions and ideas on new actions that could accommodate the growing interest of the crystallographic community in topics related to structural chemistry on the one hand, and that in parallel could encourage interdisciplinarity and links to other Commissions by stimulating exchanges of experiences with neighbouring communities. This issue was thoroughly discussed through the second semester of 2008 by the newly installed Commission; as the first action it was suggested to share consultants between the Commission on Structural Chemistry and other Commissions with closely related cultural interests.

The activities of the CSC in 2009 opened with a wide and vivid discussion, carried out by e-mail exchanges, that followed the comments made during the CSC meeting at the Osaka Congress. The CSC had been stimulated to consider how to relate with other Commissions that could express a potential partial overlap of interests, such as the Commission on Inorganic and Mineral Structures (CIMS) and the Commission on Crystallographic Teaching (CCT). After recognizing the great importance of interdisciplinary connections between Commissions, expressed also by the proposal of several joint Microsymposia involving the CSC in the scientific programme for the Osaka Congress, the CSC suggested the building of permanent links between related Commissions by exchanging consultants, after the approval of the IUCr President. Consequently, CSC member A. Beatty was appointed as consultant to the Commission on Inorganic and Mineral Structures, and conversely CIMS member P. Mercier was appointed as consultant to the CSC. The CSC consultant P. Mueller was also added as a consultant for the CCT. This arrangement has proved very effective, since in many instances information was passed smoothly between Commissions, for example in redirecting requests for support for scientific and educational events.

The activities of the CSC in 2009-2010 were mainly focused on the preparation of a strong scientific programme for the Madrid Congress. Three members of the International Programme Committee represented the interests of the CSC. R. Kuroda, L. R. Nassimbeni, T. N. Guru Row and the CSC submitted a list of 18 possible titles for Microsymposia, together with potential names for Chairs and Keynote speakers. Of these, 12 Microsymposia strictly related to the CSC have been selected for the final programme, covering all the areas of structural chemistry. The organization of joint Microsymposia with other Commissions has also been promoted. A proposal for a satellite meeting for the Madrid Congress has also been submitted with the endorsement of the CSC, namely Categorizing Halogen Bonding and Other Noncovalent Interactions Involving Halogen Atoms, chaired by P. Metrangolo and G. Resnati.

Regarding other activities, the CSC has been asked to contribute a member to the IUCr Working Group of Database Users; A. Bacchi has joined the Working Group, which started its activity in October 2010. In this context, the CSC has also set up a stable connection with the Cambridge Crystallographic Data Centre (CCDC) by inviting one representative of the CCDC to join the list of consultants. E. Pidcock has accepted to serve as consultant for the CSC.

As a general comment, it seems that the exchange of consultants between related Commissions, initiated by the CSC together with the Commission on Inorganic and Mineral Structures, and extended also to the Commission on Crystallographic Teaching, is really working very well, providing, especially for the former case, an effective sharing of information and opinions, particularly useful in the process of evaluating the support to schools and meetings, and in setting up the scientific programme for international crystallographic confer- ences - initially for the IUCr Congress, where a synergy between Commissions can strengthen the programme.

The inclusion among the consultants of a scientist working in industry has also been considered by the CSC, in order to improve the potentially significant links between pure and applied research that are traditionally strong in the field of structural chemistry. After considering many potential candidates and with the approval of the IUCr President, Ö. Almarsson (Vice-President, Pharmaceutical R\&D at Alkermes Inc.) was appointed as a consultant to the CSC.

Some points still need to be addressed by the CSC, mainly a stronger effort to link with the Commission on Crystallographic Nomenclature in order to implement the contents of the IUCr Online Dictionary of Crystallography. Some tentative suggestions have been made in this context, but the Commission members did not enter into a complete evaluation of the potential CSC contributions to the Online Dictionary. In 2010 the web site of the CSC was updated and harmonized to the new format on the IUCr site.

Events endorsed by the Commission. Several requests for the support of the CSC have been received during the triennium. All the applications have been thoroughly examined and discussed among the Commission, in particular the organizers should be advised to encourage the participation of young researchers from less advantaged countries, and to ensure a gender balance in the scientific programme.

\section{A. Bacchi, Chair}

A5.19. Commission on Synchrotron Radiation. The mission of the Commission is to promote access to and awareness of crystallographers worldwide to the world's synchrotron-radiation (SR) facilities. To this end, the Commission promotes the development of crystallographic, in a broader sense, instrumentation technology and standards, and synergies between storage-ring-based and LINACbased next-generation sources such as X-ray free-electron lasers (XFELs) and energy recovery linacs (ERLs). The Commission is very pleased to note the tremendous progress made by several XFEL projects including the European XFEL and FLASH in Hamburg, Germany, LCLS in Stanford, CA, USA, and SACLA in Harima, Japan, which successfully lased at 1.2 A wavelength on 7 June 2011, as well as ERL projects of CHESS in Ithaca, NY, USA, and KEK in Tsukuba, Japan. They triggered many new projects for building FEL facilities in many countries. The initial scientific outputs from the LCLS have been enormous and transformative, and have already affected the courses of new developments in various fields, including crystallography, scattering, spectroscopy and imaging. Detector developments were also accelerated in preparation for these nextgeneration light sources as well as new demands from the storagering-based light sources.

In summer 2008, four Commission members, I. Robinson (UK), S. Gruner (USA), L. T. J. Delbaere (Canada) and D. McMorrow (UK), finished their terms and were succeeded by J.-L. Hodeau (France), P. Lee (USA), P. Grochulski (Canada) and Shin-Ling Chang (Taiwan), and a new Chair, S. Wakatsuki (Japan, replacing H. Graafsma). L. T. J. Delbaere, who was a member of the Commission until he joined the Executive Committee in 2008, stayed as a liaison between the Commission and the Executive Committee until he passed away in October 2009, news of which left all the Commission members deeply saddened. Commission members usually communicate via e-mail, but throughout the three-year period subsets of the Commission met at international conferences to discuss relevant and current issues of the Commission. For example, in September 2009 in Melbourne, Australia, we met during SRI 2009 to discuss possible collaboration 
with the Commission on XAFS to co-organize a workshop (Q2XAFS) on XAFS standardization of experimental protocols and data analysis, which is now scheduled to be held in December 2011 (see below).

Recognition of beamline scientists. In response to IUCr President S. Larsen's concern on how to improve the recognition of beamline scientists at macromolecular protein crystallography beamlines, the Commission held discussions on the role of staff scientists and how best their work can be acknowledged and credited by the community. This is a long-standing issue in protein crystallography as well as small-molecule crystallography, powder diffraction and XAFS; as the techniques mature it becomes less and less frequent to acknowledge properly the scientists who have developed and operate the methods/ instruments. We discussed the issue via e-mail exchanges as well as face-to-face meetings at SRI in 2009 and BSR/MASR in 2010. At the latter conference, in particular, some of the Commission members attended a meeting organized by S. Larsen to discuss the issue with protein-crystallography beamline scientists worldwide. The Commission considers that it is indeed a serious issue not only in structural biology but also in the other areas of synchrotron sciences and there is a strong need to introduce some effective measures to ameliorate the situation. The discussion continued with two editors of relevant IUCr journals of some new developments such as a new form of short publication to disseminate information on beamline characteristics. We considered establishing a new section on beamlines in the Journal of Synchrotron Radiation. P. Zwart (ALS), Z. Dauter (APS) and S. Wakatsuki have proposed a format for such brief publications, which has been implemented.

Supported meetings and workshops. During the years 2008-2010 the Commission endorsed the following meetings and workshops.

(1) A symposium at the European Materials Research Society (MRS) meeting in Strasbourg, France, 8-12 June 2009.

(2) RapiData courses on automated data collection at NSLS, Brookhaven National Laboratory, NY, USA: 6-11 April 2008, 20-24 April 2009, 11-16 April 2010 and 3-8 April 2011. We encouraged the organizers to support participation of Latin-American students.

(3) International Conference on Neutron and X-ray Scattering 2009, Kuala Lumpur, Malaysia, 29 June - 1 July 2009, on a theme of Neutron and X-ray Scattering in Materials Research Advancement.

(4) International School/Conference on Resonant Elastic X-ray Scattering in Condensed Matter to be held in Aussois, Savoie, France, 13-17 June 2011, and the eighth School on Crystallography and X-ray Diffraction, Havana, Cuba, 21-26 November 2011.

Asia-Oceania Forum for Synchrotron Radiation Research (AOFSRR). AOFSRR is an international organization whose mission is to foster collaboration among synchrotron-radiation facilities to promote SR sciences in Asia and Oceania, as well as promoting collaborations with facilities in America and Europe. Several members of our Commission play active roles in the organization. In December 2008, the third AOFSRR was hosted by the Australian Synchrotron. The meeting was held 4-5 December in conjunction with the Australian Synchrotron User's Meeting. Two sessions, Next Generation Photon Science I \& II, were organized on the potential scientific applications of next-generation sources (FELs and ERLs). The fourth AOFSRR workshop was held 31 November - 1 December 2009 in Shanghai, People's Republic of China. Special issues focused on AOFSRR were published in Synchrotron Radiation News with articles featuring developments in Asia and Oceania. The fifth AOFSRR workshop was held in Pohang, Korea, 5-9 July 2010. R. Garrett continues his role as treasurer of AOFSRR and together with the other Commission members contributed to the activities of the AOFSRR. The next AOFSRR workshop will be held in Bangkok,
Thailand, in October 2011. Shih-Lin Chang of our Commission has joined the organization as an executive member from April 2011. As one of the core activities of AOFSRR, an international school series, the Cheiron School, has been held annually at SPring- 8 . About 50 to 60 young students and postdocs from countries in Asia and Oceania attended the school each year. Members of the Commission were involved in the Programme Committee and lecturing.

SRI 2009 and BSR 2010 in Melbourne. Members of the Commission were involved in the triennial international Synchrotron Radiation Instrumentation (SRI) meeting in Melbourne, Australia, September 2009. In particular, R. Garrett served as the Chair of the Technical Programme Committee, of which H. Graafsma was also a member. G. Kulipanov and S. Wakatsuki were members of the SRI 2009 International Advisory Committee. The meeting attracted 681 delegates drawn from 28 countries, and highlights included the remarkable progress in the FEL sources. Half a year later, 15-18 February 2010, the Biology and Synchrotron Radiation (BSR) meeting, another triennial international meeting, was held in Melbourne, Australia, and again some Commission members were involved in the planning of the meeting during 2009. In particular, S. Wakatsuki, as a member of its International Advisory Committee, arranged a timely invitation to A. Yonath to act as a plenary speaker at the BSR and Medical Applications of Synchrotron Radiation (MASR), a concurrent international workshop, shortly after the announcement of her award of the 2009 Nobel Prize in Chemistry for her work on ribosome structures.

Radiation Damage meetings. C. Nave played an active role in the preparation of the 6th Radiation Damage Conference that was held in March 2010 in Stanford, CA, USA. This is a biennial international meeting to discuss the fundamental processes of radiation damage in biological samples, implications for structure interpretation and exploitation of radiation damage in structural determination. A Special Issue of Journal of Synchrotron Radiation was compiled from the talks in the workshop. The next biennial meeting is scheduled to be held 14-16 March 2012, at the Diamond Light Source, UK, to continue the discussions as well as evaluation of radiation damage in XFEL 'diffract and destroy' experiments. Another Special Issue in Journal of Synchrotron Radiation will be prepared from talks at the 2012 workshop.

SR Related Microsymposia at the Madrid Congress. S. Pascarelli, a consultant of the Commission, has played an important role as a member of the International Programme Committee of the Madrid Congress in promoting synchrotron-related topics and speakers. We have placed particular emphasis on featuring the recent spectacular progress in LINAC-based light sources, and are organizing MS37 X-ray Lasers and Other New Frontiers in Synchrotron Applications to Structural Science, in which the most up-to-date science and technology developments will be presented. Other important areas include detectors and instrumentation, coherence, inelastic X-ray scattering, materials under extreme conditions, surfaces and interfaces, combined methods, structural biology, cultural heritage etc.

Preparation of Q2XAFS 2011 workshop in Tsukuba, Japan. During SRI 2009 in September 2009 in Melbourne we discussed possible collaboration with the Commission on XAFS to co-organize a workshop on XAFS standardization of experimental protocols and data analysis. Since then we continued the preparation of the workshop in collaboration with Commission on XAFS, the International X-ray Absorption Society and the Japanese XAFS society. The purpose of this workshop, which we named Q2XAFS (Improving the Data Quality and Quantity for XAFS Experiments), is to establish international standards for XAFS experiments and data analysis with well defined quality control. This topic has been discussed for more 
than ten years, but there have been some difficulties in finalizing the proposal and implementing it in practice. During the Q2XAFS workshop, we will learn from the experiences in small-molecule crystallography and protein crystallography in establishing similar international standards. Our intention is to establish a set of standard protocols for experiments, data analysis and verification. We will make special efforts in approaching editors of relevant international journals, including those of the IUCr, and ask them to implement such protocols and verification as part of the requirement for publication. To this end, we will be compiling a Special Issue in Journal of Synchrotron Radiation with manuscripts prepared by the key participants, including the final proposal and scientific highlights from the workshop. After exploring several possibilities for the workshop venue, we decided to hold the meeting at the Photon Factory and scheduled it for 11-12 April 2011. Unfortunately, owing to the devastating earthquake on 11 March 2011 and the subsequent Fukushima nuclear reactor crisis, the meeting has been postponed to December 2011. The Commission on XAFS is planning MS77 XAFS Instrumentation: Automation, Standardization and Validation of XAFS Experiments at the Madrid Congress, and we intend to take advantage of this Microsymposium to discuss the subject matter and prepare for the December meeting in Tsukuba.

International Year of Crystallography. The Commission will promote and be actively involved in various activities on the 100th anniversary of X-ray crystallography during the International Year of Crystallography. For instance, the SCANZ/AsCA Bragg Symposium will be held in December 2012 in Adelaide, Australia. The next International Conference on Structural Genomics (ICSG) will be held in Tsukuba, Japan, in 2013 (dates to be decided) and organized by S. Wakatsuki as Chair of the Organizing Committee. Although the scope of the meeting is very wide, protein crystallography is certainly one of the most important aspects of structural genomics and proteomics projects. We intend to include special sessions on the 100th year of X-ray crystallography in ICSG 2013. The 4th Workshop on XFEL Science will he held in Cairns, Australia, 29 August - 2 September 2011. This is primarily an Asia-Oceania workshop and focuses on the proposed scientific programmes of the new XFEL facilities, in particular the SACLA facility currently being commissioned at SPring-8. R. Garrett is a member of the Organizing Committee. We will also encourage synchrotron facilities to highlight the achievements of crystallography and the contribution of synchrotron radiation to this field.

\section{S. Wakatsuki, Chair}

A5.20. Commission on XAFS. Commission organization. In order to increase its efficiency further, the Commission on XAFS (CXAFS) defined an internal organization, in line with the general statement of principles regarding IUCr Commissions. A steering committee has been formed consisting of I. Ascone (Chair), C. T. Chantler, (Secretary) and B. Hedman. Two of CXAFS' consultants (S. S. Hasnain and A. M. Molenbroek) have joined the steering committee for the preliminary formulation of plans.

CXAFS has kept close contact with the IUCr Executive Committee to develop projects.

Commission meetings and communication. A Commission meeting was held in the Palazzo Ducale (Camerino, Italy), on 27 July 2009, during the International XAFS Conference (XAFS14). Moreover, several discussions followed during this Conference among Commission members [I. Ascone (Chair), K. Asakura, G. Azavedo, F. Boscherini, C. T. Chantler (Secretary), P. Glatzel, B. Hedman, F.
Jalilehvand]. A detailed report has been sent to the IUCr Executive Committee.

The ISRP-11 international symposium in Melbourne, Australia, was also an opportunity to develop the Commission's activity (participants: I. Ascone, C. T. Chantler and P. Glatzel).

Many meetings and discussions among members of the Working Group on XAFS Nomenclature were also organized by P. Glatzel in July (during the XAFS14 Congress in Italy) and in September 2009 (during the ISRP-11 Symposium, in Melbourne).

Discussions among the steering-committee members occurred during the BSR Conference in Melbourne in February 2010. Another meeting was planned in April 2011 at Tsukuba but has been cancelled owing to the earthquake in Japan. A final meeting and an Open Meeting are planned during the Madrid Congress.

Moreover, the Chair communicated with Commission members by e-mail and during personal meetings at other conferences or in visits to laboratories.

Web site. For several years, F. Boscherini has been in charge of the Commission's web site, hosted by University of Bologna. In 2009, F. Boscherini, with the agreement of the IUCr and CXAFS, transferred it to the centralized IUCr site. The advantages of the transfer have been multiple: the web site is officially maintained, modifications are easier and it should encourage the involvement of other Commission members in its development.

During the triennium, this new web site has been updated (especially the part concerning the compendium of XAFS beamlines) and expanded with information on Commission activity (including the list of meetings supported by the Commission and definitions of XAFSrelated terms).

Contribution of the Commission to the IUCr Online Dictionary of Crystallography. In the increasingly active field of X-ray absorption techniques, over 12000 papers have been published in the last five years, and the Commission has made it a priority to draw up a set of definitions contributing to the Online Dictionary. An important objective of this endeavour is to identify ambiguous or incorrect usage of XAFS expressions in the scientific language. Rather than attempt to formulate 'perfect' definitions, we set out to propose currently used definitions and to allow the possibility of the community's improving them through open debate. In 2009, CXAFS created a Working Group (WG) on XAFS Nomenclature and, to ensure a clear connection between CXAFS and IXAS (the International X-ray Absorption Society), both communities were represented in the membership of the WG.

P. Glatzel (CXAFS and IXAS) was nominated to coordinate the WG. Other members are: C. T. Chantler (CXAFS), A. M. Molenbroek (CXAFS), M. Newville (IXAS), J. Rehr (Theory), Tsun-Kong Sham (IXAS and Theory) and R. Strange (Biology).

Proposed definitions have been reviewed by seven members of the Advisory Committee (AC). They are C. Brouder, D. Creagh, J. Garcia, C. Natoli, J. Penner-Hahn, R. Sarangi and E. I. Solomon.

$\mathrm{AC}$ members have sent detailed reports, indicating comments, corrections and, in some cases, proposing alternative definitions to the XAFS Commission Chair, who transmitted anonymous reports to P. Glatzel.

In the revised document, the WG has taken into account nearly all suggestions and is indebted to F. Neese, F. de Groot, A. Kotani and S. Huotari for their advice and valuable contributions concerning some definitions.

The revised text is a compromise in order to obtain definitions with a consensus as large as possible. The XAFS community will be able to debate the proposed definitions using the forum available at http:// forums.iucr.org. 
The first document produced by the Working Group and Advisory Committee on XAFS Nomenclature is available from the Commission's web site. G. Chapuis, Editor-in-Chief, has recently agreed to include proposed items in the Online Dictionary.

Volume of International Tables for Crystallography dedicated to $X A F S$. This project would be a great opportunity for the XAFS community and several exchanges/contacts have been dedicated to this item.

During the meeting of the International Programme Committee for the Madrid Congress in May 2010, discussions started between C. J. Gilmore and I. Ascone about the opportunity of including XAFS-related items in the new volume of International Tables for Crystallography covering mainly powder-diffraction techniques.

Following the IUCr's decision to consider the dedication of a specific volume to the XAFS technique, a detailed document with suggestions for the content of the volume was submitted to the IUCr Editorial Office at the beginning of December 2010.

Development of XAFS standards and criteria. CXAFS promoted the development and acceptance of standards and criteria in XAFS measurements and analysis so as to improve the overall quality of the research being performed in the field.

In the triennium, particular efforts were dedicated to the organization of a Workshop on Improving the Data Quality and Quantity for XAFS Experiments, and CXAFS decided to involve the Commission on Synchrotron Radiation (CSR). Discussions on the project with the CSR started in September 2009.

In 2010, several meetings and exchanges took place with the ESRF, who had agreed to host this event. Unfortunately, CXAFS met difficulties completing the budget and other synchrotron-radiation facilities were approached. S. Wakatsuki, the CSR Chair, played a key role in the realization of this project, proposing the Photon Factory as the hosting laboratory and also involving in the organization eminent Japanese colleagues from KEK, the Japanese XAFS Society and IXAS. The workshop was planned to be held in April 2011, but has been postponed to 8-9 December 2011 owing to the terrible earthquake that occurred in the region a few weeks before the event.

Data interchange format for data deposition. The Commission has been asked to develop a project on XAFS data deposition. Members started discussions in a July 2009 meeting in order to define relevant information on data (format, file size and total number of files). Technical aspects have been examined and different solutions proposed. The International XAFS Society has been involved in this project in the framework of the organization of the Workshop on Improving the Data Quality and Quantity for XAFS Experiments. CXAFS will give its advice during the Commission meeting in August 2011, also taking into account suggestions that will come from IXAS, which is now working on this item.

Organization of Congresses, workshops, symposia. CXAFS members contributed to the increase of interactions among XAFS researchers and other groups in the IUCr, through the organization of Congresses/meetings, symposia and workshops. The Commission endorsed/supported the following meetings during the triennium:

Workshop on Resonant Inelastic X-ray Scattering (RIXS): The conference was co-organized at ESRF by P. Glatzel on 29 June - 1 July 2009. The overlap between the communities for IXS and XAFS is rapidly increasing owing to user-friendly experimental stations, the development of data-evaluation software and advances in theoretical understanding. The ESRF and P. Glatzel are playing a major role in these activities.

F. Boscherini has co-organized the meeting on X-ray Techniques for Advanced Materials, Nanostructures and Thin Films: From Laboratory Sources to Synchrotron Radiation. This meeting was held in the framework of the European Materials Research Society Spring Meeting, Strasbourg, France, 8-12 June 2009. It was endorsed/ supported by CXAFS and three other IUCr Commissions (SAS, Synchrotron Radiation, and Crystal Growth and Characterization of Materials).

CXAFS has organized the Symposium S3 of the XAFS14 Conference on the Complementarity of XAS and Diffraction Techniques. It was held on 29 July 2009 in the morning, allowing a high attendance. This was the first joint symposium organized by CXAFS and IXAS during an XAFS Conference.

Moreover, during the plenary section at the end of the XAFS14 Conference, I. Ascone presented the activity of CXAFS to approximately 500 delegates from the XAFS community.

ISRP-11 International Conference, 21-25 September 2009 (organized by C. T. Chantler). The Symposium presented new fundamental experiments and applications across biomedical, chemical and engineering fields, and in border protection, geothermal and many other areas. Subjects that were once regarded as fundamental research in experimental and theoretical atomic and molecular physics now make vital contributions to developing new materials, forensic sciences, pharmaceuticals and metrology standards. Over 305 abstracts, 200 participants and 38 countries were represented; this was the second largest of the series.

The International Workshop on Advances in Analytical Techniques, also organized by C. T. Chantler in Melbourne, Australia, 26-27 September 2009, linked to both the ISRP-11 and to the SRI conference, with sub-themes Geology, Conservation Science, Forensic Science, Border Technology and Environmental Science. Sessions were held on XRF and XRD, XAFS, Raman, IR, SEM and Imaging.

BioXAS study weekend, satellite meeting of Biology and Synchrotron Radiation Conference, Melbourne, Australia, 14-15 February 2010. This was the fourth meeting of a series dedicated to the biological applications of XAFS. As for previous meetings, CXAFS supported the organization and three CXAFS members (I. Ascone, S. S. Hasnain and B. Hedman) have participated in the steering committee.

7th International Conference on Inelastic X-ray Scattering (IXS 2010), World Trade Center, Grenoble, France, 11-14 October 2010. This Conference, co-organized by P. Glatzel, covered electronic resonant and non-resonant scattering (in the soft- and hard-X-ray regime), emission spectroscopy, meV-resolved atomic dynamics, nuclear inelastic scattering, Compton scattering, and thermal diffuse scattering (http://www.esrf.eu/events/conferences/ixs2010).

Symposium on Synchrotron Radiation: Emerging Techniques and Applications, co-organized by K. Asakura during Pacifichem 2010 (Pan Pacific Chemical Society Meeting), Honolulu, Hawaii, 15-20 December 2010.

Symposium M on X-ray Techniques for Materials Research - From Laboratory Sources to Free Electron Lasers. This has been coorganized by F. Boscherini in Nice, France, 9 May 2011, in the framework of the 2011 Spring Meeting of the European Materials Research Society (9-13 May 2011).

During the Madrid Congress there will be five XAFS-related Microsymposia. Many of them have received support from several Commissions (indicated in parentheses). These are: MS42 XAFS Studies in Biology Coupled to Crystallography (CXAFS); MS56 Spectroscopic Approaches (XAFS, NMR ...) in Crystallography (CXAFS, CSC); MS70 Radiation Damage: Consequences and Uses (CXAFS, CSR, CBM); MS77 XAFS Instrumentation: Automation, Standardization and Validation of XAFS Experiments (CXAFS, CSR); MS91 X-ray Absorption, Diffraction and Imaging in Forensic Science and Ancient Materials (CCACH, CPD, CXAFS). MS42, 
MS56, MS70 and MS77 have been organized by CXAFS in collaboration with IXAS. Many members of the Commission have put considerable effort into helping to organize the Madrid Congress. I. Ascone is a member of the International Programme Committee. K. Asakura and C. T. Chantler are organizing MS77 and F. Jalilehvand is co-organizing MS42. S. S. Hasnain will give a Keynote Lecture (KN27) on XAFS Contribution to Protein Structure-Function Investigations and B. Hedman will chair this session.

Organization of schools/tutorials. The Commission endorsed/ supported the following schools/tutorials during the triennium:

A Summer School on Structural Molecular Biology Low- $Z$ XAS has been promoted by B. Hedman at SSRL/SLAC Stanford, USA, 20-23 July 2010. The goal of this Summer School was to disseminate information about the scientific opportunities in low-energy XAS applications and train participants on the theoretical aspects and practical data analysis of different experimental techniques (http:// www-conf.slac.stanford.edu/smbxas-ss/2010/).

A full-day lecture and hands-on analysis session on Charge Transfer Multiplet Calculations for X-ray Absorption Spectroscopy $(C T M 4 X A S)$ has been promoted by B. Hedman at SSRL/SLAC Stanford, USA, 24 May 2011. CTM4XAS is a semi-empirical program for analysing transition-metal $L$ - and $M$-edge transitions by evaluating the effects of crystal field and charge-transfer parameters on the atomic multiplets (https://www-ssrl.slac.stanford.edu/conferences/ workshops/xas-rixs/index.php).

The Commission has supported the Madrid Congress XAFS Tutorial for Crystallographers and Beginners organized by I. Ascone and J. García Ruiz in cooperation with the Madrid Local Organizing Committee and the International X-ray Absorption Society (http:// www.iucr2011madrid.es/index.php/program/workshops). Like the Tutorial organized on the occasion of the Osaka Congress by $\mathrm{K}$. Asakura, its purpose is to give a general introduction and analytical methods for crystallographers and beginners in the field of XAFS. In order to increase the interactions with crystallographers, this time the Tutorial will be held in the same building and linked (22 August 2011) to the Madrid Congress. Commission members giving a lecture are B. Hedman, C. T. Chantler and I. Ascone.

Contact with other organizations. In the triennium, CXAFS strengthened ties with IXAS and other organizations.

CXAFS is grateful to IXAS members and in particular to $\mathrm{H}$. Oyanagi, the IXAS Chair, for valuable contributions and suggestions. In particular, CXAFS collaborated with IXAS on the organization of the above-mentioned events:

Workshop on Improving the Data Quality and Quantity for XAFS Experiments.

Four Microsymposia at the Madrid Congress.

XAFS Tutorial for Crystallographers and Beginners during the Madrid Congress.

S3 symposium held during XAFS14 Conference. A similar event is planned during the XAFS15 Conference (in 2013).

Acknowledgements. The CXAFS warmly thanks S. Larsen and all Executive Committee Members for their continuous and encouraging support during the triennium. Moreover, the crucial roles of S. S. Hasnain in the definition of CXAFS plans and of Brian McMahon in the web-site implementation are gratefully acknowledged.

I. Ascone, Chair, and C. T. Chantler, Secretary

\section{A6. Committee for the Maintenance of the CIF Standard}

Introduction. COMCIFS is responsible for maintaining and developing the Crystallographic Information Framework (CIF) on behalf of the IUCr. These activities include development and approval of new dictionaries as well as development of the underlying standards for syntax and dictionary construction. In 2005, Volume G of International Tables was published, providing comprehensive documentation of the CIF standard, associated dictionaries and software tools. COMCIFS activities in the following triennium (20052008) were generally aimed at increasing the coverage of approved dictionaries.

Dictionaries. A key aspect of the CIF project over the last two decades has been codification of crystallographic knowledge into machine-readable dictionaries. The rate at which these dictionaries have appeared has slowed markedly since the publication of Volume $\mathrm{G}$ of International Tables. In the last triennium, one new dictionary, the constraints and restraints dictionary, was approved. An update to the symmetry dictionary incorporating the material in Volume A1 of International Tables is in progress. More recently, a twinning dictionary commenced development and should be completed in the near future.

In the current triennium COMCIFS introduced a 'fast-track' procedure for adding new definitions to existing dictionaries. Any member of the community may now submit suggestions for new definitions, or additions to existing definitions, through an IUCrmaintained web portal (http://www.iucr.org/resources/cif/dictionaries/ new-item). The suggestion is forwarded to the relevant dictionary maintenance group for discussion and approval, following which COMCIFS approval is sought. Almost a dozen changes to the core dictionary have now been approved in this fashion.

Towards a new DDL. For historical reasons, CIF dictionaries are currently written using one of two dictionary definition languages (DDLs). Recognizing that a single DDL would be preferable, about a decade ago COMCIFS commissioned work on a replacement DDL that would incorporate the advantages of the earlier DDLs. The new DDL, dubbed 'DDLm', was accepted in draft form at the Osaka Congress. As DDLm includes new data structures, an update to the CIF syntax was required. COMCIFS has taken the opportunity to modernize the syntax as part of the syntax updating effort, and as a result the bulk of COMCIFS activity over the past triennium has been devoted to refining the details of this 'CIF2' syntax. Highlights in the current draft include full support for nonASCII characters and the availability of lists and tables for presenting data values.

Membership. COMCIFS participants include a large number of advisers/observers and a small number of voting members. At the start of the triennium N. Spadaccini and myself replaced outgoing voting members H. Berman, S. R. Hall, G. Madariaga and I. D. Brown. Following the resignation of N. Spadaccini halfway through the triennium, COMCIFS will operate with five voting members until the Madrid Congress.

\section{J. Hester, Chair}

\section{A7. IUCr Newsletter}

The IUCr Newsletter continues to be a vehicle for broadcasting and promoting the interests and activities of the IUCr and its Commissions. It also strives to enhance communication within the global community of crystallographers. Special effort is made to promote meetings and publications sponsored by the IUCr.

This report covers 12 issues (Vol. 16 Nos. 1-4, Vol. 17 Nos. 1-4 and Vol. 18 Nos. 1-4). In the first two issues of 2008, the President's column was written by Y. Ohashi and all subsequent columns were written by S. Larsen. 
Each issue contained at least two pages highlighting articles from each of the IUCr journals, along with news of various IUCr Commissions, notices of elections, awards to crystallographers, and information on web sites, resources and other activities of interest to crystallographic practioners. The reports covered topics such as highthroughput protein crystallography, materials microstructure, radiation damage, crystals in art and science, crystal growth, synchrotron updates, structural genomics, methods, supramolecular chemistry, small molecules, biomaterials, electron crystallography, applied crystallography, high-pressure studies, new materials, and aperiodic crystals. Contributions are received from crystallographers in many countries and other material is gathered from the newsletters of crystallographic associations and science news magazines. Almost all submitted contributions are published and all material is edited to varying degrees.

The reports included reviews of the meetings of IUCr Regional Associates and national crystallographic associations as well as extensive coverage of the Osaka Congress. Reports were published covering meetings in Argentina, Belgium, Canada, China, Croatia, Czech Republic, Egypt, France (2), Germany (3), India, Italy (4), Poland (4), Portugal, Spain, Switzerland, UK (2) and USA (4).

A series of articles on crystallography in countries adhering to the IUCr began in 2003. In the last triennium issues appeared on Great Britain and Ireland (Vol. 17 Nos. 1 and 3, R. O. Gould, Editor), Canada (Vol. 17 No. 4 and Vol. 18 No. 2, L. M. D. Cranswick, Editor) and Spain (Vol. 18 Nos. 3 and 4, M. Martínez Ripoll, Editor).

IUCr Regional Associates took advantage of the Newsletter to advertize their upcoming meetings. In addition, a calendar of future meetings throughout the world was published in every issue and, sadly, obituaries of 11 prominent crystallographers were reported during the triennium. Two book reviews were published. Covers highlighted art in crystallography and images from the countries featured in 'national' issues.

Three of the 12 issues published in the triennium contained 32 pages, eight had 24 pages, and one had 24 pages with a 28-page insert (the second circular for the Madrid Congress). This amounted to a total of 340 pages compared to the 364 pages for the twelve issues in the previous triennium.

A significant portion of the support for the publication and distribution of the Newsletter comes from advertising revenue. There were from 12.25 to 16 advertisements in each issue during the triennium with an average of 13.7 advertising pages per issue.

The mailing list was $1 \%$ higher than in 2007 with an average distribution of 18 576. Nineteen countries assist in the effective and economic distribution of the Newsletter. (Distributors: Hamzaoui Fodil: Algeria; Paul Jensen: Australia; Jaime Valderrama: Colombia; Biserka Kojić-Prodić: Croatia; Jindrich Hasek: Czech Republic; Ashwini Nangia: India; Ismunandar: Indonesia; P. Spadon: Italy; Ayano Satomi: Japan; A. Hamid Othman: Malaysia; Janusz Lipkowski: Poland; Margaida Costa: Portugal; Wim Klooster: Singapore; Luigi Nassimbeni: South Africa; Jurg Schefer: Switzerland; Yu Wang: Taiwan; Kenneth Haller: Thailand; Huub Kooijman: The Netherlands; Graciela Diaz de Delgado: Venezuela). Individual distributions were sent to 84 additional countries.

Patti Potter is responsible for the desktop preparation of all copy, all negotiations with the printer, postal authorities and distribution houses, maintenance and production of the mailing list, and solicitation and handling of all advertising. She began working remotely from Alaska in June 2010. Jean Gallmeyer assisted with copy preparation and correspondence with contributors.

\section{J. L. Flippen-Anderson and W. L. Duax, Editors}

\section{A8. IUCr/Oxford University Press Book Series}

In the period from September 2008 to 2011, the cooperation between Oxford University Press (OUP) and the IUCr/OUP Book Series Selection Committee was very productive.

The complete list of published books includes four IUCr Texts on Crystallography and five Monographs on Crystallography plus one in production.

Fundamentals of Crystallography, Third Edition, by C. Giacovazzo, H. L. Monaco, G. Artioli, D. Viterbo, M. Milanesio, G. Ferraris, G. Gilli, P. Gilli, G. Zanotti and M. Catti, published 2011, IUCr Texts on Crystallography No. 15.

Crystal Structure Analysis - A Primer, Third Edition, by J. P. Glusker and K. N. Trueblood, published 2010, IUCr Texts on Crystallography No. 14.

Crystal Structure Analysis - Principles and Practice, Second Edition, by A. J. Blake, W. Clegg, J. M. Cole, J. S. O. Evans, P. Main, S. Parsons and D. J. Watkin, published 2009, IUCr Texts on Crystallography No. 13.

The Basics of Crystallography and Diffraction, Third Edition, by C. Hammond, published 2009, IUCr Texts on Crystallography No. 12.

Electron Crystallography - Electron Microscopy and Electron Diffraction, by Xiaodong Zou, S. Hovmöller and P. Oleynikov - in production, expected September 2011.

Neutron Protein Crystallography - Hydrogen, Protons, and Hydration in Bio-macromolecules, by N. Niimura and A. Podjarny, published 17 February 2011, IUCr Monographs on Crystallography No. 25.

Macromolecular Crystallization and Crystal Perfection, by N. E. Chayen, J. R. Helliwell and E. H. Snell, published 25 March 2009, IUCr Monographs on Crystallography No. 24.

Diffuse X-ray Scattering and Models of Disorder, by T. R. Welberry, published in paperback edition 14 January 2010, IUCr Monographs on Crystallography No. 16.

The Nature of the Hydrogen Bond - Outline of a Comprehensive Hydrogen Bond Theory, by G. Gilli and P. Gilli, published 25 June 2009, IUCr Monographs on Crystallography No. 23.

Structural Crystallography of Inorganic Oxysalts, by S. V. Krivovichev, published 22 January 2009, IUCr Monographs on Crystallography No. 22.

Three new books have been approved by the Committee and are in the pipeline. The Committee and the OUP editing staff are now reviewing four new proposals.

The Committee encourages prospective authors to propose new volumes and readers to suggest topics and/or authors for new books on important subjects that are not well covered in the literature.

D. Viterbo, Chair

\section{A9. Sponsorship of meetings: Sub-committee on the Union Calendar}

The present membership of the Sub-committee comprises: G. Díaz de Delgado (Venezuela), R. O. Gould (UK), L. B. McCusker (Switzerland), S. W. Suh (Korea), D. Viterbo (Italy) and P. Spadon (Italy; ex officio as Chair of the Commission on Crystallographic Teaching), being chaired by J. M. Perez-Mato (Spain). The Sub-committee members, including the Chair, for the next triennium will be decided in Madrid.

During the past three years, the Sub-committee has considered and analyzed many requests to the IUCr for sponsorship and financial support, and subsequently has made recommendations to the Executive Committee. The main policy consists of giving financial support to help young scientists, meaning graduate students, post- 
graduate students or post-doctoral fellows, with a maximum age of 30 (exceptionally 35). Additional financial support for organizational expenses was considered by the Executive Committee whenever necessary and justified. Special attention was given to applications from regions where crystallography is less developed. The entire procedure, from the submission of proposals to the final decision by the Executive Committee, was carried out by e-mail. The evaluation process was very efficiently conducted by e-mail discussions involving all members of the Sub-committee.

The total amount used for sponsoring the participation of young scientists in meetings was CHF 89143 in 2008, CHF 146902 in 2009 and CHF 126513 in 2010.

The following meetings received support during this three-year period:

European Powder Diffraction Conference (EPDIC-11), Warsaw, Poland, 19-22 September 2008.

Second African School and Workshop on X-rays in Materials: Some Established Techniques and Practical Applications, Dakar, Senegal, 19-26 January 2009.

Role of Synchrotron Radiation in the Advancement of Materials, Red Sea, Egypt, 1-5 February 2009.

II Latin-American Symposium on Polymorphism and Crystallization of Drug and Pharmaceutical Products (LAPOLC 2009), Estância de São Pedro, Brazil, 9-11 March 2009.

XII Intensive Course on X-ray Structure Analysis, Durham, UK, 28 March - 6 April 2009.

RapiData 2009, Brookhaven, USA, 19-24 April 2009.

Second International School on Biological Crystallization and International School on Crystallization: Drugs, Foods and Agrochemicals, Granada, Spain, 18-22 and 25-29 May 2009.

High-Pressure Crystallography: From Novel Experimental Approaches to Applications in Cutting-Edge Technologies, Erice, Italy, 4-14 June 2009.

Symposium R on X-ray Techniques for Advanced Materials, Nanostructures and Thin Films - From Laboratory Sources to Synchrotron Radiation, Strasbourg, France, 8-12 June 2009.

2nd School and Workshop on X-ray Micro- and Nanoprobes, Palinuro, Italy, 11-19 June 2009.

ICCOSS XIX (International Conference on the Chemistry of the Organic Solid State), Genoa, Italy, 14-19 June 2009.

Crystallography Online: International School on the Use and Applications of the Bilbao Crystallographic Server, Lekeitio, Spain, 21-27 June 2009.

International Conference on Neutron and X-ray Scattering 2009, Kuala Lumpur, Malaysia, 29 June - 1 July 2009.

XX Jubilee International School on Physics and Chemistry of Condensed Matter, Bialowieza, Poland, 4-11 July 2009.

Advances in the Characterization of Industrial Materials, Chania, Greece, 10-20 July 2009.

VII International School on Crystallography (Protein Crystallography), Havana, Cuba, 13-17 July 2009.

ACA Annual Meeting, Toronto, Canada, 25-30 July 2009.

XAFS14 International Conference, Camerino, Italy, 26-31 July 2009.

25th European Crystallographic Meeting (ECM-25) and Satellite Meeting on Mathematical and Theoretical Crystallography 'Symmetry and Crystallography in Turkish Art and Culture', 16-21 August 2009.

International Summer School on Fundamentals and Basic Methods of Crystal Growth, Brasov, Romania, 24-29 August 2009.

Advanced Crystallography at High Pressure, Harbin, People's Republic of China, 27-31 August 2009.
Zürich School of Crystallography, Zürich, Switzerland, 30 August 12 September 2009.

XIX Brazilian Crystallographic Meeting, Belo Horizonte, Brazil, 9-11 September 2009.

Aperiodic 2009, Liverpool, UK, 13-18 September 2009.

XIV International Conference on Small-Angle Scattering (SAS 2009), Oxford, UK, 13-18 September 2009.

Clay, Clay Minerals and Layered Materials 2009, Moscow, Russia, 21-25 September 2009.

Fourth Crystallographic School 'Structural Analysis using SingleCrystal X-ray Diffraction Data: Crystallography under Applied Constraints', Nancy, France, 22-26 September 2009.

Summer Schools on Polycrystalline Structure Determination and Diffraction-Based Structure Analysis, Zakopane, Poland, 25-27 September 2009.

Joint Conference of the Asian Crystallographic Association and the Chinese Crystallography Society (AsCA '09), Beijing, People's Republic of China, 22-25 October 2009.

Charge Density Refinement and Analysis, Marrakech, Morocco, 28-30 October 2009.

RapiData 2010, Brookhaven, USA, 11-16 April 2010.

Powder Diffraction and Rietveld Refinement School, Durham, UK, 18-22 April 2010.

Adsorption, Absorption and Crystal Growth, Gargnano, Italy, 1823 April 2010.

Third Annual School on Advanced Neutron Diffraction Data Treatment using the FullProf Suite, Tenerife, Spain, 2-8 May 2010.

Second International School of Crystallization: Drugs, Foods, Agrochemicals, Minerals, New Materials, Granada, Spain, 24-28 May 2010.

Diffraction at the Nanoscale: Nanocrystals, Defective and Amorphous Materials, Villigen, Switzerland, 24-30 May 2010.

International Symposium of Diffraction Structural Biology (ISDSB 2010), Paris, France, 25-28 May 2010.

Second Chemical Crystallography Workshop, Hamilton, Ontario, Canada, 25-29 May 2010.

Structure and Function from Macromolecular Crystallography: Organization in Space and Time, Erice, Italy, 3-13 June 2010.

Gordon Research Conference on Crystal Engineering, Waterville

Valley Resort, New Hampshire, USA, 6-11 June 2010.

Summer Schools on Mathematical and Theoretical Crystallography, Nancy, France, 21 June - 2 July 2010.

ACA Annual Meeting, Chicago, USA, 24-29 July 2010.

Fourteenth International Summer School on Crystal Growth (ISSCG-14), Dalian, People's Republic of China, 1-7 August 2010.

Third K. H. Kuo Summer School of Electron Microscopy and Crystallography: International Workshop of 3D Molecular Imaging by Cryo-Electron Microscopy, Beijing, People's Republic of China, 8-12 August 2010.

Sixteenth International Conference on Crystal Growth in conjunction with the Fourteenth International Conference on Vapor Growth and Epitaxy, Beijing, People's Republic of China, 8-13 August 2010.

12th European Powder Diffraction Conference, Darmstadt, Germany, 27-30 August 2010.

26th European Crystallographic Meeting (ECM-26), Darmstadt, Germany, 29 August - 2 September 2010.

Structure under Extreme Conditions of Pressure and Temperature, Knoxville, Tennessee, USA, 19-23 September 2010.

International School on Aperiodic Crystals, Carqueiranne, France, 26 September - 2 October 2010. 
Modern Methods of Biocrystallography - BioCrys 2010, Oeiras, Portugal, 9-16 October 2010.

IXS 2010 - Seventh International Conference on Inelastic X-ray Scattering, Grenoble, France, 11-15 October 2010.

Tenth Conference of the Asian Crystallographic Association, Busan, Korea, 31 October - 3 November 2010.

XII Seminario Latinoamericano de Análisis por Técnicas de Rayos X (Latin-American Seminar on Analysis by X-ray Techniques) SARX 2010, Puebla, Mexico, 15-19 November 2010.

First North African Crystallographic Conference - NACCI, Casablanca, Morocco, 23-26 November 2010.

International School on Fundamental Crystallography, Montevideo, Uruguay, 29 November - 3 December 2010.

Symposium No. 239 of Pacifichem 2010: Chemistry and Materials Science under High Pressures, Honolulu, Hawaii, USA, 18-19 December 2010.

XIII Intensive School on X-ray Structure Analysis, Durham, UK, 26 March - 3 April 2011.

RapiData 2011, Brookhaven, USA, 3-8 April 2011.

Improving the Data Quality and Quantity for XAFS Experiments, Tsukuba, Japan, 12-13 April 2011 [postponed].

School on Fundamental Crystallography, Mahdia, Tunisia, 25-29 April 2011 [postponed].

X-ray Techniques for Materials Research - from Laboratory Sources to Free Electron Lasers, a Symposium at the European Materials Research Society Spring Meeting, Nice, France, 9-13 May 2011.

Workshop on Crystallographic Software, Tokyo, Japan, 22-26 May 2011 [postponed].

Third International School on Biological Crystallization, Granada, Spain, 22-27 May 2011.

SMARTER 2 Structure Elucidation by Combining Magnetic Resonance, Computation Modelling and Diffraction, Aveiro, Portugal, 23-27 May 2011.

Annual Meeting of the ACA, New Orleans, USA, 28 May - 2 June 2011.

Electron Crystallography - New Methods to Explore Structure and Properties of the Nanoworld, Erice, Italy, 2-12 June 2011.

The Power of Powder Diffraction, Erice, Italy, 2-12 June 2011.

International School on Resonant Elastic X-ray Scattering in

Condensed Matter (REXS 2010), Aussois, France, 13-17 June 2011.

Zürich School of Crystallography - Bring Your Own Crystals, Zürich, Switzerland, 13-26 June 2011.

XVII International Conference on Crystal Chemistry, X-ray Diffraction and Spectroscopy of Minerals, St Petersburg, Russia, 2024 June 2011.

\section{A10. Reports of Representatives on Regional and Scientific Associates}

A10.1. American Crystallographic Association (ACA). This triennial report for the activities of the ACA as a Regional Associate contains an overview of the more detailed Annual Reports presented each year since the Osaka Congress, as well as an outline of future activities announced by the ACA. The ACA membership of about 1850 is dominated by crystallographers from within the USA and Canada, although there are many ACA members from countries around the world. Although the ACA strives to find ways to cooperate and extend regional activities to Central and South America, there are far more attendees from Europe and Asia at ACA meetings than there are attendees from Central and South America. One option that has been under active discussion at both the ACA Council and the US National Committee for Crystallography (USNCCr) is whether sponsorship of an IUCr group membership for LatinAmerican countries that are not currently members of the IUCr is a viable option. However, identifying funding for this and other details are yet to be resolved. ACA finances rely heavily on individual membership dues and are used primarily to cover expenses for the ACA office headquarters in Buffalo.

ACA officers change each year. Serving as ACA Presidents during this period were Marv Hackert (2008), Robert Von Dreele (2009) and Judy Kelly (2010). Tom Koetzle is ACA President and George Phillips ACA Vice-President for 2011. ACA activities are primarily focused on its Annual Meetings, support for its summer schools and the publication of the newsletter RefleXions, which is an excellent source of information on all ACA activities. Past issues of RefleXions are available online.

The 2008 Annual Meeting took place in Knoxville, 31 May - 5 June with over 650 registrants. Programme Co-Chairs were Paul Butler and Dean Myles, while the Local Chair was Jason Hodges. Oak Ridge National Laboratory is nearby and on Sunday evening nearly 350 attendees had the opportunity to take a field trip to ORNL to tour the new ultra-high-intensity (1.4 MW) Spallation Neutron Source. Special thanks go to Al Ekkebus and others at ORNL for their hospitality. The programme included four workshops, one on neutron macromolecular crystallography and another on small-angle scattering. The Transactions Symposium focused on Complementary Methods to Crystallographic Techniques for Structure/Function Studies of Biological Macromolecules. The Patterson Award was presented to Bi-Cheng Wang (University of Georgia) for his 'significant contribution to the methodology of structure determination from single isomorphous replacement or single-wavelength anomalous scattering data and for its impact on structural biology.' The 2008 Etter Award was presented to Radu Custelcean, Research Staff Member at ORNL, recognizing his 'creative research in crystal engineering of novel and functional metal organic framework structures for selective ion binding.'

The 2009 Annual Meeting took place in Toronto, Ontario, Canada, 25-30 July with over 900 in attendance, and about 275 lectures and 360 posters presented. The Programme Chair for the meeting was Jim Britten and the Local Chair was David Rose. Two workshops were held before the meeting: JANA - Incommensurate Crystal Structures with Chairs Jim Kaduk and Olivier Gourdon; and Handling Twinning in Macromolecular Crystallography with George Sheldrick, Garib Murshudov and Peter Zwart. A Transactions Symposium - Phase Transitions was organized by R. J. Angel and I. Swainson. The ACA Warren Award was presented to Shih-Lin Chang of National Tsing Hua University in Taiwan, the ACA Buerger Award to Michael James (University of Alberta, Edmonton) and the Etter Early Career Award to Svilven Bobev (University of Massachusetts). In addition, attendees were treated to Plenary Lectures by Ted Baker on Celebrating Crystallography and Philip Coppens on New Developments in X-ray Photocrystallography. A total of 74 students were provided with travel grants; many international students received funds from the IUCr travel grant.

The 2010 Annual Meeting took place in Chicago from 24-29 July with over 620 abstracts and 963 attendees. The Programme Chair for this meeting was Ross Angel and the Local Chair was Bernie Santarsiero. The meeting featured five workshops: Global Phasing Software Suite for Macromolecular Crystallography (G. Bricogne); PLATON (Lee Daniels); Sulfur-SAD Data Collection and Phasing (B. C Wang, J. Rose and others); Getting the Most out of the CCP4 Suite With Particular Emphasis on Low Resolution Refinement and Model Building (Charles Ballard); and an unusual outreach/profes- 
sional development workshop organized by Cora Lind entitled Crystallography: World of Wonders for high-school teachers in the Chicago area. The meeting also featured a number of excellent Plenary Lectures and transaction symposia. The operation of the ribosome was presented from three different perspectives by those who shared the 2009 Nobel Prize in Chemistry - Tom Steitz, Venki Ramakrishnan and Ada Yonath. Jim Ibers gave a Plenary Lecture in the Transactions Symposium - The First Element, organized in memory of Bob Bau, and a special symposium New Tools - New Lights was organized in memory of Louis Delbaere. Symposia were also organized in honour of Ton Spek (Trueblood Award) for his outstanding contributions to chemical crystallography and crystallographic computing, and Ray Trievel (Etter Early Career Award) for his achievements in elucidating the substrate specificity and catalytic mechanism of histone methyltransferases. David Watkin was selected as the Fankuchen Awardee for his stewardship of the crystallographic software package CRYSTALS. His lecture was postponed and will be presented in New Orleans in 2011. Several poster prizes were awarded to the best poster presentations in various areas of crystallography, including an IUCr poster award.

The ACA solicits applications for schools to extend its educational mission. Financial support for these schools is often shared by the USNCCr, commercial vendors and others through fundraising. In 2010, the only summer school was the Small Molecule Crystallography Summer School run by Charles Lake at Indiana University of Pennsylvania. There was no Macromolecular Crystallography Summer School in 2010. In addition, the Canadian National Committee for Crystallography offers training in various areas of crystallography. A Second Chemical Crystallography Workshop (CCW) was held at McMaster University, 25-29 May 2010, as a satellite to the Chemical Society of Canada meeting in Toronto. Also, the 8th Canadian Powder Diffraction Workshop took place 21-23 June 2010, Pavillon Ringuet, Université du Québec à Trois-Rivières, Québec, Canada. Several of the national laboratories also offer short courses on the use of synchrotron light sources for data collection.

The ACA Council continues to monitor its finances carefully. Owing to wise steps taken by their financial adviser, S. N. Rao, the ACA was able to avoid the large losses that impacted most of the world economy during the fall of 2008. However, membership of the ACA has seen a slight decline in recent years, and the high costs associated with putting on an ACA meeting at a 'convention centre' or a 'conference hotel' are concerns going forward.

Upcoming ACA Annual Meetings include New Orleans (2011) with Programme Chair Chris Cahill and Local Chairs Ed and Cheryl Stevens; Boston (2012); and Hawaii is being considered for 2013. The ACA Council decided to move to a four-day Annual Meeting in 2013, and investigate the possibility of also doing this in 2012. The ACA has also decided to hold an early meeting in 2014. The undersigned has taken part in several teleconference calls discussing plans for the Montreal Congress in 2014. Plans for that meeting are progressing well, and a web site for the Montreal Congress should be ready before Madrid. The ACA Council announced plans for the new ACA Fellows Programme with plans to announce the first group of ACA Fellows in New Orleans in 2011.

\section{L. Hackert, Representative}

A10.2. Asian Crystallographic Association (AsCA). AsCA continues to play a leading role in the nurturing of collective crystallographic activities in the Asia-Pacific region.

AsCA executive officers. The past office bearers for 2007-2010 were J. M. Guss (President, Australia,) Se Won Suh (Vice-President,
Korea) and K. Haller (Secretary/Treasurer, Thailand). The current executive officers for the term 2010-2013 were elected as follows: Se Won Suh (President, Korea), P. Chakrabarti (Vice-President, India), A. Vrielink (Secretary/Treasurer, Australia).

AsCA scientific meetings in the period 2008-2010. In the past three years, the AsCA calendar ran as follows: IUCr Congress (in 2008); joint AsCA/Chinese Crystallographic Society meeting (in 2009); and full triennial AsCA meeting in Busan, Korea (in 2010). No AsCA scientific meetings are held in the year when the IUCr Congress takes place.

$A s C A$ 2009. The major activity in 2009 was the joint meeting of AsCA and the Chinese Crystallographic Society in Beijing, People's Republic of China, held 22-25 October 2009. This meeting was a great success with a large attendance $(\sim 200)$ for a joint AsCA/local society meeting. In addition to the exciting science, the 'rising stars' session, which is a first for an AsCA meeting or a meeting of any of the Regional Associates, provided the opportunity for six earlycareer researchers selected from the submitted abstracts to present their work to a plenary session on the final day of the meeting. The presentations in this final plenary session were of a very high standard. P. Colman served as the Chair of the International Programme Committee and Zhi-Jie (James) Liu was the Chair of the Local Organizing Committee.

AsCA 2010. The major activity in 2010 was the 10th Conference of AsCA (AsCA 2010), which was held 31 October - 3 November 2010 in BEXCO, Busan, Korea. There were 415 presentations ( 83 oral and 332 posters). The distribution of presentations was 155 biological, 156 non-biological, 90 technology and 7 others. Attendance was the highest yet for an AsCA meeting, with 626 registrations, of which 229 were Korean and 235 were students. Exhibitors had taken 31 booths. Travel-support applications numbered 58, and 15 travel awards were made [to India (8), Thailand (4), Taiwan (1), People's Republic of China (1) and The Philippines (1)]. Rising-star applications numbered 38; with two pre-awards selected by the awards committee for oral presentations in Microsymposia sessions and an additional six rising stars selected by the Poster Award Committee for oral presentations in the rising-stars session [to Australia (3), India (2), Japan (1), Taiwan (1) and Vietnam (1)]. Five poster prizes were awarded (two IUCr, two AsCA, one RCSB PDB). J. Martin served as the Chair of the International Programme Committee and Se Won Suh was the Chair of the Local Organizing Committee.

Future AsCA scientific meetings. The AsCA Council in 2009 approved the proposal to host a joint AsCA meeting in Adelaide, Australia in 2012. W. L. Bragg was born in Adelaide and received his first degree from the University of Adelaide. The joint AsCA/ SCANZ conference and Bragg centenary celebration will be held in the Adelaide Convention Centre, Adelaide, Australia, 2-6 December 2012. November 2012 will mark the centenary of the presentation to the Cambridge Philosophical Society of Lawrence Bragg's paper defining Bragg's equation. The Bragg symposium will be a public forum with speakers including descendants of Lawrence Bragg, his former students and high-profile scientists. Proposed fees for the meeting including the Bragg commemoration are AUD 650 for full registrants and AUD 350 for students. Fees for the Bragg symposium only will be AUD 120 . The budget is estimated to be AUD 330000 and the committee is expecting about 500 registrants.

The Scientific Advisory Committee of AsCA 2012 is as follows: G. R. Desiraju (India), Zhi-Jie (James) Liu (People's Republic of China), Se Won Suh (Korea), M. Takata (Japan), S. Wakatsuki (Japan), B. J. Kennedy (Australia), A. Vrielink (Australia), B. Kobe (Australia), D. Goossens (Australia), R. Withers (Australia), S. 
Batten (Australia), E. N. Baker (New Zealand), S. W. Wilkins (Australia), J. Varghese (Australia).

Traditionally, alternate AsCA meetings are held in smaller countries. The venue for AsCA 2013 will be finalized by the AsCA Council Meeting in Madrid, Spain, in August 2011.

AsCA 2015. The location of AsCA 2015 will be determined based on the location of AsCA 2013. There is no lack of interest from member countries in holding this meeting.

AsCA Council meetings in 2009-2010. The 2009 AsCA Council meeting was held in October in Beijing, People's Republic of China. A proposal from Adelaide in Australia to host a joint AsCA/SCANZ conference and Bragg centenary celebration in November 2012 (centenary of the presentation of Lawrence Bragg's paper to the Cambridge Philosophical Society that detailed the first crystal structure and Bragg's equation) received strong support from the AsCA Council. A detailed proposal including dates, costs, accommodation and registration fees was presented by A. Vrielink and was approved.

The 2010 AsCA Council meeting was held on 2 November in Busan, Korea. S. Larsen presented a report from the IUCr Executive Committee covering the Regional Associates to the IUCr (ACA, ECA, AsCA). She discussed the outcomes of the IUCr Executive Committee meeting, and the proposal for the International Year of Crystallography (IYCr). New executive officers for the term 20102013 were elected.

Se Won Suh outlined the statistics for the AsCA 2010 meeting held 31 October - 3 November in Busan, Korea (see above).

There was support for the proposal that AsCA 2013 be held in a small country, and interest was expressed by a representative of Japan on behalf of Vietnam. A. Hussain presented a bid on behalf of Bangladesh. India indicated their keen interest in hosting AsCA 2015, as a prelude to possibly hosting the IUCr Congress in 2017. Representatives from India indicated that if no suitable bids were made to host AsCA 2013 and AsCA asked India to organize the 2013 meeting, they could manage this, though their preference was for 2015. In the event that a country other than India was selected for AsCA 2013, then AsCA would commit to selecting India for the 2015 conference.

Initiatives and financial matters of AsCA. It is necessary to mention some of AsCA's major initiatives and some of the problems it faces. The first initiative, originally proposed by Y. Ohashi as IUCr President, was the formation of a regional grouping of five Asian nations (Bangladesh, Malaysia, Singapore, Thailand, Vietnam), who are recognized as a joint member of the IUCr. Together they have a single vote at IUCr General Assemblies but individuals from the countries may attend. For 2009-2011, the annual dues of CHF 1000 per annum have been shared by the Society for Crystallographers in Australia and New Zealand (SCANZ) and the Crystallographic Society of Japan. From 2012, other sources of funding will be found to support the dues.

The second major initiative is to utilize interest from the accumulated reserves of AsCA, currently about AUD 164 000, to support attendance at AsCA meetings by students and early-career scientists from the region. AsCA offered five such scholarships to attend AsCA 2009 and AsCA 2010 meetings, providing up to about USD 1000 each. It is the intention of the AsCA Executive that a similar or a higher level of support will be provided for forthcoming meetings. In order to sustain these initiatives in the long term, AsCA needs to secure additional sources of funding to increase the total AsCA investment portfolio.

The third initiative by Y. Ohashi, supported by past AsCA President J. M. Guss, is an agreement from the IUCr President, S. Larsen, to provide direct financial support from the IUCr for attendance by two members of the AsCA Council who would not otherwise be able to afford to attend Council meetings. The agreement is for three years but one individual can receive support on only one occasion. This initiative recognizes the special circumstances faced by a number of member countries of AsCA. AsCA appreciates the continued support from the IUCr.

Some of the problems that the Asian crystallographic community face today are different from elsewhere. The various countries are geographically separated by large distances by the oceans and there needs to be more in the way of systematic bilateral and multilateral initiatives among the countries of the region so that the scientific communities in these countries get to know each other better. Travel and research support for students and young workers is also very limited and there is a need for more funding in these areas. Economic growth in the Asian region should be paralleled by scientific and infrastructural growth. IUCr support is critical to ensure that crystallographic research in some of the more disadvantaged regions of Asia is put on a firmer footing. A greater representation of younger crystallographers from the Asia-Pacific region in the activities of the IUCr is strongly desirable. The IUCr could also become more involved in mentoring activities even as some of the Asian countries are rapidly trying to become integrated with the international scientific mainstream. In conclusion, the AsCA Council thanks the strong support of the IUCr in the past to promote crystallography in the Asia-Pacific region and anticipates continued IUCr support in the future.

Some of the AsCA Council members suggested that the IUCr establish an Ethics Committee. The proposed Committee could handle issues such as publication of forged structural data in the $\mathrm{IUCr}$ journals.

Summary. There is no doubt that the creation and continued success of AsCA has had a positive effect on education and research in crystallography in this region. AsCA continues to grow in strength but it needs special consideration from the IUCr, especially with regard to the growth and development of crystallography in small, far-flung Asian countries. For example, AsCA needs IUCr support to hold small bilateral and trilateral meetings within the Asian region. The student population in Asia is the largest but they are the least endowed in terms of being able to attend international scientific meetings. Scientists from Europe and North America are sincerely invited to attend meetings of AsCA, which are becoming scientifically very competitive. AsCA might become a good role model for other regions of the world such as North Africa, Latin America and South America in terms of organizing themselves into a critical mass of scientific activity.

I thank Se Won Suh and A. Vrielink for their assistance in preparing this report, as I thank J. M. Guss, K. Haller and I. Williams who assisted similarly in the past.

\section{G. R. Desiraju, Representative}

A10.3. European Crystallographic Association (ECA). The present membership of the ECA Executive Committee is: S. Garcia-Granda, President; J. R. Helliwell, Past President; A. Roodt, Vice-President; P. Bombicz, Secretary; R. Kuzel, Treasurer; A. Bacchi, Officer; L. Van Meervelt, Officer; W. Depmeier, Officer; M. Nespolo, Education Coordinator. P. Scardi attends Executive meetings as EPDIC Chair. Meetings. ECA meetings were held as follows:

ECM-25 Istanbul, Turkey, August 2009 (810 participants).

ECM-26 Darmstadt, Germany, August 2010 (1047 participants). This was held along with EPDIC-12. 
Future ECA meetings will be held as follows:

ECM-27 Bergen, Norway, 2012.

ECM-28 Warwick, UK, 2013.

Bids for 2015 will be reviewed at the Madrid Congress.

The ECA supported six workshops or schools in both 2009 and 2010 with grants of EUR 7250 and EUR 7000, respectively. In 2011 the ECA provided support for eight meetings with a total value of EUR 10 000. The condition for students to receive a bursary is for them to be registered in the World Directory of Crystallographers (WDC) and to be individual members of the ECA.

Overview of supported meetings. The following meetings were supported in 2011:

EMU School 2011: Layered Mineral Structures and Their Application In Advanced Technologies, Rome, Italy: EUR 750.

School on Fundamental Crystallography, Mahdia, Tunisia: EUR 750 .

Electron Crystallography: New Methods to Explore Structure and Properties of The Nano World, Erice, Italy: EUR 1250.

Heart of Europe Bio-Crystallography Meeting HEC, Zagan, Poland: EUR 1000.

The Power of Powder Diffraction, Erice, Italy: EUR 1250.

The 2011 Zürich School of Crystallography, Zürich, Switzerland: EUR 1000.

5th European Conference on Neutron Scattering, Prague, Czech Republic: EUR 1000.

The ECA provided EUR 3000 to ECM-26 to waive the registration fees of senior researchers from less-developed countries. A limit of two from any country was imposed.

The following meetings were supported in 2010:

Summer School on Mathematical Crystallography, Nancy, France: EUR 1250.

International Symposium on Diffraction Structural Biology, Paris, France: EUR 1000.

Structure and Function From Macromolecular Crystallography: Organization in Space and Time, Erice, Italy: EUR 1500.

Diffraction at The Nanoscale: Nanocrystals, Defective and Amorphous Materials, Villigen, Switzerland: EUR 500.

MISCA II, Oviedo, Spain: EUR 500.

First North African Crystallographic Conference, Casablanca, Morocco: EUR 2000.

The following meetings were supported in 2009:

Crystallography Online: International School on the Use and Applications of the Bilbao Crystallographic Server, Lekeitio, Spain: EUR 1250.

The Role of Symmetry in Condensed Matter, Giens Peninsula, France: EUR 750.

High Pressure Crystallography: From Novel Experimental Approaches to Cutting-Edge Technologies, Erice, Italy: EUR 1500.

4th Crystallographic School on Structural Analysis Using Single-

Crystal X-ray Diffraction, Nancy, France: EUR 750.

ECM-25, Istanbul, Turkey: EUR 2000.

International School on Physics and Chemistry of Condensed Matter, Bialowieza, Poland: EUR 1000.

Prizes. The Max Perutz Prize was awarded to C. Lecomte, Nancy University and CNRS, France, in 2010. The 4th Max Perutz Prize was awarded but not accepted, therefore there was no prize in 2009.

The Felix Bertaut Prize was awarded to T. Fennel, Institut LaueLangevin, Grenoble, France in 2010.

L. Palatinus, Institute of Physics, Prague, Czech Republic, was the recipient of the Bertaut Prize in 2009.

The number of poster prizes awarded has increased significantly in the past years to 10 in 2009 and 12 in 2010.
Membership issues. The membership fee for National Members is determined by the number of crystallographers in that country. This information is taken from the WDC.

The adhering body 'Chemists and Technologists of Macedonia' has been a new National Member of the ECA since 2010; contact has been re-established with Russia and Serbia. The Regional Committee of Crystallographers from Algeria, Latvia, Morocco, Tunisia, Turkey and Ukraine was established as a member of the IUCr in 2008. The Adhering Bodies of these countries are ECA National Members. The ECA pays one group IUCr membership fee for these countries for a period of two terms. Crystallography in Africa continues to grow. The first ECM to be held in Africa was in Durban in 2003; four years later ECM-24 was organized in Marrakech, Morocco. Half of the income from this meeting was donated to Morocco in order to promote crystallographic activity in the North African region. The First North African Crystallography Conference was held in Casablanca, Morocco, at the end of 2010. Tunisia has started to plan a bid for an ECM. The SESAME synchrotron-radiation facility in Jordan is a centre for regional development in crystallography. Intentions of interest have been received by Iran and Armenia to become future National Members of the ECA.

Individual members currently have three representatives on the ECA Council.

A leaflet is issued annually publicizing ECA activities. As a result, the number of Corporate Affiliate Members (CAMs) has more than doubled. The CAMs have their own representative on the ECA Council.

A new system of networking groups is being introduced. These are named 'General Interest Groups' (GIGs) and follow the same rules as the Special Interest Groups (SIGs). They will start to operate after a change in ECA Statutes in Madrid 2011. The GIG 'Young Crystallographers' is already established and has been operating enthusiastically ad interim since 2010. GIGs for 'Senior Crystallographers' and for 'Teaching' may be established in the future.

The number of individual members assigned to one or more Special or General Interest Groups is increasing. A new evaluation system has been developed to measure the activity of the SIGs and to compare them. The SIGs are reviewed annually, and they are required to contribute to the scientific programme at the ECMs, and to have their own web pages and mailing lists. SIG10 (Diffraction Physics and Optics) has been closed through lack of activity; SIG6 hosts the remaining activity in this field. Contact between the SIGs and the Commissions of the IUCr is well established.

Other issues. A major initiative by the ECA has led to the establishment of the European Graduate School of Crystallography: a Mundus Master School involving the collaboration of several universities with the support of industrial companies within the EU Framework 7 programme. An application for funding was on the reserve list in 2010, and a new application was submitted in 2011. Plans are underway to establish a European Crystallography Service.

A long-term goal is to increase ECA income to the point that staff could be employed to create a permanent ECA secretariat.

The ECA is keen to participate in the International Year of Crystallography and would welcome discussions with the IUCr.

The ECA is also grateful to the IUCr for providing column space on a regular basis in the IUCr Newsletter in which the ECA Officers write on topics of policy and community interest within the ECA, and thereby encourage wider debate within the IUCr as a whole.

\section{J. Gilmore, Representative}


A10.4. International Centre for Diffraction Data (ICDD). During 2009 the Chair of the Commission on Powder Diffraction (CPD) was invited to attend the annual meeting of the International Centre for Diffraction Data (ICDD). One other CPD member, B. Toby, was in attendance, as well as the President of the ACA, R. Von Dreele. At the time, exploratory negotiations were ongoing between the ICDD and the ACA about the possibility of holding a joint 2013 meeting of the powder-diffraction-focused Denver X-ray Conference and the ACA meeting. Unfortunately, despite a willingness to develop a common scientific programme, the organizations could not develop a financial framework for this to occur, but future interactions between the two major meetings in the USA are to be encouraged. There is a formal mechanism for cooperation between the IUCr and the ICDD, as an observer from the ICCD sits on the CPD and the CPD Chair is the IUCr representative to the ICDD. Other formal linkages are lacking, although during the current triennium a member of the European EPDIC Committee sits on the CPD. No such linkage exists with the Australian X-ray Analytical Association (AXAA) and efforts were made to improve communication between the AXAA and the CPD. To that end the CPD Chair wrote a short article on the history and role of the CPD within the IUCr and the wider powder diffraction community for the $A X A A$ Newsletter.

P. Whitfield, Representative

A10.5. International Organization of Crystal Growth (IOCG). After a very successful 13th International Summer School on Crystal Growth, Park City, USA (http://www.crystalgrowth.us/ isscg13/index.php), followed by the 15th International Conference on Crystal Growth (in conjunction with the 13th Conference on Vapour Growth and Epitaxy and the US Biennial Workshop on Organometallic Vapor Phase Epitaxy) in Salt Lake City, USA, the main activity of the IOCG (http://iocg.org/) in the triennium 2008-2010 was preparation for coming events, which were scheduled for August 2010. These were:

16th International Conference on Crystal Growth (ICCG-16), CoChairs: M. Jiang (People's Republic of China), C. Chen (People's Republic of China), attended by about 1100 crystal growers from around the world, and the 14th International School on Crystal Growth (ISCG-14), Chair Mu Wang, 20 lectures and a very innovative experimental, hands-on approach. Both meetings were well organized in the People's Republic of China and were very successful; the detailed reports can be found in the 2010 IOCG report and on the web site of the Commission on Crystal Growth and Characterization of Materials. The Conference and School were both supported by the IUCr and 18 young scientists were able to attend these venues as a result of this support.

The new Executive Committee (EC) of the IOCG was confirmed during the General Assembly of the IOCG in Beijing: President: R. Fornari (Germany); Co-Vice Presidents: T. F. Kuech (USA) and E. Vlieg (The Netherlands); Secretary: K. Kakimoto (Japan); Treasurer: V. Fratello (USA); Members: H. A. Dabkowska (Canada), J. Derby (USA), T. Duffar (France), J. M. García-Ruiz (Spain), Y. Mori (Japan), K. Roberts (UK), P. Rudolph (Germany), A. Voloshin (Russia); Past President: A. A. Chernov (USA); Honorary Principal Founder: M. Schieber (Israel). The ex officio members of the Executive Committee are the Chair of ICCG-17: S. Krukowski (Poland), and the Co-Chairs of ICCG-16: M. Jiang (People's Republic of China) and C. Chen (People's Republic of China).

The IOCG Prizes, which are highly regarded within the crystalgrowth community, were awarded as follows:
Frank Prize: M. E. Glicksman (USA) for basic contributions to resolve fundamental issues associated with dendritic growth kinetics.

Laudise Prize: J. J. DeYoreo (USA), N. P. Zaitseva (Russia) and L. N. Rashkovich (Russia) for their outstanding work in creating the technology and scientific basis for rapid growth of perfect crystals from solutions.

Scheiber Prize: V. Maltsev (Russia) for his outstanding work as a young author in developing 'Single crystal growth of novel rareearth-doped orthoborates for a new generation of bulk and waveguide near-infrared lasers'.

These prizes help to promote crystal-growth science in different countries as well as collaboration between national crystal-growth organizations.

The next international meetings, ICCG-17 (Chair: S. Krukowski) and ISCG-16 (Chair: W. Sadowski), will be held in Poland, in Warsaw and Gdansk respectively, in 2013, and the 2016 meetings will take place in Japan.

In the meantime, there were many other conferences and meetings devoted to crystal growth around the world organized and attended by members and consultants of the Commission on Crystal Growth and Characterization of Materials. These meetings and conferences are listed in the annual reports of the IUCr Representative to the IOCG.

In November 2010, after a very important, IOCG-organized meeting of European Chairs, Secretaries and Representatives of national groups and institutions involved in crystal growth in Berlin, the Irish National Association of Crystal Growth was created (and later accepted) as a new Member of the IOCG.

\section{H. A. Dabkowska, Representative}

\section{A11. Reports of Representatives on bodies not belonging to the Union}

A11.1. Interdivisional Committee on Terminology, Nomenclature and Symbols of the International Union of Pure and Applied Chemistry (IUPAC ICTNS). During the triennium 2008-2010, ICTNS continued its activities on behalf of IUPAC in reviewing and approving Technical Reports and Recommendations submitted to IUPAC. Most of these Technical Reports and Recommendations were, or are about to be, published in Pure and Applied Chemistry. A few comprise what are essentially research papers containing new results but emanating from IUPAC projects, and these have been reviewed with publication recommended in research journals. A few others emanated from publications in preparation or prepared by international bodies of which IUPAC is a member; these were reviewed in the usual way.

The following Technical Reports and Recommendations have been reviewed by referees chosen among members of the Commission on Crystallographic Nomenclature:

Towards Defining Materials Chemistry.

Evaluation of Measurement Data. The Role of Measurement Uncertainty in Conformity Assessment.

Definitions of Terms Relating to Crystalline Polymers.

Definition of The Hydrogen Bond.

\section{A. Authier, Representative}

A11.2. International Council for Science (ICSU). The International Council for Science (ICSU) was founded in 1931 as a federation of International Scientific Unions and National Scientific Councils. The numbers of members of Unions and National Councils are 30 and 97, respectively. The IUCr is one of the member Unions. 
The activities of ICSU are closely correlated with those of the organizations of The United Nations such as UNESCO. The General Assembly is held every three years. The Executive Board (EB), including President, Immediate Past President or President-Elect, two Vice-Presidents, Treasurer, Secretary-General, and eight Ordinary Members, usually manages the Council.

I attended the 29th General Assembly (GA) of ICSU, which was held at Maputo in Mozambique in October 2008, as the representative of the IUCr. Each Scientific Union and National Scientific Council has one voting right in the GA. However, since the total voting rights for Union and Council groups should be equal, each Scientific Union has a voting-right weight of 97/30 (the ratio of the numbers of their members).

Before the Opening Ceremony on the first day, an Open Forum of the Union members was held. Pre-discussions of the important items were carried out. It seemed very important to attend the Open Forum and understand the background of the important items in the GA. I displayed a poster showing the history and activity of the IUCr on the poster board and the leaflets of the IUCr journals and International Tables on a table in front of the poster. About two thirds of the Unions had poster presentations.

On the second day, the Secretary-General reported the activities over the last three years, especially the establishment of Regional Offices, the celebration of ICSU's 75th anniversary in 2006 and the organization of the Young Scientists' Conference in 2007. The reports from the Unions and National Councils were presented. The ICSU Strategic Plan had been approved at the previous GA in 2006, because the plan covers the six-year period 2006-2011. The implementation of this Plan during the first three years was reported. The Strategic Plan is composed of four Projects: (1) International Polar Year (IPY), (2) Integrated Research on Disaster Risk, (3) Ecosystem Change and Human Well-Being, and (4) Health and Well-Being in the Changing Urban Environment. These projects are very important but the IUCr has no contribution to them. All the reports were accepted and the projects were encouraged to continue for the next three years.

On the third day, the Global Environmental Change Programmes were reviewed. The discussion was very intense. The proposed decision was modified so that the planning group of ICSU (CSPR: Committee on Scientific Planning and Review) should organize the high-level meeting and outline the overall framework after this. Then the item Scientific Commission on Problems of the Environment (SCOPE) was discussed. This Commission was reviewed last year, since several environmental organizations with a similar role to SCOPE have had a competitive assessment. Finally, the decision was accepted that after a suitable transition period of no more than two years SCOPE will cease to be an ICSU Interdisciplinary Body.

The report of the Committee on Freedom and Responsibility in the conduct of Science (CFRS) was presented and it was decided that the booklet on Freedom, Responsibility and Universality of Science should be endorsed. In the Strategic Plan, ICSU will increasingly seek productive collaboration in the area of Social Sciences, where it lacks expertise. To encourage this Plan, the Unions were divided into four groups in the 28th GA as follows: (1) Physical, chemical and mathematical sciences; (2) Biological sciences; (3) Earth and space sciences; and (4) Social sciences. In addition, one member of the Executive Board should be elected from each group. After lunch, the Election of Officers was performed. Then the reports from the Strategic Committee on Information and Data (SCID), from the three Regional Offices (Africa, Asia and Pacific, Latin America and the Caribbean), and from the Policy Committee on Developing Countries (PCDC) were delivered and accepted.
On the fourth day, the reports on the other Strategic Activities and Planning for the next Strategic Plan 2012-2017 were presented. Then the report on Dues Structure and Recommendation from the Executive Board was presented; this is because the previous GA decided to set up a working group to modify the dues structure. The following structure was accepted: (1) dues to be based on a model based on raw GDP figures, (2) ten bands to be used, rather than the current 51, (3) a minimum payment of EUR 1000 to be required, (4) a cap to be placed on the top band amount (currently paid by the USA), (5) in-kind contribution to ICSU to be encouraged and recognized in some way, (6) four bands to be created for Union dues, (7) Unions to be assigned to bands which would be based on their declared income from dues, (8) the dues for Scientific Associates to be maintained at EUR 500, (9) the new dues structure to be regarded as a 'lower bound' by each member, with higher voluntary payments being encouraged, (10) members may voluntarily move to a higher subscription band, and (11) the new mechanisms for National Members, Unions and Scientific Associates to become operative from 2012.

The previous year the working group had proposed a plan in which the Union dues should depend on the total income of the Union. This indicated that the IUCr should pay EUR 30000 per year. Objections from 14 Unions, including the IUCr, were sent to the working group. The plan was withdrawn and the above dues structure was proposed. According to the above proposed list, the IUCr will be included in the third band (the declared income less than EUR 240000 per year) with dues EUR 3200 per year. Another problem concerns the weighted voting. This was strongly supported by the large countries, such as USA and Japan. The developing countries strongly supported the equal voting currently used. No decision was made, so that the equal voting continues.

The election of the Ordinary Members of the Executive Board was then held. Four members were elected from National members and four members were elected from Union members. The candidates were already accepted and pre-selection was carried out at each Forum before the Opening Ceremony.

The Executive Secretary was recommended by the Executive Board. It had already been decided to hold the next GA in Rome, Italy, in 2011.

In 2009, there were no important decisions or meetings. The ICSU Regional Office for Africa reported four science plans and has established functioning networks of experts and students.

In 2010, the Meeting of the International Scientific Unions of ICSU was held at the Pasteur Institute, Paris, France, in April. Representatives of 27 of the total of 30 Unions attended the meeting. From the Executive Board, the President, Past President, President-Elect, two Vice-Presidents, Treasurer, Secretary-General and seven out of eight board members attended.

On the first day, the item concerning Implementation of the ICSU Strategic Plan 2006-2011 was discussed. After the discussion several reports on International Years and trans-Union activities were delivered. The representative of IUPAC reported the preparation of the International Year of Chemsitry IYC2011. Since he asked IUCr to support IYC2011, I answered that the IUCr will support IYC2011 but the IUCr also expects that IUPAC will support the IUCr's proposal for IYCr. Then the item on Development of the ICSU Strategic Plan 2012-2017 was discussed. In the evening, the French Academy of Sciences invited us to a reception. On the second day, the three important items, ICSU finances, weighted voting and grants programme, were discussed. Then the activities of the ICSU Regional Offices (African, Asian and Pacific, Latin America and the Caribbean) were reported. In the afternoon, the item Science for Policy, 
ICSU's Role in Sustainable Development, was discussed, including the relation with the USA, Intergovernmental Platform on Biodiversity and Ecosystem Services, and other Union interactions.

In the Summary of the second day, I asked all the ICSU Scientific Union members to support our proposal for IYCr. (After the Meeting, the President of the IUCr met officers of UNESCO and the organizer of IYC2011, and received some important information about proposing the IYCr to UNESCO and the UN.)

The most important and urgent item was the weighted voting system. In the Assembly at Maputo, the dues structure was significantly changed and the annual membership fees for most members, especially for National members of large countries, were raised. Although the National members whose membership fees were raised mostly accepted the decision in the GA, they demanded to change the equal-voting system to the weighted-voting one. This problem will be decided at the next GA to be held in Rome in 2011 .

All the activities of ICSU are strongly inclined to environmental problems, such as a new Global Initiative, Earth System Research for Global Sustainability. Most of the Scientific Unions, Mathematics, Physics, Chemistry, Biology and Geology, have shown great contributions to the ICSU activities. I expect that IYCr will contribute to the activities of ICSU such as International Education, Data and Information and Universality of Science.

Y. Ohashi, Representative

A11.2.1. ICSU Committee on Data for Science and Technology (CODATA). CODATA is the interdisciplinary Committee on Data for Science and Technology of the International Council for Science (ICSU). It is currently a worldwide network of 18 national data committees, two Associate National Members, 16 International Scientific Unions, 3 co-opted delegates, and 19 supporting organizations from industry, government and academia, which define and lead its scientific programme. Its mission is stated as 'to strengthen international science for the benefit of society by promoting improved scientific and technical data management and use.' Specific projects are addressed by Task Groups answerable to the CODATA General Assembly, by Working Groups, by themed workshops or conferences, and by publications on specific aspects of data handling or data compilation.

The major activities of CODATA in the past triennium were as follows.

The 21st International CODATA Conference took place in Kyiv, Ukraine, in October 2008. Its theme was Scientific Information for Society - From Today to the Future. Over 400 delegates considered the impact of scientific data and information management on the world community, and also focused on the importance of engaging the younger generation of scientists to lead future developments.

The 22nd International CODATA Conference took place in Stellenbosch, South Africa, in October 2010, with over 220 attendees. Its theme was Scientific Data and Sustainable Development, and it continued an emphasis on young scientists.

The IUCr representative made formal presentations at both conferences, on interactive visualization of crystal structures in online publications, and on the challenges for long-term preservation of the scientific record in integrating data with publication, respectively. (These complemented the workshop on interactive publications organized by the undersigned for ICSTI in Paris, France, in February 2010.) Full reports on these meeting can be found at http://www. iucr.org/news/meeting-reports/meeting-reports/.

Work continued on the Strategic Plan for CODATA arising from the ICSU Priority Area Assessment exercise of 2004. Relevant activities under this umbrella included the development of a global information commons for science (GICSI), collaboration with the COMMUNIA network, development of the GEOSS data-sharing principles for GEO (Group on Earth Observations), launch and management of a Polar Information Commons, and partnership with the World Data System created by ICSU to supersede the earlier network of World Data Centres. Members of CODATA are also involved with the ICSU Strategic Coordinating Committee on Information and Data (SCCID).

Full details of CODATA activities are available from its web site at http://www.codata.org.

During the triennium, there were a number of activities of common interest to CODATA and ICSTI, such as the formal summit meeting between the executive bodies of these organizations in Paris in early 2009, the ICSTI public conference on Managing Data for Science in Montreal, Canada, in June 2009, and the First DataCite Summer Meeting in Hannover, Germany, in June 2010. I was able to attend all these as alternate for J. R. Helliwell, IUCr representative to ICSTI. I acknowledge the close collaboration with J. R. Helliwell and with the IUCr journals Managing Editor P. R. Strickland, which has informed and enhanced the IUCr's interaction with these ICSU bodies in the past triennium.

\section{B. McMahon, Representative}

A11.2.2. ICSU Committee on Space Research (COSPAR). During 2008-2010 there were two COSPAR Assemblies: in Montreal, Canada, and in Bremen, Germany. The IUCr representative was present at both meetings.

COSPAR was established during an international meeting in London in 1958 (following the launch of Sputnik I in 1957), and a 50th Anniversary Celebration took place during the Assembly in July 2008 in Montreal, Canada.

The detailed report from this meeting was presented in my report in 2008, and the Assembly Programme can be found at http:// cosparhq.cnes.fr/. A total number of 2464 participants took part in this successful event.

The 2010 COSPAR Assembly took place in Bremen, Germany one of the most important Europe aerospace centres, where essential parts of the Airbus and Columbus module are being produced. Bremen is also the home of the famous Bremen drop tower.

Here the number of participants was 4836 (including about 1000 local visitors to the interdisciplinary lectures and to local exhibitions). The detailed report from this meeting was presented in my report in 2010, and the scope of the Programme can be found at http:// cosparhq.cnes.fr/.

The main topics at both meetings were the role of space governance, the viability of space tourism and colonization, and resource mining to solve problems on Earth.

Other interesting subjects are alternative propulsion systems and their availability within the next 50 years.

The questions of extraterrestrial intelligence, the possibility of biological evolutionary paths that may be significantly different from those seen on the Earth, and the theological and social implications of such discoveries are fascinating from the point of view of humanity. From the point of view of the IUCr the behaviour of materials in space - in microgravity conditions - is of some interest. Experiments of growing different crystals in microgravity have held the attention of our community for many years now.

Since the creation of COSPAR its main objective has been to promote international collaboration at various levels in scientific research in space, with an emphasis on the exchange of results, 
information and opinions. Developing world standards for the space environment and its protection requires the creation of national and international organizations and specialist working groups.

The 2012 Assembly will take place in Mysore, India, and the next will be in Moscow, Russia. More information can be found at http:// cosparhq.cnes.fr/.

\section{H. A. Dabkowska, Representative}

A11.3. International Council for Scientific and Technical Information (ICSTI). ICSTI offers a unique forum for interaction among organizations that create, disseminate and use scientific and technical information. ICSTI is a scientific associate of ICSU, the International Council for Science. ICSTI's mission cuts across scientific and technical disciplines as well as international borders, to give member organizations the benefit of a truly global community.

During 2009, 2010 and 2011 there were significant efforts to attract new members to ICSTI, and to increase cooperation with other stakeholders led by ICSTI's new Executive Officer A. Llewellyn. These efforts included a summit meeting between the Executive Board and the CODATA Executive at ICSU Headquarters in Paris, France, in March 2009, at which common approaches to the ICSU Priority Area Assessment (PAA) on scientific data and information were discussed. B. McMahon, the IUCr's CODATA Representative, represented the IUCr at this meeting and throughout 2009 on the ICSTI Executive Board as alternate for J. R. Helliwell, who was busy with duties and activities as President of the European Crystallographic Association.

The ICSTI Summer Conference in 2009 took place in the Library and Archives Canada building, in Ottawa, Canada, held in June, with the theme Managing Data for Science. The 16 speakers discussed the challenges for the publishing and library communities arising from the increasing availability of research data. They showed that many of these challenges and difficulties - identified, for example, in successive CODATA conferences - are becoming more generally recognized, and that progress is being made in addressing them in some scientific fields, and in the formulation of science policy at national levels. An account of the conference can be found at http://www. iucr.org/resources/data/meeting-reports/icsti-2009.

The ICSTI Technical Activities Coordinating Committee (TACC) project on Numeric Data: Citation Techniques and Integration with Text culminated in a workshop establishing a consortium of major scientific libraries to act as registration agencies for unique identifiers for data sets. This consortium, led by the German National Library of Science and Technology, subsequently adopted the name DataCite (http://www.datacite.org). B. McMahon delivered a presentation on Visualization of Chemical Data at the first DataCite Summer Conference in Hannover, Germany, in June 2010. Another TACC project of interest, Multimedia Search and Retrieval, continued through 2009 to collect multimedia materials for indexing full-spoken content in audio or video files through voice-recognition technology.

The IUCr took the lead in a new TACC project, Interactive Journal Articles, intended to survey existing examples in fields such as optical sciences, crystallography, chemistry, structural biology and chemistry, mathematics, astronomy and statistics. An associated workshop on Interactive Publications and the Record of Science was held at the 2010 ICSTI Winter Meeting in Paris, France, and led to a number of relevant open-access publications in a Special Issue of the journal Information Services and Use, including The Record of Experimental Science: Archiving Data with Literature [Helliwell, J. R. \& McMahon, B. (2010). Information Services and Use, 30, 31-37] and Interactive Publications and the Record of Science, a full account of
Table 7

Estimated budget for the General Fund.

\begin{tabular}{lrr}
\hline & CHF & CHF \\
\hline Income & & \\
Subscriptions from Adhering Bodies & 474000 & 774000 \\
Yield from investments and banking accounts & 300000 & \\
\cline { 2 - 2 } & & \\
Expenditure & 1555000 & \\
Administration & 36000 & \\
Subscriptions to ICSU and bodies of ICSU & 305000 & \\
Administrative meetings & 54000 & -11700000 \\
Scientific meetings & & -17000 \\
& & \\
Estimated profit or deficit & & \\
\hline
\end{tabular}

the Workshop [McMahon, B. (2010). Information Services and Use, 30, 1-16]. Video recordings of the Workshop are available at http:// www.congres.upmc.fr/ICSTI_2010/index.html.

The summer ICSTI Congress for 2010 was held in Helsinki, Finland, and was organized by the Society of Finnish Information Specialists, entitled From Information to Innovation. The finale of the Conference was the launch of the World Wide Science Alliance project, which includes use of the Microsoft language translation tools. The Conference was accompanied by a well represented commercial exhibition of mainly Finnish companies but also companies from other countries. The conference was as usual preceded by the ICSTI business meetings. An interesting project report presented at the Technical Advisory Committee was the South Korean Library technical development project for accessing scientific journal literature from the iPhone.

The winter ICSTI Conference in February 2011 was held in Redmond, Washington, USA, at the Headquarters of the Microsoft Corporation and was on Multimedia and Visualization Innovations for Science. The science areas covered in 12 talks included crystallography and structural science in a talk by R. Hanson (see http:// prezi.com/khaylnfjmbls/jmol-icsti/). The summer ICSTI Congress for 2011 will be held in Beijing, People's Republic of China. The IUCr is unfortunately not able to send a delegate to this event.

J. R. Helliwell acknowledges with gratitude the close collaboration with the IUCr Journals Managing Editor, P. R. Strickland, and with the IUCr's delegate to CODATA, B. McMahon.

\section{J. R. Helliwell, Representative}

\section{A12. Budget estimates for period to Twenty-Third General} Assembly: determination of unit contribution

A12.1. Budget estimates. The estimated budget for the General Fund is set out in Table 7, for the period until the next General Assembly. Since the budget estimates had to be prepared at a time when the decisions on many activities were still to be made, these estimates should be considered with due reserve. With this proviso, and in accordance with Statute 9.3, the Executive Committee presents to the General Assembly the following estimates for the three-year period 1 January 2011 - 31 December 2013.

A12.2. Unit Contribution. According to Statute $5.10(k)$, the General Assembly has to determine the Unit Contribution to be paid by the Adhering Bodies for the period to the next General Assembly. The Executive Committee recommends to the General Assembly that the Unit Contribution should remain at its present level of CHF 1000 (set at the Beijing Congress in 1993) for the years 20122014. 


\section{APPENDIX $B$}

\section{Statutes and By-Laws of the International Union of Crystallography}

as Adopted by the Fourth General Assembly in 1957 and Amended by the Fifth General Assembly in 1960, the Sixth General Assembly in 1963, the Seventh General Assembly in 1966, the Eighth General Assembly in 1969, the Ninth General Assembly in 1972, the Tenth General Assembly in 1975, the Eleventh General Assembly in 1978, the Seventeenth General Assembly in 1996, the Eighteenth General Assembly in 1999, by unanimous postal agreement of the Adhering Bodies in 2010 and the Twenty-Second General Assembly in 2011

\section{Statutes}

\section{Objects of the Union}

1.1. The objects of the Union are

(a) to promote international cooperation in crystallography;

(b) to contribute to the advancement of crystallography in all its aspects, including related topics concerning the non-crystalline states;

(c) to facilitate international standardization of methods, of units, of nomenclature and of symbols used in crystallography;

(d) to form a focus for the relations of crystallography to other sciences.

1.2. For these purposes the Union shall have the power

(a) to adhere to the International Council for Science;

(b) to organize international meetings and conferences on subjects falling within the purview of the Union;

(c) to promote international publication of crystallographic research and of crystallographic works;

(d) to set up Commissions or other bodies for special objects;

(e) to initiate, promote and coordinate crystallographic research requiring international cooperation;

$(f)$ to organize Special Projects which shall be financed independently of the regular operations of the Union;

(g) to participate in Joint Commissions with other Unions or other scientific bodies in matters of interest to the Union;

(h) to perform all such other legal acts as are essential for or conducive to the objects of the Union including the constitution or organization of separate or independent bodies having an appropriate legal status;

(i) to receive into association existing regional organizations of crystallographers having substantially the same aims and objects as the Union; these organizations shall be known as Regional Associates of the Union;

$(j)$ to receive into association existing international scientific organizations whose interests overlap with the aims and activities of the Union; these organizations shall be known as Scientific Associates of the Union.

\section{Organization and Legal Domicile}

2.1. Under the name of International Union of Crystallography an Association has been organized and incorporated; it is governed by Articles 60 and following of the Swiss Civil Code and by the present Statutes of Incorporation.

2.2. The duration of the Union is not limited.

2.3. The legal domicile of the Union is in Geneva, Switzerland.

\section{Membership}

3.1. The members of the Union are its Adhering Bodies.

3.2. There shall be only one member for each country. Only under extraordinary circumstances the General Assembly may admit a suitably designated additional Adhering Body from a country, provided a corresponding Adhering Body of that country has already been admitted as a National Member of the International Council for Science (ICSU). In this case, each Adhering Body will have separate delegates and will be treated separately in questions of voting and finances.

3.3. The Adhering Body can be a National Academy, National Research Council or similar body, or a scientific society or group of such societies. Each Adhering Body shall form a National Committee for Crystallography to represent it in the Union.

3.4. Any number of Countries may agree to form a group in order to name or establish a single Adhering Body. This Body shall form a joint National or Regional Committee for Crystallography. Wherever the terms Country and National Committee for Crystallography are used in these Statutes or in the By-Laws, they shall be taken to include such groups of Countries and joint National or Regional Committees for Crystallography.

3.5. Membership in the Union shall be fully effective when the nature of the Adhering Body and the membership of the National Committee have been reported to and accepted by the General Assembly. Any replacement of an Adhering Body is subject to the approval of the Executive Committee and acceptance by the General Assembly. Any major change in the nature of an Adhering Body shall be considered valid only after it has been reported to and accepted by the General Assembly.

3.6. Adherence to the Union shall be in one of five Categories I-V with corresponding voting powers and contributions as set out in Statutes 5.5 and 9.4. A Body applying for adherence to the Union shall specify in which Category it wishes to adhere; this choice of Category, or any desired change in the Category, is subject to the approval of the Executive Committee and confirmation by the General Assembly.

3.7. Any extension of a joint adherence formed in accordance with Statute 3.4 is subject to the approval of the Executive Committee and acceptance by the General Assembly.

3.8. Participation in Special Projects [Statute 1.2(f)] shall not be obligatory. The extent of financial participation shall be a matter for special negotiation for each such project, except that the relationship between contribution and voting power within the project shall be that of the Category scheme defined in Statutes 5.5 and 9.4 to determine this relationship in the General Assembly.

3.9. Each National Committee has the right to submit to the Union through the General Secretary questions within the competence of the Union.

3.10. Any Adhering Body may withdraw from the Union if it has given notice of withdrawal at least six months before the end of the current financial year; it is required to fulfil its obligations relating to the time period when it was a member of the Union. Its membership and any further obligations shall then be suspended by the Executive Committee at the expiry of the notice of withdrawal. The withdrawal shall take effect when it has been reported to the General Assembly.

3.11. An Adhering Body which withdraws from the Union in accordance with Statute 3.10, or any Adhering Body whose membership is cancelled in accordance with Statutes 5.12 or 9.6, loses all rights in connexion with the Union.

3.12. If the Countries of a group formed in accordance with Statute 3.4 agree that the group should be dissolved, or if a Country wishes to withdraw from such a group, with or without the agreement of the other Country or Countries of the group, the adherence of the original group shall be suspended by the Executive Committee at the expiry of an appropriate notice, provided that the original group has fulfilled its obligations. The termination of the original adherence 
shall take effect when the matter has been reported to the General Assembly. Pending this report, the Countries of the group, or any of them, may submit proposals for the continuation of their representation in the Union. In each of such proposals the nature of the Adhering Body, the membership of the National Committee and the desired Category of adherence shall be specified. These proposals are subject to the approval of the Executive Committee, which shall then make ad interim arrangements concerning these adherences. These arrangements are subject to acceptance by the General Assembly.

\section{Administration}

4.1. The work of the Union shall be conducted by

(a) the General Assembly;

(b) the Officers of the Union, constituting the Executive Committee;

(c) the Commissions as defined in Statute 8.1.

The composition and function of these bodies are defined in the following paragraphs, whose application is governed by the By-Laws.

\section{General Assembly}

5.1. The work of the Union shall be directed by the General Assembly which is composed of delegates appointed by the Adhering Bodies.

5.2. The Executive Committee is responsible to the General Assembly and shall participate in its deliberations. Members of the Executive Committee have no voting power in the General Assembly, except for the casting vote of the Chair [Statute 5.8].

5.3. The General Assembly shall, as a rule, hold an ordinary meeting once every three years. The date and the place of the meeting, unless determined by the previous General Assembly, shall be determined by the Executive Committee. The General Secretary shall communicate the date and the place of the meeting to the National Committees and to the Commissions at least twelve months in advance.

5.4. In special cases, the President of the Union, with the consent of the Executive Committee, may call an extraordinary meeting of the General Assembly. This shall be performed at the request of one-fifth of the Adhering Bodies. The routine business of a General Assembly prescribed in Statute 5.10 shall normally be omitted, unless specifically included in the agenda; but an extraordinary General Assembly shall have the same powers, and be subject to the same rules, as an ordinary General Assembly, except where otherwise is stated in the Statutes and By-Laws. The General Secretary shall communicate the date and the place of the extraordinary General Assembly to the National Committees and to the Commissions at least eight months in advance if amendment of the Statutes is contemplated, or at least four months otherwise.

As an alternative, in special cases not requiring an amendment to or a change of the Statutes, the President of the Union with the consent of the Executive Committee may ask for a postal or electronic ballot of the Adhering Bodies. This shall be performed at the request of one-fifth of the Adhering Bodies. The voting power of an Adhering Body in a postal or electronic ballot is the same as that at General Assemblies. The General Secretary will communicate the matter for determination to the National Committees and to the Commissions four months before the deadline for the votes to be received by the General Secretary. In order to facilitate a full discussion between the participants in the postal or electronic ballot, the comments and questions of the Adhering Bodies, the responses of the President as well as any amendment to the initial proposal will be circulated among the Adhering Bodies using fast means of communications at the latest one month before the deadline.
5.5. The voting power of an Adhering Body at General Assemblies and in postal or electronic ballots shall be in accordance with its Category of adherence, as follows:

\begin{tabular}{llllll}
\hline Category & I & II & III & IV & V \\
Number of votes & 1 & 2 & 3 & 4 & 5 \\
\hline
\end{tabular}

5.6. Each Adhering Body, through its National Committee, shall make known to the General Secretary before the opening of each General Assembly the names of its delegates (and of their alternates, if any), and also the name of the Chair of the national or regional delegation. No Officer of the Union may be a member of any delegation, nor shall any person serve as a member of more than one delegation.

5.7. Normally each of the delegates present at a General Assembly shall have one vote only, but when for special reasons an Adhering Body cannot be fully represented at a General Assembly it may distribute its votes among a number of delegates smaller than the number of votes which that Adhering Body has in accordance with the Category in which it adheres; such a decision has to be made known to the General Secretary before the opening of the General Assembly concerned. Any Adhering Body not represented at a General Assembly may forward its views to the General Secretary by letter, and such views shall be made known to the General Assembly if received before voting takes place.

5.8. Except where otherwise provided in the Statutes and By-Laws, decisions of the General Assembly are taken by a majority of the votes cast. In the event of an equal division of votes the Chair shall take the final decision.

5.9. No question which has not been placed on the agenda of business to be transacted at the General Assembly shall be discussed or put to the vote unless a proposal to that effect be approved by at least two-thirds of the votes there represented.

5.10. The General Assembly shall

(a) take appropriate action on any matters concerning membership in the Union [Statutes 3.5, 3.6, 3.7, 3.10, 3.12 and 5.12];

(b) elect the President, the Vice-President, the General Secretary, the Treasurer and the other Officers of the Union [Statutes 6.1 and 6.3];

(c) consider, and make decisions regarding, the confirmation of the appointments of Editors of publications of the Union [Statute 7.1];

(d) determine the number of elected members of each Commission set up by the General Assembly [Statutes 5.11(c) and 8.2];

(e) elect the Chairs and members of the Commissions [Statute 8.2];

( $f$ ) elect representatives of the Union on Joint Commissions with other Unions, and on other scientific bodies [Statutes 1.2( $g)$ and 8.5];

( $g$ ) receive the reports on the activities of the Union and of its Commissions [Statutes 6.8 and 8.4 ];

(h) receive the audited accounts for the years elapsed since the previous General Assembly [Statute 9.1];

(i) on receipt of satisfactory reports or accounts, release the Treasurer, or any other Officer, or the Chair or any member of any Commission or other body, from financial or other liability to the Union;

(j) determine the budget for general expenditure for the period to the next General Assembly, on the basis of the estimate prepared by the Executive Committee [Statutes 9.2 and 9.3];

(k) determine the unit contribution for the period to the next General Assembly [Statute 9.5]; 
(l) determine the general policy and the timetable for the period to the next General Assembly;

( $m$ ) give preliminary consideration to the activities of the Union for the three-year period following the next General Assembly.

5.11. The General Assembly shall have the power

(a) to amend these Statutes in accordance with Statute 13.1;

(b) to formulate and amend By-Laws on any matters not covered by these Statutes;

(c) to set up any Commission or other body it may deem necessary for the administrative and scientific work of the Union, and to determine the terms of reference of such a body [Statute 1.2(d)];

(d) to dissolve any Commission or other body set up in accordance with Statute 5.11(c) when its existence is deemed no longer necessary;

(e) to determine the nature of Special Projects which shall be financed independently of the regular operations of the Union [Statute 1.2(f)];

$(f)$ to accept Regional Associates, to determine the nature of the association in each case, and to determine any mutual financial commitments;

(g) to accept Scientific Associates, to determine the nature of the association in each case, and to determine any mutual financial commitments;

(h) to decide on all other questions falling within the competence of the Union.

5.12. The General Assembly may cancel the membership of any Adhering Body of the Union for any serious cause; such a decision may only be taken after the member in question has been previously given an opportunity to furnish an explanation to the Executive Committee for forwarding to the General Assembly. At least threefourths of the total number of the votes of all Adhering Bodies are required for cancellation.

\section{Executive Committee}

6.1. The Officers of the Union constituting the Executive Committee are

(a) the President;

(b) the Vice-President;

(c) the General Secretary;

(d) the Treasurer;

(e) the immediate Past President;

$(f)$ six ordinary members.

6.2. The election of Officers of the Union shall be arranged in such a way that there will not be more than two Officers from any one Country and that amongst the six ordinary members there will be at least one Officer from a Country from each of the three geographical regions (i) Europe and Africa, (ii) the Americas and (iii) Asia/ Oceania. A person is regarded as belonging to the Country in which he or she is normally resident and where the main part of his or her work is conducted. In cases of doubt the General Assembly shall decide to which Country a person is considered to belong.

If during the period between General Assemblies the number of Officers from a Country is increased above two because of any change of Country of residence, the Officer or Officers who changed their Country of residence may continue to serve until the close of the next General Assembly. If at that time the number of Officers from the Country concerned would remain above two, one or more of the Officers who changed their Country of residence shall be considered to have resigned.

6.3. The offices of General Secretary and Treasurer may be combined and shall then be considered as a single office. Otherwise no person shall hold more than one office simultaneously. The voting power of the Officer holding the combined office of General Secre- tary and Treasurer shall not be more than that of either the General Secretary or the Treasurer.

6.4. The President holds office as President until the close of the ordinary General Assembly following his or her election, and continues as a member of the Executive Committee until the close of the ordinary General Assembly next but one following that of his or her election. He or she is not then eligible for immediate re-election to the office of President, nor to any other office in the Executive Committee.

The Vice-President holds office until the close of the ordinary General Assembly following his or her election. He or she is not eligible for immediate re-election to the same office.

The General Secretary and the Treasurer hold office until the close of the ordinary General Assembly following that of their election. They are eligible for immediate re-election to the same office, but shall not serve in that office for more than three full consecutive terms.

Three ordinary members are elected at each ordinary General Assembly and hold office until the close of the ordinary General Assembly next but one following that of their election. They are not eligible for immediate re-election to the same office.

In the event of a vacancy, through resignation, death or other cause, any Officer elected by the General Assembly to fill the unexpired term of office shall serve only to the end of the normal term of the Officer he or she replaces; at the end of this service he or she may be nominated for re-election for a full term to the same office.

6.5. The Executive Committee shall carry out the decisions of the General Assembly and give effect to the general policy of the Union as determined by the General Assembly.

6.6. During the periods between General Assemblies the Executive Committee shall have full power to carry on the business of the Union in all matters not specifically assigned by the Statutes, the ByLaws or the General Assembly to individuals or to Commissions or other bodies. If necessary, it may make ad interim arrangements in all matters assigned by the Statutes and By-Laws to the General Assembly.

6.7. In the event of an individual, a Commission or another body of the Union failing to act in any matter assigned to him or her or it by the Statutes, By-Laws or the General Assembly, the Executive Committee may, after reasonable notice to the individual or body in question, take action on behalf of the Union.

6.8. The Executive Committee shall report on its activities to the General Assembly. The action taken by the Executive Committee in accordance with Statutes 3.5, 3.6, 3.7, 3.10, 3.12, 6.6, 6.7, 7.1, 7.2, 8.2, 9.6 and 9.9 shall be included in this report. The report to the General Assembly shall be dispatched by the General Secretary to the National Committees and to the Commissions at least ten weeks before the meeting.

\section{Publications of the Union}

7.1. The Editors of the publications of the Union are appointed by the Executive Committee for initial terms extending through not more than six years beyond the ordinary General Assembly following the appointment. Each initial appointment is subject to confirmation by that General Assembly. Reappointments may be made by the Executive Committee for terms of not more than three years, and are subject to confirmation by the ordinary General Assembly following the reappointment.

7.2. Co-editors and Assistant Editors are appointed by the Editors for terms of not more than three years, but they may be reappointed immediately for terms of the same length. The appointments and 
reappointments are subject to the approval of the Executive Committee.

7.3. Editors and Co-editors are members of the Commissions set up for their respective publications.

\section{Commissions and Joint Commissions}

8.1. The term Commission shall be understood to include all Commissions, Committees, and other bodies of the Union with the exception of National Committees for Crystallography, and the Executive Committee and its subcommittees.

8.2. The Chairs and members of the Commissions are elected at each General Assembly. Subject to the approval of the Executive Committee, Commissions may co-opt further members during the periods between General Assemblies, and may fill vacancies arising from resignation, death or other cause. Members (but not Chairs) may be nationals of or residents in a Country not adhering to the Union.

8.3. The Commissions shall be responsible to the General Assembly. They shall generally have full freedom in arranging their internal structure and work. They may formulate their own Rules of Procedure within the framework of the Statutes and By-Laws of the Union, and within their terms of reference.

8.4. The Chairs shall report on the activities of the Commissions to the General Assembly. These reports shall reach the General Secretary at least fourteen weeks before the General Assembly and shall be dispatched by him or her to the National Committees and the Commissions at least ten weeks before the meeting.

8.5. The representatives of the Union on Joint Commissions and on other scientific bodies [Statute 1.2(g)] are elected at each General Assembly. For each such body one representative shall be designated as the chief representative of the Union. His or her obligations to report are the same as those of the Chairs of the Commissions.

\section{Finance}

9.1. The Executive Committee shall be responsible to the General Assembly for all the financial affairs of the Union.

9.2. The Chair of each Commission (or other member approved by the Executive Committee) shall be responsible to the Executive Committee for any expenditure of funds by this Commission. Five months before each General Assembly he or she shall submit to the Executive Committee an estimate of the budget of the Commission for the period between that General Assembly and the one following it. He or she shall submit annually to the Executive Committee a revised budget for the ensuing year and a statement of accounts for the preceding year. These accounts shall be available for audit by the Executive Committee or its appointees.

9.3. The Executive Committee shall prepare an estimate of the budget for the period between the next General Assembly and that following it. This estimate shall be dispatched by the General Secretary to the National Committees and to the Commissions at least ten weeks before the meeting.

9.4. Each Adhering Body shall pay an annual subscription in accordance with its Category of adherence, as follows:

\begin{tabular}{llllll}
\hline Category & I & II & III & IV & V \\
Number of unit contributions & 1 & 3 & 6 & 10 & 15 \\
\hline
\end{tabular}

The annual subscriptions are payable during the calendar year to which they apply.

9.5. The unit contribution, stated in terms of a currency to be designated by the Executive Committee, shall be determined by the General Assembly for the period to the next General Assembly.
9.6. Any Adhering Body which is in arrears with its subscription for two years shall be warned and shall be deprived of its voting power. The membership of any Adhering Body which is in arrears for four years shall be automatically suspended and may be cancelled by the General Assembly under Statute 5.12. An Adhering Body whose membership has been suspended shall receive no privileges of the Union and incur no further responsibility for dues; it may be reinstated by action of the Executive Committee.

9.7. The financing and management of publications of the Union shall be kept distinct from general expenditure. Editors and Coeditors shall be responsible to the Executive Committee for any receipts or expenditure of funds by them with respect to their publications.

9.8. The financing and management of Special Projects of the Union shall be kept distinct from the regular operations of the Union.

9.9. No funds may be solicited or accepted on behalf of the Union or any of its Commissions from any international, governmental or other agency or person without the prior approval of the Executive Committee. Any National Committee for Crystallography may however solicit funds within its own Country for the support of its own activities or in its capacity as host for a General Assembly, Congress or other meeting sponsored by the Union. Any funds, in the form of donations, legacies, or grants, accepted by the Executive Committee shall be used so far as is possible in accordance with the wishes of the donors.

\section{Liability}

10.1. The Union is liable only to the extent of its assets, and the Adhering Bodies are not individually liable for its corporate debts and liabilities.

10.2. The liabilities of the Adhering Bodies are limited to the payment of their annual subscriptions and to such contributions to the Special Projects of the Union as they may have pledged.

10.3. No Officer of the Union shall be individually liable for the corporate debts and liabilities of the Union. The Union shall indemnify any Officer or former Officer in respect of any claims laid against him or her in respect to his or her authorized actions on behalf of the Union. At its discretion the Executive Committee may extend this indemnity to other persons in respect of their authorized actions on behalf of the Union.

10.4. The Union shall not accept any liability for any personal loss, damage or accident sustained by an individual, not being an employee of the Union, engaged in any activity, including travel, on behalf of the Union.

\section{Auditor and Representation of the Union}

11.1. The Auditor of the Union shall be a person or corporation authorized to act as a public accountant. The Auditor shall be appointed by the Executive Committee on the recommendation of the Treasurer and maintained thereafter subject to the approval of the General Assembly.

11.2. With the exception of cheques, all contracts and formal agreements involving the Union shall be signed by two Officers of the Union. The Executive Committee may restrict the power to sign a particular document or type of document to specific persons among the Officers; and it shall determine rules for the signing of cheques.

11.3. The President shall be the official representative of the Union on all other civil and legal occasions and in dealing with other organizations. The President may in this respect delegate his or her powers to another Officer of the Union, or, with approval of the Executive Committee, to any other person. 


\section{Dissolution of the Union}

12.1. The Union shall not be dissolved except on a motion presented at a General Assembly. If a motion to dissolve is to be presented, the notice for that General Assembly as given under Statute 5.3 or 5.4 shall include a statement of the motion to dissolve and shall refer specifically to this Statute. Such a motion shall be presented to the General Assembly without amendment and at least three-fourths of the votes there represented shall be required for dissolution.

In the event that less than three-fourths of the total number of the votes of all Adhering Bodies are represented at the General Assembly, a postal or electronic ballot may be arranged, and in such a postal or electronic ballot at least three-fourths of the total number of the votes of all Adhering Bodies shall be required for dissolution.

12.2. In the event of dissolution of the Union in accordance with Statute 12.1, the General Assembly shall appoint a special Committee, reporting to the International Council for Science, for the liquidation of the assets of the Union. The available assets will be entirely attributed to one or more institutions in pursuit of a goal of similar public interest to that of this association and that also benefits from tax exemption. In no case can the property be returned to its current or founding members, nor be used for their profit in whole or part in any manner whatsoever.

\section{Statutes}

13.1. Amendments to the Statutes require action at a General Assembly. An amendment is adopted at such an Assembly only if (i) at least two-thirds of the votes represented at the General Assembly are affirmative and (ii) if these affirmative votes amount to more than half the total number of the votes of all Adhering Bodies. In the event that the vote on a proposed amendment satisfies condition (i) but not condition (ii), the Executive Committee may refer the proposed amendment to a postal or electronic ballot of the Adhering Bodies. If the proposed amendment then obtains affirmative votes amounting to more than half the total number of the votes of all Adhering Bodies, the amendment is adopted.

Proposals for amendments may be made by the Executive Committee or by any National Committee. Such proposals made by National Committees shall reach the General Secretary at least six months in advance of the General Assembly. The General Secretary shall dispatch these proposals, and those made by the Executive Committee, to the National Committees and to the Commissions at least four months before the meeting.

13.2. The present English text shall be considered the authoritative text in the interpretation of these Statutes. Where disputes arise concerning this interpretation, the matter shall be decided by the General Assembly, or, during the periods between General Assemblies, by a ruling of the President of the Union.

\section{By-Laws}

\section{General Assembly}

1.1. The agenda of business to be transacted at a General Assembly shall be determined by the Executive Committee and shall be dispatched by the General Secretary to the National Committees and to the Commissions at least ten weeks before the meeting.

1.2 Any National Committee and any Commission of the Union may propose business to be transacted at a General Assembly. Such proposals shall reach the General Secretary at least four months before the meeting, and shall be included in the agenda of the General Assembly.
1.3. The General Assembly may determine the date and the place of the next but one ordinary meeting of the General Assembly.

1.4. Chairs of the National Committees and of the Commissions, and representatives of Regional Associates and Scientific Associates may attend the General Assembly and take part in the discussions but shall have no voting power. The President may invite representatives of scientific bodies, or individuals, to attend the General Assembly; such invited guests may take part in the discussions but shall have no voting power. Other interested persons may also attend the General Assembly but they shall not take part in the discussions, unless specifically invited or permitted to do so by the Chair, and they shall have no voting power.

At the discretion of the Chair any or all of the persons attending the General Assembly under this By-Law may be required to withdraw.

1.5. If a delegate to a General Assembly is absent from a session of the Assembly, his or her place may be taken by any of the alternates nominated to the Assembly under Statute 5.6 provided that the Secretary of the Assembly is notified before the beginning of the session of the name of the delegate and of the name of the alternate, either by the delegate or by the Chair of his or her delegation. In general no such substitution may take place during a session of the Assembly, but the Chair of the Assembly may permit substitution to be made under special circumstances.

1.6. The names of the representatives of a Body whose application for adherence to the Union has been received and declared in good order by the Executive Committee under By-Law 2.9(a) shall be made known to the General Secretary as prescribed in Statute 5.6. These representatives shall be seated with the delegates of the Adhering Bodies during the preliminary ceremonies and the initial business of the General Assembly. At the discretion of the Chair or by a vote of the Assembly, the representatives may be required to withdraw during the discussion of and voting on matters concerning adherence to the Union. The delegates of a new member may take their seats among the other delegates as soon as the General Assembly has accepted their Adhering Body as a member of the Union.

1.7. Unless decided otherwise by the General Assembly, matters concerning adherence to the Union shall take precedence over all other business at the first business session of the General Assembly, and shall normally precede the reading of the minutes and the discussions of matters arising therefrom.

1.8. Delegates of an Adhering Body may not vote on any matter concerning its membership in the Union.

1.9. In the event of the General Assembly considering a change in a group of Countries according to Statute 3.12, the delegates from the Countries belonging or previously belonging to the group may not vote on any matters concerning the representation in the Union of any of these Countries. After acceptance of the ad interim arrangements made by the Executive Committee under Statute 3.12, these delegates have full voting power.

1.10. The delegates of new members may not vote on any matters concerning adherence to the Union, nor on any matters concerning the adoption of the minutes of the previous General Assembly, during the General Assembly at which they themselves are admitted.

1.11. The General Secretary shall post on the official bulletin board of the General Assembly the names of the Chairs and members (and alternates, if any) of the delegations and the numbers of votes represented by them.

1.12. During the General Assembly any delegate (or alternate) and any Officer of the Union is considered to have been notified of any 
action of the General Assembly, or of the Executive Committee, or of any Commission, if one of the two following procedures is adopted

(a) a notice is placed in the mail box or other location at which the delegate (or alternate) or the Officer is accustomed to receive mail during the course of the General Assembly, or

(b) a notice is handed to the designated Chair of each delegation with the specific request that he or she communicate its contents to his or her delegation, and to the General Secretary with the specific request that he or she communicate its contents to the Executive Committee, provided that in either case a similar notice is posted on the official bulletin board.

1.13. Minutes of the meetings of the General Assembly shall be made. Copies of the draft minutes shall be communicated by the General Secretary to the National Committees, to the Officers of the Union and to the Chairs of its Commissions. After approval at a subsequent General Assembly, two copies of the definitive minutes shall be signed by the Chair and the Secretary of the session at which they are approved, and shall be kept by the President and the General Secretary.

\section{Executive Committee}

2.1. The Executive Committee shall meet at each General Assembly. There shall be at least two additional meetings during the period between General Assemblies, unless the Executive Committee by a postal or electronic vote decides otherwise.

2.2. The Executive Committee shall make nominations to the General Assembly for the Officers of the Union, for the Chairs and members of the Commissions, and for representatives on Joint Commissions and on other scientific bodies. Normally these nominations shall be made after a preceding postal or electronic communication with the National Committees. In each case in which an Officer of the Union is nominated for another office, either by the Executive Committee or by delegates to the General Assembly [ByLaw 8.2], the Executive Committee shall also include a nomination for the office which would be vacated if the election to the other office occurs. If the election to the other office does not occur and if the Officer's term has not expired, the nomination to the office which would have been vacated shall not be considered.

2.3. In the event of the resignation, death or disability of the President, the Vice-President shall assume the office of President until the close of the next ordinary General Assembly.

In the event of the resignation, death or disability of the VicePresident, the Executive Committee may appoint one of its members to serve as Vice-President until the close of the next ordinary General Assembly.

In the event of such circumstances that the General Secretary or the Treasurer cannot carry out his or her duties, the other shall assume those duties until the Executive Committee has considered the situation. In that event the Executive Committee may, but need not, appoint a new General Secretary or Treasurer to serve until the close of the next ordinary General Assembly.

In the event of the resignation, death or disability of an ordinary member of the Executive Committee, the Executive Committee may co-opt a new member to serve until the close of the next ordinary General Assembly.

The accession of an Officer of the Union to a new office under the conditions of this By-Law shall be accompanied by his or her resignation from the office to which he or she was previously elected, but service under this By-Law shall not affect his or her eligibility for immediate re-election to the new office.

2.4. Any Officer unable to attend a meeting of the Executive Committee may designate a deputy to attend that meeting. Such a deputy shall be named in writing to the President or the General Secretary. He or she shall have no voting power and shall not be counted as part of a quorum.

2.5. The President, on his or her own initiative or at the request of the Executive Committee, may invite any individual to be present at a meeting of the Executive Committee; such an invited guest may take part in the discussions but shall have no voting power.

2.6. At a meeting of the Executive Committee two-thirds (fractional parts neglected) of the Officers specified by Statutes 6.1 and 6.3 , excluding any who have resigned or died, shall constitute a quorum; and decisions shall be taken by a simple majority of the Officers present and voting. The Chair of the meeting shall not vote in open ballots; but in the event of an equal division of votes the Chair may take the final decision. In secret ballots required by the Statutes or By-Laws or ordered by the Chair, he or she may vote at his or her discretion. If the Chair does not vote and there is an equal division of votes, he or she may take the final decision. If the Chair has voted in a secret ballot, he or she may not take the final decision, and must leave it to further discussion and ballot.

2.7. During the period between meetings of the Executive Committee, voting may take place by post or electronic means. Adoption of a proposal shall require affirmative votes from two-thirds (fractional parts neglected) of the Officers specified by Statutes 6.1 and 6.3, excluding any who have resigned or died. No decision on any proposal other than calling or cancelling a meeting of the Executive Committee shall be made by postal or electronic vote in the event that at least two Officers express the wish that the matter concerned should first be given more or further consideration, either by correspondence or at a meeting of the Executive Committee.

2.8. Minutes of the meetings of the Executive Committee shall be made. Two copies of the minutes shall be signed by the Chair and the Secretary of the meeting at which they are approved, and shall be kept by the President and the General Secretary. A summary of the draft minutes of meetings of the Executive Committee shall be despatched by the General Secretary to the National Committees within ten weeks of the conclusion of each meeting.

2.9. In addition to the obligations described in the Statutes and elsewhere in these By-Laws, the Executive Committee shall

(a) receive and report on applications for adherence to the Union if the nature of the applying Body and the membership of the National Committee have been duly reported to and considered to be in good order by the Executive Committee; pending the next General Assembly the Executive Committee may in the case of such applications provide such services of the Union as it deems proper;

(b) consider and report on any other questions concerning adherence to the Union;

(c) present an annual report, including an audited statement of receipts and expenditure, to the National Committees;

(d) report to the Commercial Registry of Geneva any changes in the registered information concerning the Union;

(e) have the power to appoint representatives on scientific bodies not belonging to the Union.

\section{President}

3.1. The President of the Union is Chair of the General Assembly and of the Executive Committee. In the absence of the President from a session or meeting, the Vice-President, or if he or she is not present another Officer of the Union designated by the Executive Committee, shall act as Chair. 
3.2. The President of the Union is an ex officio member, with voting power, of all Commissions of the Union.

\section{General Secretary}

4.1. The General Secretary of the Union is Secretary of the General Assembly and of the Executive Committee. In the absence of the General Secretary from a session or meeting, another Officer of the Union designated by the Executive Committee shall act as Secretary.

4.2. The General Secretary of the Union is an ex officio member, with voting power, of all Commissions of the Union.

4.3. The General Secretary is responsible for conducting the ordinary business of the Union, with the exception of the financial administration, and for keeping its records.

4.4. The General Secretary may appoint a permanent Executive Secretary to assist with the running of the Union. In the event that an Executive Secretary is appointed the posts of General Secretary and Treasurer will be combined. In these Statutes and By-Laws administrative tasks assigned to the General Secretary will be considered to have been fulfilled if carried out by the Executive Secretary.

\section{Treasurer}

5.1. The Treasurer of the Union is responsible for the financial administration of the Union and for keeping its accounts.

5.2. The Treasurer is an ex officio member of all Commissions of the Union, with voting power only for those questions which may involve the Union in financial commitments.

\section{Sub-committees of the Executive Committee}

6.1. The Finance Committee is appointed by the Executive Committee to advise on finances, establishment and salaries. The Convener of the Finance Committee should normally be a resident of the same country as the Union Secretariat. If the Convener is not an elected member of the Executive Committee he or she will attend $e x$ officio the meetings of the Executive Committee without voting rights.

6.2. The Sub-committee on the Union Calendar is appointed by the Executive Committee to advise on the sponsorship of the Union for meetings, symposia and schools. The Chair of the Calendar Subcommittee should be a member of the Executive Committee.

6.3. The Executive Committee may establish, modify or abolish any other Sub-committees.

\section{Commissions of the Union}

7.1. The Chairs of the Commissions and the chief representatives on Joint Commissions or other bodies shall forward records of all meetings of the Commissions to the President and the General Secretary. They shall report annually on the activities of these bodies to the Executive Committee.

7.2. If funds are provided for the use of a Commission, it may make its own financial arrangements, with the prior approval of the Executive Committee and subject to the provisions of the Statutes and By-Laws. In cases where the Executive Committee has given prior approval, payments toward travelling expenses of Chairs and members of Commissions may be made from the general funds of the Union.

7.3. No person who has served for three consecutive full terms of office on a Commission is eligible for nomination for a fourth consecutive term of service on the same Commission except as Chair. In no case is any person eligible for more than four consecutive full terms of service on the same Commission. These limitations do not apply to Editors [Statute 7.1], Co-editors [Statute 7.2] and ex officio members. Any Commission, in its Rules of Procedure, may reduce the length of service specified here.

7.4. In the event of the resignation, death or disability of the Chair of any Commission, the Executive Committee shall appoint a member of that Commission to serve as Chair until the close of the General Assembly following this appointment.

\section{Nominations and Elections}

8.1. All delegates (and alternates) shall be notified of the nominations presented by the Executive Committee under By-Law 2.2 for the Officers of the Union as early as possible and at least ninety-six hours before the scheduled commencement of the session of the General Assembly at which the vote is to be taken.

8.2. After the delegates have been notified of the nominations by the Executive Committee as prescribed in By-Law 8.1, other nominations for Officers of the Union may be made by any six or more delegates. Such nominations shall be made in writing to the General Secretary not less than thirty-six hours before the voting session and shall be accompanied by a written statement that the consent of the nominees has been obtained. These nominations shall be posted by the General Secretary on the official bulletin board not less than twenty-four hours before that session.

8.3. Recommendations from each Commission for the Chair and members of the Commission shall be made in writing to the General Secretary not less than seventy-two hours before the voting session of the General Assembly. These recommendations shall be approved by a majority of the members of the Commission and shall be accompanied by a written statement that the consent of the persons recommended has been obtained. All delegates (and alternates) shall be notified of the nominations presented by the Executive Committee under By-Law 2.2 for the Chair and members of each Commission at least forty-eight hours before the voting session.

8.4. After the delegates have been notified of the nominations by the Executive Committee as prescribed in By-Law 8.3, other nominations for the Chair and members of each Commission may be made by any six or more delegates. Such nominations shall be made in writing to the General Secretary not less than twenty-four hours before the voting session and shall be accompanied by a written statement that the consent of the nominees has been obtained. These nominations shall be posted by the General Secretary on the official bulletin board not less than twelve hours before that session.

8.5. In voting for the President, Vice-President, General Secretary and Treasurer of the Union, each of these offices shall be taken separately and voting shall be by secret ballot. A simple majority of the votes represented by the delegates present at the voting session shall be required for election. If there is only one candidate for one of these offices, his or her nomination shall be presented to the General Assembly and the candidate concerned shall be considered as elected. If there are two candidates or more, and an election is not achieved after two ballots, the candidate receiving the smallest number of votes in the second ballot shall be removed from the list unless this will lead to a candidate being elected without receiving a simple majority of the votes. If an election is not achieved after a third ballot, this procedure shall be repeated until an election is achieved. Any ballot form showing more than one mark shall be invalid. Any contingency arising during the balloting shall be resolved by a ruling of the Chair of the General Assembly.

8.6. The election of the ordinary members of the Executive Committee shall be by secret ballot, the ballot form showing the nominations presented by the Executive Committee and the nominations made by delegates. Balloting shall be conducted in such a way that the requirements of Statute 6.2 are met. A simple majority of the 


\begin{tabular}{|c|c|c|c|}
\hline & & Statute & By-Law \\
\hline 12 months & $\begin{array}{l}\text { Notice of date and place of ordinary General Assembly to National } \\
\text { Committees and Commissions }\end{array}$ & 5.3 & - \\
\hline 8 months & $\begin{array}{l}\text { Notice of date and place of extraordinary General Assembly to } \\
\text { National Committees and Commissions, if amendment of Statutes is } \\
\text { contemplated }\end{array}$ & 5.4 & - \\
\hline 6 months & Proposals for amendments to Statutes to General Secretary & 13.1 & - \\
\hline 5 months & Estimated budgets from Commissions to Executive Committee & 9.2 & - \\
\hline 4 months & Proposals for agenda of General Assembly to General Secretary & - & 1.2 \\
\hline 4 months & $\begin{array}{l}\text { Notice of date and place of extraordinary General Assembly to } \\
\text { National Committees and Commissions, if amendment of Statutes is } \\
\text { not contemplated }\end{array}$ & 5.4 & - \\
\hline 4 months & $\begin{array}{l}\text { Proposals for amendments to Statutes to National Committees and } \\
\text { Commissions }\end{array}$ & 13.1 & - \\
\hline 14 weeks & Reports of Commissions to General Secretary & 8.4 & - \\
\hline 10 weeks & $\begin{array}{l}\text { Report of Executive Committee to National Committees and } \\
\text { Commissions }\end{array}$ & 6.8 & - \\
\hline 10 weeks & Reports of Commissions to National Committees and Commissions & 8.4 & - \\
\hline 10 weeks & Budget to National Committees and Commissions & 9.3 & - \\
\hline 10 weeks & Agenda to National Committees and Commissions & - & 1.1 \\
\hline \multicolumn{4}{|c|}{ Timetable during General Assembly } \\
\hline 'Before' & $\begin{array}{l}\text { Notice by National Committees to General Secretary of names of } \\
\text { delegates, alternates and Chairs of delegations, and of distribution } \\
\text { of votes if not one per delegate }\end{array}$ & $5.6,5.7$ & - \\
\hline 96 hours & Nominations by Executive Committee for Officers of Union & - & 8.1 \\
\hline 72 hours & $\begin{array}{l}\text { Recommendations by Commissions to General Secretary for Chairs } \\
\text { and members of Commissions }\end{array}$ & - & 8.3 \\
\hline 48 hours & $\begin{array}{l}\text { Nominations by Executive Committee for Chairs and members of } \\
\text { Commissions }\end{array}$ & - & 8.3 \\
\hline 48 hours & Notification of motion to amend or suspend By-Laws & - & 9.1 \\
\hline 36 hours & $\begin{array}{l}\text { Notice to General Secretary of nominations by delegates for Officers } \\
\text { of Union }\end{array}$ & - & 8.2 \\
\hline 24 hours & Posting of nominations by delegates for Officers of Union & - & 8.2 \\
\hline 24 hours & $\begin{array}{l}\text { Notice to General Secretary of nominations by delegates for Chairs } \\
\text { and members of Commissions }\end{array}$ & - & 8.4 \\
\hline 12 hours & $\begin{array}{l}\text { Posting of nominations by delegates for Chairs and members of } \\
\text { Commissions }\end{array}$ & - & 8.4 \\
\hline
\end{tabular}

votes represented by delegates present at the voting session shall be required for election. If there are not more candidates than vacancies, the nominations shall be presented to the General Assembly and the candidates shall be considered as elected. If there are more candidates than vacancies and all vacancies are not filled by election at the first ballot, a second ballot shall be arranged containing the names of the candidates not elected. If there are vacancies after the second ballot, the balloting procedure shall be repeated until all vacancies are filled; for second and subsequent ballots the name of the candidate receiving the smallest number of votes on the preceding ballot shall be removed from the list unless this will lead to a candidate being elected without receiving a simple majority of the votes. Any ballot form showing more marks than the appropriate number of vacancies shall be invalid. Any contingency arising during the balloting shall be resolved by a ruling of the Chair of the General Assembly.

8.7. In the event that an election must be held to fill the unexpired term of an office vacated by an ordinary member [Statute 6.4], the nominations for this office shall be distinct from the nominations for ordinary members for full terms. A person may be nominated for both categories, but can be elected to only one office [Statute 6.3]. If ballots are required in the elections for both categories, the ballots for the full-term offices shall take place first. A person who has been elected to two consecutive non-full terms is not eligible, on completion of his or her second term, for immediate re-election as an ordinary member of the Executive Committee.

8.8. In voting for the Chairs and members of the Commissions each Commission shall be considered separately. For the election of the
Chairs the procedure described in By-Law 8.5 shall be followed. For the election of the members of the Commissions the procedure described in By-Law 8.6 shall be followed except that no more than two ballots shall be held. Any vacancies still remaining may be filled as provided in Statute 8.2.

8.9. The procedure for the nomination and election of representatives of the Union on Joint Commissions and on other scientific bodies is so far as is possible the same as that for the nomination and election of the Chairs and members of the Commissions.

\section{By-Laws}

9.1. These By-Laws may be amended or suspended at any General Assembly and at least two-thirds of the votes there represented are required for an amendment or suspension. A motion to amend or suspend, if not already included in the agenda of business of the General Assembly, may be placed there by the procedure of Statute 5.9. No notice is required for a proposal to suspend the time limits prescribed by By-Laws 8.2 and 8.4. Notification of any other motion to amend or suspend the By-Laws must be given by its originators to all delegates (and alternates) and to all Officers of the Union in accordance with the procedure prescribed in By-Law 1.12, at least forty-eight hours before the session of the General Assembly at which the motion is to be considered.

9.2. The present English text shall be considered the authoritative text in the interpretation of these By-Laws. Where disputes arise concerning this interpretation, the matter shall be decided by the General Assembly, or during the periods between General Assemblies, by a ruling of the President of the Union. 


\section{APPENDIX C}

\section{Committees, Commissions and Representatives}

C1. Membership of bodies belonging to the Union

Executive Committee

President

G. R. Desiraju (Solid State and Structural Chemistry Unit, Indian Institute of Science, Bangalore 560 012, India)

Vice-President

C. Lecomte (France)

\section{General Secretary and Treasurer}

L. Van Meervelt (Chemistry Department, Katholieke Universiteit Leuven, Celestijnenlaan 200F, BE-3001, Leuven, Belgium)

\section{Immediate Past President}

S. Larsen (Denmark)

\section{Ordinary members}

E. Boldyreva (Russia), H. A. Dabkowska (Canada), W. Depmeier (Germany), J. M. Guss (Australia), M. L. Hackert (USA),

J. M. Perez-Mato (Spain)

[G. R. Desiraju, C. Lecomte, L. Van Meervelt, E. Boldyreva, W. Depmeier and J. M. PerezMato will hold office until the close of the Twenty-Third General Assembly (2014). H. A. Dabkowska, J. M. Guss and M. L. Hackert will hold office until the close of the Twenty-Fourth Assembly (2017).]

\section{Executive Secretary}

M. H. Dacombe (International Union of Crystallography, 2 Abbey Square, Chester CH1 2HU, UK)

\section{Commission on Journals}

Chair and Editor-in-Chief of IUCr journals G. Kostorz (ETH Zürich, Wolfgang-PauliStrasse 16, CH-8093 Zürich, Switzerland; Acta $A+B+C+D+E+F ; J A C ; J S R)$

\section{Section Editors of Acta Crystallographica} W. Steurer (Laboratory of Crystallography, Wolfgang-Pauli-Strasse 10, ETH Zürich, CH-8093 Zürich, Switzerland; Acta A), S. van Smaalen (Laboratory of Crystallography, University of Bayreuth, Universitatsstrasse 30, D-95440 Bayreuth, Germany; Acta B), A. Linden (Institute of Organic Chemistry, University of Zürich, Winterhurerstrasse 190, CH-8057 Zürich, Switzerland; Acta C), E. N. Baker (School of Biological Sciences, University of Auckland, Private Bag 92-019, Auckland, New Zealand; Acta D), Z. Dauter (Argonne National Laboratory, Biosciences Division, Bldg 202, Room Q142, Argonne, IL 60439, USA; Acta D), W. T. A. Harrison (Department of Chemistry, University of Aberdeen, Aberdeen AB24 3UE, UK; Acta E),
H. Stoeckli-Evans (Institute of Physics, University of Neuchâtel, Switzerland; Acta E), E. R. T. Tiekink (Department of Chemistry, University of Malaya, Kuala Lumpur 50603, Malaysia; Acta E), M. Weil (Institute of Chemical Technologies and Analytics, Division of Structural Chemistry, Vienna University of Technology, Getreidemarkt 9/164-SC, Austria; Acta E), H. M. Einspahr (PO Box 6395, Lawrenceville, NJ 08648-0395, USA; Acta F), M. S. Weiss (EMBL Hamburg Outstation, c/o DESY, Notkestrasse 85, D-22603 Hamburg, Germany; Acta F)

Editor of Journal of Applied Crystallography A. Kaysser-Pyzalla (Helmholtz-Zentrum Berlin für Materialien und Energie $\mathrm{GmbH}$, Wissenschaftliche Geschäftsführung, Glienicker Strasse 100, 14109 Berlin, Germany)

Editor of Journal of Synchrotron Radiation G. E. Ice (Materials Science and Technology Division, Oak Ridge National Laboratory, PO Box 2008, Oak Ridge, TN 37831-6132, USA)

\section{Co-editors of Acta, JAC and ISR}

D. Albov (Russia; Acta E), A. J. Allen (USA; $J A C$ ), A. Authier (France; Acta A), R. F. Baggio (Argentina; Acta $C+E$ ), R. Banerjee (India; Acta E), J. Barbier (Canada; Acta C), L. J. Barbour (South Africa; Acta $C+E$ ), M. G. Bartlam (People's Republic of China; Acta $D+F$ ), L. J. Beamer (USA; Acta F), T. M. Bergfors (Sweden; Acta F), L. E. Berman (USA; JSR), S. Bernès (Mexico; Acta E), D. G. Billing (South Africa; Acta $B+E$ ), S. Billinge (USA; Acta A), K. Biradha (India; Acta E), O. Blacque (Switzerland; Acta E), A. J. Blake (UK; Acta $B+C$ ), E. Boldyreva (Russia; Acta $B)$, N. B. Bolotina (Russia; Acta B), M. Bolte (Germany; Acta E), A. D. Bond (Denmark; Acta C), C. S. Bond (Australia; Acta D), A. Borbély (France; $J A C$ ), P. Bordet (France; Acta B), I. Brito (Chile; Acta E), I. D. Brown (Canada; Acta E), A. M. Brzozowski (UK; Acta $D+F$ ), R. J. Butcher (USA; Acta E), $\mathrm{O}$. Büyükgüngör (Turkey; Acta $E$ ), C. W. Carter (USA; Acta A), G. Chapuis (Switzerland; Acta B), D. Chateigner (France; JAC), N. Chayen (UK; Acta D), V. V. Chernyshev (Russia; Acta E), E. Y. Cheung (USA; Acta C), K. Chinnakali (India; Acta E), S. Ciccariello (Italy; $J A C$ ), P. Coppens (USA; Acta A), A. F. Craievich (Brazil; JSR), M. Czugler (Hungary; Acta E), J.-C. Daran (France; Acta $C+E$ ), P. Dastidar (India; Acta E), W. I. F. David (UK; $J A C$ ), Z. S. Derewenda (USA; Acta D), V. E. Dmitrienko (Russia; Acta $A$ ), E. Dodson (UK; $J A C$ ), D. L. Dorset (USA; $A c t a A+B)$, M. T. L.
Duarte (Portugal; Acta $C$ ), P. Dunten (USA; Acta F), M. Dusek (Czech Republic; Acta B), S. E. Ealick (USA; Acta $D+J A C$ ), M. R. J. Elsegood (UK; Acta $C+E$ ), U. Englert (Germany; Acta C), J. G. Eon (Brazil; Acta A), L. Eriksson (Sweden; Acta E), C. Esterhuysen (South Africa; Acta E), L. Fabian (UK; Acta E), J. Fabry (Czech Republic; Acta E), L. R. Falvello (Spain; Acta C), P. E. Fanwick (USA; Acta C), L. J. Farrugia (UK; Acta E), V. FavreNicolin (France; JSR), K. Fejfarova (Czech Republic; Acta E), G. Ferguson (UK; Acta C), P. F. Fewster (UK; Acta $A+J A C$ ), A. Fischer (Sweden; Acta E), J. L. Flippen-Anderson (USA; Acta E), U. Flörke (Germany; Acta E), V. T. Forsyth (France; $J A C$ ), F. Frolow (Israel; Acta $D+F$ ), G. J. Gainsford (New Zealand; $A c t a C+E$ ), J. F. Gallagher (Ireland; Acta $C+E$ ), J. M. Garcia-Ruiz (Spain; Acta F), E. F. Garman (UK; Acta $D+J A C$ ), M. Gdaniec (Poland; Acta E), C. Glidewell (UK; Acta $C+E$ ), A. Goeta (UK; Acta C), L. R. Gomes (Portugal; Acta E), C. H. Görbitz (Norway; Acta B), H. Graafsma (Germany; JSR), G. Grübel (Germany; JSR), T. N. Guru Row (India; Acta B+E), J. M. Guss (Australia; Acta $D+F$ ), I. A. Guzei (USA; Acta $C$ ), K. J. Haller (Thailand; Acta E), W. T. A. Harrison (UK; Acta E), S. S. Hasnain (UK; JSR), B. Hazes (Canada; Acta F), S. M. Heald (USA; JSR), P. C. Healy (Australia; Acta E), J. R. Helliwell (UK; JAC), M. Helliwell (UK; Acta $C+E$ ), E. F. C. Herdtweck (Germany; Acta E), J. L. Hodeau (France; $J A C$ ), H. M. Holden (USA; Acta D), C. J. Howard (Australia; Acta B), N.-H. Hu (People's Republic of China; Acta E), W. N. Hunter (UK; Acta $D+F)$, A. Iida (Japan; $J S R$ ), W. Imhof (Germany; Acta E), H. Ishida (Japan; Acta E), J. P. Jasinski (USA; Acta E), O. Johnson (UK; Acta E), P. G. Jones (Germany; Acta C), J. A. Kaduk (USA; Acta $B$ ), K. A. Kantardjieff (USA; $J A C$ ), A. R. Kennedy (UK; Acta $C$ ), H. Kitamura (Japan; $J S R$ ), G. J. Kleywegt (Sweden; Acta $D+F)$, B. Kojic-Prodic (Croatia; Acta E), H. Kooijman (The Netherlands; Acta E), M. Kubicki (Poland; Acta C), W. F. Kuhs (Germany; Acta $A)$, V. Langer (Sweden; Acta $C$ ), U. Lee (Korea; Acta E), S. V. Lindeman (USA; Acta $E)$, P. J. Loll (USA; Acta F), M. LopezRodriguez (Spain; Acta E), A. J. Lough (Canada; Acta E), J. N. Low (UK; Acta E), V. Y. Lunin (Russia; Acta D), P. McArdle (Republic of Ireland; Acta E), R. McKenna (USA; Acta D), A. McPherson (USA; Acta F), S. McSweeney (France; JSR), J. T. Mague (USA; Acta E), A. Mar (Canada; Acta E), K. Mereiter (Austria; Acta E), J. Miao (USA; Acta A), K. Miki (Japan; Acta D), R. P. Millane 
(New Zealand; Acta A), A. Momose (Japan; $J S R$ ), B. C. Muddle (Australia; $J A C$ ), P. Mueller (USA; Acta C), M. R. N. Murthy (India; Acta $D)$, C. Näther (Germany; Acta E), J. M. Newman (Australia; Acta $D+F$ ), S. W. Ng (Malaysia; Acta E), G. S. Nichol (USA; Acta E), M. Nieger (Finland; Acta E), K. Ogawa (Japan; Acta B), B. H. Oh (Korea; Acta F), K.-I. Ohshima (Japan; $J A C$ ), A. G. Oliver (USA; Acta $C$ ), M. M. Olmstead (USA; Acta E), S. Parkin (USA; Acta E), D. Parrish (USA; Acta E), S. Parsons (UK; Acta B), M. Parvez (Canada; Acta E), J. M. Perez-Mato (Spain; Acta $A+B$ ), V. Petricek (Czech Republic; Acta $A$ ), P. A. Pianetta (USA; $J S R$ ), A. A. Pinkerton (USA; Acta B), M. L. Pusey (USA; Acta $D+F$ ), R. J. Read (UK; Acta D), W. Reimers (Germany; $J A C$ ), D. A. Reis (USA; $J S R$ ), G. Renaud (France; $J A C$ ), J.-P. Renaud (France; Acta F), C. Rizzoli (Italy; Acta E), A. Roodt (South Africa; Acta E), G. M. Rosair (UK; Acta $E)$, P. Roussel (France; Acta E), V. B. Rybakov (Russia; Acta E), U. Rychlewska (Poland; Acta $B$ ), R. Sankaranarayanan (India; Acta F), B. D. Santarsiero (USA; Acta C), S. Sasaki (Japan; $J A C$ ), H. Schenk (The Netherlands; Acta A), M. Schiltz (Switzerland; Acta D), H. W. Schmalle (Switzerland; Acta E), M. L. Scudder (Australia; Acta $C+E$ ), A. M. Z. Slawin (UK; Acta E), G. Smith (Australia; Acta E), M. A. Spackman (Australia; Acta B), A. L. Spek (The Netherlands; Acta $C+E$ ), P. J. Squattrito (USA; Acta $C+E$ ), W. C. Stallings (USA; Acta F), R. L. Stanfield (USA: Acta F), S. W. Suh (Korea; Acta $F)$, S. Svensson (Sweden; JSR), I. Tanaka (Japan; Acta F), K. Tanaka (Japan; Acta A), M. Taniguchi (Japan; $J S R$ ), T. C. Terwilliger (USA; Acta F), A. L. Thompson (UK; Acta C), P. A. Timmins (France; Acta D), K. W. Törnroos (Norway; Acta $C$ ), T. T. Tsai (USA: Acta F), K. Tsuda (Japan; Acta C), H. Uekusa (Japan; Acta C), A. Van der Lee (France; Acta E), L. Van Meervelt (Belgium; Acta E), J. F. van der Veen (Switzerland; JSR), S. Wakatsuki (Japan; $J S R$ ), D. G. Watson (UK; Acta E), T. R.

Welberry (Australia; Acta B+JAC), J. D.

Westbrook (USA; Acta F), J. White (Australia; Acta $C$ ), T. J. White (Singapore; Acta B), S. W. Wilkins (Australia; Acta A), P. R. Wilmott (Switzerland; Acta A), C. Wilson (UK; Acta E), W.-T. Wong (People's Republic of China; Acta E), D. J. Xu (People's Republic of China; Acta $E)$, B. M. Yamin (Malaysia; Acta E), A. I. Yanovsky (Russia; Acta E), G. P. A. Yap (USA; Acta C), A. V. Yatsenko (Russia; Acta E), T. O. Yeates (USA; Acta D), D. S. Yufit (UK; Acta C), M. Zeller (USA; Acta E), H. Zimmermann (Germany; Acta A)

Book-Review Editor

P. Paufler (Germany; Acta, JAC, JSR)

\section{Commission on International Tables \\ Chair}

C. P. Brock (Department of Chemistry, University of Kentucky, 505 Rose St, Lexington, KY 40506-0055, USA)

Editor of Volume A

M. I. Aroyo (Spain)

Editor of Volume B

U. Shmueli (Israel) (retired; replacement to be appointed)

Editor of Volume C

T. R. Welberry (Australia)

Editor of Volume D

A. Authier (France)

Editors of Volume $E$

V. Kopský (Czech Republic), D. B. Litvin (USA)

Editors of Volume $F$

E. Arnold (USA), D. M. Himmel (USA), M. G. Rossmann (USA)

Editors of Volume $\mathbf{G}$

S. R. Hall (Australia), B. McMahon (UK) Editors of Volume A1

U. Müller (Germany), H. Wondratschek

(Germany) (retired)

Editors of Volume $\mathbf{H}$

C. J. Gilmore (UK), J. A. Kaduk (USA), H. Schenk (The Netherlands)

\section{Commission on Aperiodic Crystals}

Chair

R. Lifshitz (School of Physics \& Astronomy, Tel Aviv University, Tel Aviv 69978, Israel)

Elected members

N. Bolotina (Russia), G. Borgstahl (USA),

U. Grimm (UK), J. Hadermann (Belgium),

G. Madariaga (Spain), N. K. Mukhopadhyay

(India), O. Perez (France), H. Takakura (Japan)

\section{Commission on Biological Macromolecules}

Chair

Xiao-Dong Su (School of Life Sciences, Peking University, No. 5 Yiheyuan Rd, Beijing, Haidian District, 100871, People's Republic of China) Elected members

R. C. Garratt (Brazil), P. L. Howell (Canada), M. Jaskolski (Poland), J. Martin (Australia),

M. Martinez Ripoll (Spain), K. Miki (Japan),

S. Onesti (Italy), A. D. Podjarny (France), D. M. Salunke (India), V. Samygina (Russia),

B. Schneider (Czech Republic), T. C. Terwilliger (USA), A. H.-J. Wang (Taipei)

Ex officio member

H. M. Berman (USA; as Director of the PDB)

Commission on Charge, Spin and Momentum Densities

Chair

B. Gillon [Laboratoire Leon Brillouin (CEACNRS), Centre d'Etudes de Saclay, 91191 Gifsur-Yvette, France]
Elected members

E. Espinosa (France), L. J. Farrugia (UK), J. M. Gillet (France), D. Jayatilaka (Australia), T. Koritsanszky (USA), P. Macchi (Switzerland), U. Pietsch (Germany), Y. Sakurai (Japan), M. Takata (Japan)

Ex officio member

M. T. Fernandez-Diaz (Spain; as Chair of the Commission on Neutron Scattering)

Commission on Crystal Growth and Characterization of Materials

Chair

A. Zappettini (Istituto Materiali Elettronica Magnetismo, Consiglio Nazionale delle Ricerche, parco Area delle Scienze 37/a, Parma 43010, Italy)

Elected members

S. Baldochi (Brazil), H. A. Dabkowska (Canada), J. M. Garcia-Ruiz (Spain), K. Kakimoto (Japan), Ch. Klemenz (USA), D. Klimm (Germany), A. Moreno (Mexico), J. Wang (People's Republic of China)

\section{Ex officio members}

E. Vlieg (The Netherlands; as Representative of the International Organization of Crystal Growth), A. Kaysser-Pyzalla (Germany; as Editor of $J A C$ )

Commission on Crystallographic Computing

Chair

R. Grosse-Kunstleve (Physical Biosciences Division, Lawrence Berkeley National Laboratory, One Cyclotron Road, Berkeley, CA 94720-8118, USA)

Elected members

A. van der Lee (France), M. Lutz (The Netherlands), A. Nakagawa (Japan), H. R. Powell (UK), J. Rius (Spain), K. Sekar (India), R. Von Dreele (USA), M. Yao (Japan)

Commission on Crystallographic Nomenclature Chair

A. Authier (Université Pierre et Marie Curie, Villechenine, 87470 Peyrat-le-Chateau, France) Ex officio members

G. Kostorz (Switzerland; as Editor-in-Chief of IUCr journals), W. Steurer (Switzerland; as Editor of Acta Cryst. Section A), S. van Smaalen (Germany; as Editor of Acta Cryst. Section B), A. Linden (Switzerland; as Editor of Acta Cryst. Section C), E. N. Baker (New Zealand; as a Main Editor of Acta Cryst. Section D), Z. Dauter (USA; as a Main Editor of Acta Cryst. Section D), W. T. A. Harrison (UK; as a Main Editor of Acta Cryst. Section E), H. Stoeckli-Evans (Switzerland; as a Main Editor of Acta Cryst. Section E), E. R. T. Tiekink (Malaysia; as a Main Editor of Acta Cryst. Section E), M. Weil (Austria; as a Main Editor of Acta Cryst. Section E), H. M. Einspahr (USA; as a Main Editor of Acta Cryst. Section F), M. S. Weiss (Germany; as a Main 
Editor of Acta Cryst. Section F), A. KaysserPyzalla (Germany; as Editor of $J A C$ ), G. E. Ice (USA; as Editor of $J S R$ ), C. P. Brock (USA; as Chair of Commission on International Tables), M. I. Aroyo (Spain; as Editor of Volume A of International Tables for Crystallography), T. R. Welberry (Australia; as Editor of Volume C of International Tables for Crystallography),

V. Kopský (Czech Republic; as an Editor of Volume E of International Tables for Crystallography), D. B. Litvin (USA; as an Editor of Volume E of International Tables for Crystallography), M. G. Rossmann (USA; as an Editor of Volume F of International Tables for Crystallography), E. Arnold (USA; as an Editor of Volume F of International Tables for Crystallography), D. M. Himmel (USA; as an Editor of Volume F of International Tables for Crystallography), S. R. Hall (Australia; as an Editor of Volume G of International Tables for Crystallography), B. McMahon (UK; as an Editor of Volume G of International Tables for Crystallography), U. Müller (Germany; as an Editor of Volume A1 of International Tables for Crystallography), C. J. Gilmore (UK; as an Editor of Volume $\mathrm{H}$ of International Tables for Crystallography), J. A. Kaduk (USA; as an Editor of Volume $\mathrm{H}$ of International Tables for Crystallography), H. Schenk (The Netherlands; as an Editor of Volume $\mathrm{H}$ of International Tables for Crystallography), D. Viterbo (Italy; as Chair of the IUCr/OUP Book Series Selection Committee), K. A. Kantardjieff (USA; as Chair of the Commission on Crystallographic Teaching), J. Hester (Australia; as Chair of the Committee for the Maintenance of the CIF Standard)

\section{Commission on Crystallographic Teaching}

Chair

K. A. Kantardjieff (College of Science and Mathematics, Craven Hall 6211, California State University San Marcos, 333 South Twin Oaks Valley Road, San Marcos, CA 92096-0001, USA)

Elected members

R. F. Baggio (Argentina), G. Battle (UK), E. Boldyreva (Russia), M. Rademeyer (South Africa), M. Rossi (USA), S. Schmid (Australia), H. Uekusa (Japan), M. Weiss (Germany)

Commission on Crystallography in Art and Cultural Heritage

\section{Chair}

E. Dooryhée (CNRS - Laboratoire de Cristallographie, 25 av. des Martyrs, BP 166, 38042 Grenoble Cedex, France)

Elected members

C. Abad-Zapatero (USA), P. Bezdicka (Czech Republic), E. Makovicky (Denmark),

S. Quartieri (Italy), A. Rafalska-Lasocha
(Poland), A. Thalal (Morocco), A. Zürn (Switzerland)

Commission on Electron Crystallography

\section{Chair}

L. M. Peng (Department of Electronics, Peking University, Beijing 100871, People's Republic of China)

Elected members

A. Avilov (Russia), J. Etheridge (Australia), J. Hadermann (Belgium), U. Kolb (Germany), L. Meshi (Israel), K. Tsuda (Japan), Da-Neng Wang (USA), J. M. Zuo (USA)

\section{Commission on High Pressure}

\section{Chair}

P. Dera (Geophysical Laboratory, Carnegie

Institution of Washington, 5251 Broad Branch Road NW, Washington, DC 20015, USA) Elected members

R. Angel (USA), E. Boldyreva (Russia), F. Fabbiani (Germany), Y. Katayama (Japan), A. Katrusiak (Poland), Haozhe Liu (People's Republic of China), I. Loa (UK), S. A. T. Redfern (UK), V. Solozhenko (France)

\section{Commission on Inorganic and Mineral}

\section{Structures}

\section{Chair}

J. Rocha (Department of Chemistry, CICECO, University of Aveiro, Campus de Santiago,

Aveiro, 3810-193, Portugal)

\section{Elected members}

T. M. Gesing (Germany), F. Hatert (Belgium), P. Mercier (Canada), T. Nagai (Japan),

R. Oberti (Italy), D. Pandey (India), P. A. Thomas (UK), T. J. White (Australia), O. V. Yakubovich (Russia)

\section{Commission on Magnetic Structures \\ Chair}

L. Chapon (STFC Rutherford Appleton Laboratory, Harwell Oxford, Didcot, OX11 0QX)

\section{Elected members}

J. Brown (France), B. Campbell (USA), D. B. Litvin (USA), V. Petricek (Czech Republic),

A. Pirogov (Russia), V. Pomjakushin (Switzerland), J. Rodriguez-Carvajal (France), T. Sato (Japan), W. Sikora (Poland)

Commission on Mathematical and Theoretical Crystallography

\section{Chair}

M. Nespolo (LCM3B, UMR-CNRS 7036,

Université Henri Poincaré Nancy 1, Faculté des Sciences et Techniques, BP 239, Boulevard des Aiguillettes, F-54506 Vandoeuvre-lès-Nancy Cedex, France)

\section{Elected members}

M. I. Aroyo (Spain), R. P. Felix (The Philippines), S. Gemming (Germany), S. Hyde (Australia), K. Ohsumi (Japan), D. M. Proserpio
(Italy), E. E. Rams (Cuba), B. Souvignier (The Netherlands), H. Sowa (Germany), K. Stroz (Poland)

\section{Commission on Neutron Scattering}

\section{Chair}

M. T. Fernandez-Diaz (Institut Laue-Langevin, av. des Martyrs, BP 156, 38042 Grenoble Cedex 9, France)

\section{Elected members}

V. L. Aksenov (Russia), A. Harrison (France), P. Langan (USA), G. J. McIntyre (Australia), Y. Noda (Japan), Th. Proffen (USA), P. Radaelli (UK), W. W. Schmahl (Germany), I. P. Swainson (Canada)

\section{Commission on Powder Diffraction \\ Chair}

P. Whitfield (Institute for Chemical Process and Environmental Technology, National Research Council Canada, Building M12, 1200 Montreal Road, Ottawa, Ontario, Canada K1A 0R6)

Elected members

D. Billing (South Africa), E. Granado (Brazil),

B. Kennedy (Australia), A. Mukherjee (India), D. Rafaja (Germany), R. Rizzi (Italy), K. Shankland (UK), L. Smrcok (Slovakia),

B. H. Toby (USA)

Ex officio member

J. A. Kaduk (USA; as Representative of the International Centre for Diffraction Data)

\section{Commission on Small-Angle Scattering}

Chair

A. Allen (Ceramics Division, National Institute of Standards and Technology, 100 Bureau Drive, Gaithersburg, MD 20899-8523, USA)

Elected members

D. Babonneau (France), P. R. Jemian (USA), U.-S. Jeng (Taipei), R. Serimaa (Finland),

J. Trewhella (Australia), V. V. Volkov (Russia), N. Yagi (Japan)

\section{Commission on Structural Chemistry}

Chair

F. J. Lahoz (Inst. de Ciencia de Materiales de Aragón, Facultad de Ciencias, Universidad de Zaragoza, 50009 Zaragoza, Spain)

Elected members

S. R. Batten (Australia), S. A. Bourne (South Africa), C. W. Lehmann (Germany), P. Mueller (USA), A. Nangia (India), K. Ogawa (Japan), E. Pidcock (UK), G. Resnati (Italy),

U. Rychlewska (Poland)

Commission on Synchrotron Radiation

Chair

R. F. Garrett (ANSTO Building 1, Private Mail Bag 1, Menai, NSW 2234, Australia)

Elected members

S.-L. Chang (Taipei), M. A. Garcia-Aranda (Spain), P. Grochulski (Canada), J.-L. Hodeau (France), P. N. Lee (USA), Y. Murakami 
(Japan), C. Nave (UK), S. Pascarelli (France), J. L. Smith (USA)

\section{Commission on XAFS}

Chair

I. Ascone (Division Expériences, Synchrotron-

Soleil, L'Orme des Merisiers Saint-Aubin, BP 48, Gif-sur-Yvette Cedex, France)

Elected members

F. Boscherini (Italy), J. Chaboy (Spain),

C. T. Chantler (Australia), P. Glatzel (France),

F. Jalilehvand (Canada), K. Lawniczak-

Jablonska (Poland), M. Tabuchi (Japan)

\section{C2. Regional Associates}

American Crystallographic Association

\section{Representative}

M. L. Hackert (Department of Chemistry and Biochemistry, University of Texas at Austin, Austin, TX 78712, USA)

Asian Crystallographic Association

Representative

J. M. Guss (School of Molecular and Microbial Biosciences, University of Sydney, Sydney,

NSW 2006, Australia)
European Crystallographic Association Representative

E. Boldyreva (Institute of Solid State Chemistry, Russian Academy of Sciences, ul. Kutateladze 18, Novosibirsk 128, 630128, Russia)

\section{C3. Scientific Associates}

International Centre for Diffraction Data Representative

P. Whitfield (Canada; ex officio as Chair of the Commission on Powder Diffraction)

International Organization of Crystal Growth Representative

A. Zappettini (Italy; ex officio as Chair of the Commission on Crystal Growth and Characterization of Materials)

C4. Representatives on bodies not belonging to the Union

Interdivisional Committee on Terminology, Nomenclature and Symbols of the International Union of Pure and Applied Chemistry

Representative

A. Authier (Université Pierre et Marie Curie,
Villechenine, 87470 Peyrat-le-Chateau, France)

International Council for Scientific and Technical Information

Representative

J. R. Helliwell (Department of Chemistry, University of Manchester, Oxford Road, Manchester M13 9PL, UK)

International Council for Science (ICSU)

Representative

S. Larsen (Department of Chemistry, University of Copenhagen, Universitetsparken 5, 2100

Copenhagen, Denmark; ex officio as Immediate Past President of the IUCr)

ICSU Committee on Data for Science and Technology

Representative

B. McMahon (International Union of Crystallography, 5 Abbey Square, Chester CH1 2HU, UK)

ICSU Committee on Space Research Representative

H. A. Dabkowska (Department of Physics and Astronomy, 1280 Main Street West, Hamilton, Ontario, L85 4M1, Canada)

\section{APPENDIX $D$}

\section{Adhering Bodies and National Committees for Crystallography}

\section{D1. Adhering Bodies}

Details of the Adhering Bodies are given in Table 8.

\section{D2. National Committees for Crystallography}

\section{Argentina}

R. Baggio (Chair), D. Lamas, G. Punte, D. R.

Vega

Australia

J. M. Guss (Chair), B. J. Kennedy, S. Kennedy,

K. Nugent, J. Varghese, A. Vrielink, A. Whitten,

R. Withers

Austria

E. Tillmanns (Chair), P. Fratzl, H. Heritsch,

P. Laggner, A. Preisinger, K.-H. Schwarz,

J. Zemann

Belgium

D. Poleman (Chair), P. Charlier (Vice-Chair),

F. Blockhuys, J.-P. Declercq, J. Elsen,

J. Hadermann, D. Lamoen, D. Maes,

M. Sferrazza, R. Sporken, B. Tinant, G. G. R.

Van Den Bossche, L. Van Meervelt, L. Vincze,

J. Wouters

Brazil

N. L. Speziali (Chair), Y. P. Mascarenhas,

I. Torriani

Bulgaria

O. Petrov (Chair), R. Petrova
Canada

J. F. Britten (Chair), P. Whitfield (Vice-Chair), T. S. Cameron, M. Fraser, L. A. Groat, P. L. Howell, D. R. Rose, J. D. Schrag Chile

M. T. Garland (Chair), J. A. Costamagna, J. Garin, M. Suwalsky, A. Vega China, People's Republic of Min Nai-ben (Chair), Bai Chun-li, Chang Wen-rui, Chen Xiao-long, Fan Hai-fu, Jin Xiang-lin, Lin Shao-fan, Mai Zhen-hong, Miao Fang-ming, Niu Li-wen, Peng Lian-mao, Rao Zi-he, Tao Kun, Wang Ji-yang, Wu Xin-tao, Xian Ding-chang, Xiao-dong Su, Zhang Ze, Zheng Qi-tai

China, Taipei

Yu Wang (Chair), S. L. Chang, C. H. Lee, Y. C. Liaw, K. H. Lii, L. K. Liu, C. P. Tang, S. C. Yu, S. H. Yuan

Croatia

S. Popović (Chair), D. Matković-Calogović (Vice-Chair), M. Luić, D. Tibljas, A. Tonejc,

A. Visnjevac, K. Vlahovicek

Czech and Slovak Republics

R. Kuzel (Chair), M. Koman (Vice-Chair),

L. Caplovic, J. Cernak, N. Ganev, J. Kozisek,

I. Kuta-Smatanova, P. Mikulik

Denmark

K. Mortensen (Chair), A. D. Bond, R. K.

Feidenhans'l, K. Frydenvang, A. Horsewell, J. S.
Pedersen, K. Ståhl, T. B. Zunic

Egypt, Arab Republic of

M. S. Ahmed (Chair), Y. M. Abbas, A. M. Abdel-Rahman, N. A. Ahmed, S. A. A. Arafa, F. A. Deif, K. El-Sayed, I. S. A. Farag, M. A. Gaffar, F. M. Helmi, K. H. A. Mady, M. M. Radwan, A. A. Ramadan, A. H. Rasmy

Finland

K. Hämäläinen (Chair), T. Glumoff,

O. Ikkala, I. Mutikainen, J. Rouvinen, J. U. Valkonen

France

J. Cherfils (Chair), J.-C. Daran, E. Espinosa,

R. Guinebretière, C. Mayer, P. Roussel,

L. Vendier, V. Villeret; Representatives:

F. Bonnete, J.-L. Hodeau, J.-P. Itie, P. Launois,

O. Perez

Germany

U. Pietsch (Chair), R. X. Fischer, U. Heinemann (ex officio as President of DGK), D. Meyer,

W. Schmahl, M. Weiss, L. Wiehl

Greece

M. Calamiotou (Chair), I. M. Mavridis (ViceChair), C. A. Kavounis, F. D. Leonidas,

D. Mentzafos

Hungary

G. Faigel (Chair), A. Benyei, P. Bombicz, A. Kálmán, L. Koszegi, L. Kovacs, J. Labar, G. Naray-Szabo, G. Radnóczi, K. Simon, E. Svab, T. Ungár, T. Weiszburg 
Table 8

Adhering Bodies.

Adherence to the Union is in one of five Categories I-V, with corresponding voting powers and contributions as set out in Statutes 3.6, 5.5 and 9.4.

\begin{tabular}{|c|c|c|}
\hline Country & Category & Adhering Body \\
\hline Argentina & I & $\begin{array}{l}\text { Consejo Nacional de Investigaciones } \\
\text { Científicas y Técnicas }\end{array}$ \\
\hline Australia & III & Australian Academy of Science \\
\hline Austria & I & $\begin{array}{l}\text { Österreichische Akademie der } \\
\text { Wissenschaften }\end{array}$ \\
\hline Belgium & II & $\begin{array}{l}\text { The Royal Academies for Science } \\
\text { and the Arts of Belgium }\end{array}$ \\
\hline Brazil & I & Brazilian Crystallographic Association \\
\hline Bulgaria & I & Bulgarian Crystallographic Association \\
\hline Canada & III & National Research Council \\
\hline Chile & I & $\begin{array}{l}\text { Comision Nacional de Investigación } \\
\text { Cientifica y Tecnologia }\end{array}$ \\
\hline China, People's Republic of & IV & $\begin{array}{l}\text { Chinese Association for Science and } \\
\text { Technology }\end{array}$ \\
\hline China, Taipei & II & $\begin{array}{l}\text { The Academy of Sciences Located in } \\
\text { Taipei }\end{array}$ \\
\hline Croatia & I & $\begin{array}{l}\text { Croatian Crystallographic Association } \\
\text { (under the auspices of the Croatian } \\
\text { Academy of Science and Arts) }\end{array}$ \\
\hline Czech and Slovak Republics & II & $\begin{array}{l}\text { Regional Committee of Czech and } \\
\text { Slovak Crystallographers }\end{array}$ \\
\hline Denmark & I & $\begin{array}{l}\text { Royal Danish Academy of Sciences } \\
\text { and Letters }\end{array}$ \\
\hline Egypt, Arab Republic of & I & $\begin{array}{l}\text { Academy of Scientific Research and } \\
\text { Technology }\end{array}$ \\
\hline Finland & I & $\begin{array}{l}\text { Suomen Tiedeakatemiain } \\
\text { Valtuuskunta }\end{array}$ \\
\hline France & IV & $\begin{array}{l}\text { Académie des Sciences (Institut de } \\
\text { France) }\end{array}$ \\
\hline Germany & IV & $\begin{array}{l}\text { Deutsche Gesellschaft für } \\
\text { Kristallographie (DGK) }\end{array}$ \\
\hline Greece & I & Hellenic Crystallographic Association \\
\hline Hungary & I & Magyar Tudományos Akadémia \\
\hline India & III & Indian National Science Academy \\
\hline Ireland, Republic of & I & Irish Crystallographic Association \\
\hline Israel & I & $\begin{array}{l}\text { Israel Academy of Sciences and } \\
\text { Humanities }\end{array}$ \\
\hline Italy & III & Consiglio Nazionale delle Ricerche \\
\hline Japan & IV & Science Council of Japan \\
\hline Korea, Republic of & I & Korean Crystallographic Association \\
\hline Mexico & I & $\begin{array}{l}\text { Consejo Nacional de Ciencia y } \\
\text { Tecnologia }\end{array}$ \\
\hline Netherlands & II & $\begin{array}{l}\text { The Dutch Association for } \\
\text { Crystallography (NVK) }\end{array}$ \\
\hline New Zealand & I & The Royal Society of New Zealand \\
\hline Norway & I & Det Norske Videnskaps-Akademi \\
\hline Poland & I & Polska Akademia Nauk \\
\hline Portugal & I & Sociedade Portuguesa de Fisica \\
\hline Regional Committee - AsCA & I & $\begin{array}{l}\text { Regional Committee of Crystallogra- } \\
\text { phers from Bangladesh, Malaysia, } \\
\text { Singapore, Thailand and Vietnam }\end{array}$ \\
\hline Regional Committee - ECA & I & $\begin{array}{l}\text { Regional Committee of Crystallogra- } \\
\text { phers from Algeria, Latvia, Morocco, } \\
\text { Tunisia, Turkey and Ukraine }\end{array}$ \\
\hline Russia & V & Russian Academy of Sciences \\
\hline Serbia & I & $\begin{array}{l}\text { Serbian Ministry for Science and } \\
\text { Technology }\end{array}$ \\
\hline
\end{tabular}

Secretary of National Committee

D. R. Vega, Comision Nacional de Energía Atómica, Departamento de Física, TANDAR, Av. Gral Paz 1499, 1650 San Martin, Buenos Aires, Argentina

J. Mill, National Relations Officer, Australian Academy of Science, GPO Box 783, Canberra, ACT 2601, Australia

E. Tillmanns, Institut für Mineralogie und Kristallographie, Universität Wien - Geozentrum, Althanstrasse 14, 1090 Wien, Austria

L. Van Meervelt, Biomolecular Architecture, Chemistry Department, K. U. Leuven, Celestijnenlaan 200F, B-3001 Leuven (Heverlee), Belgium

I. Torriani, Institut de Física, Universidade Estadual de Campinas, CP 6165, 13083-970 Campinas SP, Brazil

R. Petrova, Institute of Mineralogy and Crystallography, Acad. G. Bonchev str., Block 107, Bulgaria

J. D. Schrag, Biotechnology Research Institute, NRC, 6100 Royalmount Avenue, Montreal, Quebec H4P 2RZ, Canada

A. Vega, Departamento de Ciencias Quimicas, Universidad Andres Bello, Republica 275, Santiago, Chile

Xiao-Dong Su, Life Science College, Peking University, Beijing 100871, People's Republic of China

S. M. Peng, Department of Chemistry, National Taiwan University, Taipei

M. Luic, Ruder Boskovic Institute, Bijenicka cesta 54, POB 180, 1002 Zagreb, Croatia

R. Kuzel, Faculty of Mathematics and Physics, Charles University, Ke Karlovu 3, 12116 Praha 2, Czech Republic

A. Ø. Madsen, Department of Chemistry, University of Copenhagen, Universitetsparken 5, Copenhagen, DK-2100, Denmark

M. M. Radwan, Faculty of Engineering in Fayoum, Fayoum, Egypt

M. Blomberg, Department of Physical Sciences, PO Box 64, University of Helsinki, FIN-00014 Helsinki, Finland

E. Espinosa, CRM2 (UMR UHP-CNRS 7036), Faculté des Sciences et Techniques, BP 239, Boulevard des Auguillettes, 54506 Vandouevre-lèsNancy Cedex, France

U. Pietsch, Universität Siegen, FB Physik, Walter-Flex-Str. 3, D-57068 Siegen, Germany

D. Mentzafos, Physics Laboratory, Agricultural University of Athens, Athens, Greece

P. Bombicz, Institute of Chemistry, Chemical Research Center, Hungarian Academy of Sciences, H-1525 Budapest, POB 17, Hungary

D. M. Salunke, Executive Director, Regional Centre for Biotechnology, 180 Udyog Vihar Phase I, Gurgaon, India

S. E. Lawrence, Department of Chemistry, University College, Cork, Ireland

M. Harel, Department of Structural Biology, The Weizmann Institute of Science, Rehovot 76100, Israel

M. Saviano, Istituto di Cristallografia del CNR, via Amendola 122/O, 70126 Bari, Italy

M. Takata, RIKEN SPring-8 Center, RIKEN Harima Institute, Kouto 1-1-1, Sayo-cho, Sayo-gun, Hyogo 679-5148, Japan

S. W. Suh, Department of Chemistry, College of Natural Sciences, Seoul National University, Seoul, 151-747, Republic of Korea

L. Bucio Galindo, Instituto de Fisica, UNAM, Departamento de Estado Solido, Circuito de la Investigacion Cientifica $\mathrm{s} / \mathrm{n}, \mathrm{Cd}$. Universitaria, Mexico, DF, PO Box 20-364, CP 04510, Mexico

M. Lutz, Crystal and Structural Chemistry, Utrecht University, Padualaan 8, Utrecht, $3584 \mathrm{CH}$, The Netherlands

J. Weston, The Royal Society of New Zealand, PO Box 598, Wellington, New Zealand

B. Fjaertoft, Institute of Pharmacy, University of Oslo, PO Box 1068, Blindern, 0316 Oslo, Norway

U. Rychlewska, Department of Chemistry, Adam Mickiewicz University, Grunwaldzka 6, 60-780 Poznan, Poland

A. M. Damas, Instituto de Biologia Molecular e Celular, R. do Campo Alegre, 823, 4150 Porto, Portugal

H. K. Fun, X-ray Crystallography Unit, School of Physics, Universiti Sains Malaysia, 11800 USM, Penang, Malaysia

E. Kendi, Department of Physics Engineering, Hacettepe University, 06532 Beytepe, Ankara, Turkey

N. I. Sorokina and O. A. Alekseeva, Shubnikov Institute of Crystallography, Russian Academy of Sciences, Leninsky pr. 59, Moscow 119333, Russia A. Rosic, Belgrade University Computing Center, Kumanovska bb, Belgrade, Serbia 
Table 8 (continued)

\begin{tabular}{|c|c|c|c|}
\hline Country & Category & Adhering Body & Secretary of National Committee \\
\hline Slovenia & I & $\begin{array}{l}\text { Slovenian Ministry of Science and } \\
\text { Technology }\end{array}$ & $\begin{array}{l}\text { I. Leban, Department of Chemistry and Chemical Technology, } \\
\text { University of Ljubljana, PO Box 537, SI-1001 Ljubljana, Slovenia }\end{array}$ \\
\hline South Africa & II & National Research Foundation & $\begin{array}{l}\text { B. Mnyatheli, South African ICSU Secretariat, National Research } \\
\text { Foundation, PO Box 2600, Pretoria 0001, South Africa }\end{array}$ \\
\hline Spain & III & $\begin{array}{l}\text { Subdirección General de Organismos y } \\
\text { Programas Internacionales, Minis- } \\
\text { terio de Ciencia y Tecnologia }\end{array}$ & $\begin{array}{l}\text { E. Gutiérrez Puebla, Instituto de Ciencia de Materiales de Madrid, CSIC, } \\
\text { Cantoblanco, E-28049 Madrid, Spain }\end{array}$ \\
\hline Sweden & II & Kungliga Vetenskapsakademien & $\begin{array}{l}\text { A. Sjögren, Svenska Kemistsamfundet, Wallingatan 24, } 11123 \text { Stockholm, } \\
\text { Sweden }\end{array}$ \\
\hline Switzerland & II & $\begin{array}{l}\text { Schweizerische Gesellschaft für } \\
\text { Kristallographie }\end{array}$ & $\begin{array}{l}\text { M. Hennig, F. Hoffmann - La Roche, Pharma Research 65/319, CH-4070 } \\
\text { Basel, Switzerland }\end{array}$ \\
\hline UK & $\mathrm{V}$ & $\begin{array}{l}\text { The British Crystallographic } \\
\text { Association }\end{array}$ & $\begin{array}{l}\text { G. M. Rosair, School of EPS - Chemistry, Perkin Building, Heriot-Watt } \\
\text { University, Edinburgh EH14 4AS, UK }\end{array}$ \\
\hline USA & $\mathrm{V}$ & $\begin{array}{l}\text { National Academy of Sciences } \\
\text { - National Research Council }\end{array}$ & $\begin{array}{l}\text { C. Lind, Chemistry Department, } 2262 \text { WO, University of Toledo, Toledo, } \\
\text { Ohio 43606-3390, USA }\end{array}$ \\
\hline
\end{tabular}

\section{India}

D. M. Salunke (Chair), K. Byrappa, G. R.

Desiraju, A. Nangia,

M. K. Sanyal, K. Suguna

Ireland, Republic of

P. McArdle (Chair), A. Khan, J. F. Gallagher,

N. Hamill, S. E. Lawrence, T. Soulimane

Israel

O. Livnah (Chair), O. Dym, M. Harel

Italy

R. Oberti (Chair), V. R. Albertini, G. Artioli,

E. Chiancone, C. Mealli, M. Milani, M. Saviano,

G. Zanotti

Japan

M. Takata (Chair), Y. Fujii, K. Kakimoto,

K. Kurihara, R. Kuroda, K. Ogawa,

Y. Sugawara, A. Takahara

Korea, Republic of

S. W. Suh (Chair), J. T. Ahn, U. U. Chi, S. I. Cho,

Y. K. Cho, S. J. Chung, H. J. Kim, H. S. Kim,

Y. H. Kim, Y. J. Park

Mexico

J. L. Bucio Galindo (Chair), J. L. Aragon Vera,

L. Banos Lopez, S. Bernes Flouriot, J. L. L.

Boldu Olaizola, G. Cabanas Moreno, O. Cano

Corona, M. A. Castellanos Roman, A. E.

Cordero Borboa, N. E. Garcia Calderon,

M. Hesiquio Garduno, E. Horjales Reboredo,

V. M. Malpica Cruz, E. A. Munoz Picone,

J. Ornelas Tabares, J. Palacios Gomez, A. Reyes

Arellano, J. Reyes Gasga, J. Rickards Campbell,

D. Rios Jara, R. Rodriguez Mijangos, D. Romeo

Casajuana, H. Terrones Maldonado, R. Alfredo

Toscano, E. Villafuerte Castrejon

Netherlands

R. de Gelder (Chair), H. Kooijman, M. Lutz,

D. Maes, R. B. G. Ravelli, C. A. Reiss,
A. C. Terwisscha Van Scheltinga

\section{New Zealand}

E. N. Baker (Chair), G. J. Gainsford,

G. Jameson, B. K. Nicholson, W. T. Robinson,

J. Simpson

Norway

C. H. Görbitz (Chair), B. Fjaertoft, J. K.

Gjønnes, K. W. Törnroos

Poland

M. Gdaniec (Chair), J. Lipkowski (Vice-Chair),

G. D. Bujacz, A. Pietraszko, U. Rychlewska,

D. Stróż A. Szytuła, J. Żmija

Portugal

M. M. R. Da Costa (Chair), A. M. Damas, M. T.

Duarte

\section{Regional Committee - AsCA}

W. Klooster (Chair), H. K. Fun, A. Hussain, Thammarat Aree, N. Van Tri

Regional Committee - ECA

A. Thalal (Chair), A. Bekka, N. Bouhmaida,

M. Bulanova, M. Debbabi, R. Gladyshevskii,

A. Haddad, E. Kendi, A. Mishnev, S. Özbey

Russia

M. V. Kovalchuk (Chair), V. L. Aksenov (Vice-

Chair), V. M. Kanevsky (Vice-Chair), S. M.

Aldoshin, A. S. Avilov, M. Yu. Antipin, E. V.

Antipov, L. A. Aslanov, E. V. Boldyreva, N. B.

Bolotina, E. V. Chuprunov, S. N. Chvalun, G. N.

Kulipanov, V. V. Kvardakov, V. V. Kveder, S. G.

Konnikov, S. V. Krivovichev, I. S. Lyubutin, I. P.

Makarova, V. V. Osiko, V. O. Popov, D. Yu.

Pushcharovsky, M. K. H. Rabadanov, O. G.

Sinyashin, A. E. Voloshin

Serbia

A. Kremenović (Chair), A. Kapor (Vice-Chair),

B. Antic, B. Bogdanović, A. Rosic, S. Stanković,

S. Trifunović

\section{Slovenia}

A. Meden (Chair), V. Kaučič, A. Golobic,

N. Lah, I. Leban

South Africa

S. A. Bourne (Chair), C. Esterhuysen (ViceChair), L. J. Barbour, D. G. Billing, J. C. A. Boeyens (observer), A. Jacobs, G. J. Kruger, D. C. Levendis, L. R. Nassimbeni (observer), A. Roodt, K. Stewart, A. Venter

Spain

C. Miravitlles Torras (Chair), M. I. Arriortua

Marcaida, S. Garcia Granda, J. M. Garcia Ruiz,

P. Gomez Sal, E. Gutiérrez Puebla, F. J. Lahoz

Diaz, J. Rius Palleiro

Sweden

S. Nordholm (Chair), L. I. Elding,

A. Hartmanis, K. Holmberg, Y. Lindqvist,

J.-E. Nyström, E. Sauer-Eriksson, A. Sjögren Switzerland

W. Steurer (Chair), M. Hennig, H. J. Scheel, J. Schefer, M. Schiltz, K. Yvon

UK

D. Keen (Chair), D. Allan, K. Christensen,

R. Cooper, E. F. Garman, A. Griffin,

R. Harrington, J. McGeehan, A. Mulholland,

S. Parsons, A. Pearson, G. M. Rosair, C. H.

Schwalbe, E. Shotton, A. Thompson,

A. Warren, P. Williams, P. Wood

USA

B. H. Toby (Chair), J. Ng (Vice-Chair),

G. Borgstahl, C. Cahill, M. Clegg,

P. Debenedetti, M. L. Hackert, C. Y. Jones,

B. Kahr, C. Lind, B. Matthews, S. Misture,

P. Moeck, G. Phillips, C. D. Poulter, S. N. Rao,

C. J. Rawn, J. Reibenspies, B. Rupp, A. Sarjeant,

S. Sheriff, P. Stephens, C. Stevens, K. Wheeler,

A. P. Wilkinson 